\title{
Additional Protocol (AP) Protocol Reporter Version 3.0 (PR3) System Requirements Specification (SRS)
}

March 2014

Prepared by

Ron Cain

Donald Kovacic

Kevin Hannan

Dylan Wolf

Approved for public release; distribution is unlimited.

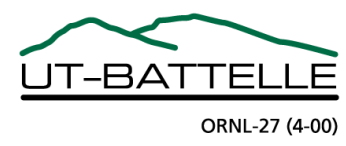




\section{DOCUMENT AVAILABILITY}

Reports produced after January 1, 1996, are generally available free via US Department of Energy (DOE) SciTech Connect.

Website http://www.osti.gov/scitech/

Reports produced before January 1, 1996, may be purchased by members of the public from the following source:

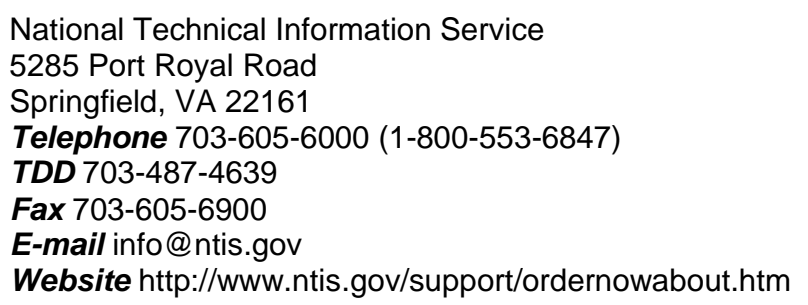

Reports are available to DOE employees, DOE contractors, Energy Technology Data Exchange representatives, and International Nuclear Information System representatives from the following source.

Office of Scientific and Technical Information

PO Box 62

Oak Ridge, TN 37831

Telephone 865-576-8401

Fax 865-576-5728

E-mail reports@osti.gov

Website http://www.osti.gov/contact.html

This report was prepared as an account of work sponsored by an agency of the United States Government. Neither the United States Government nor any agency thereof, nor any of their employees, makes any warranty, express or implied, or assumes any legal liability or responsibility for the accuracy, completeness, or usefulness of any information, apparatus, product, or process disclosed, or represents that its use would not infringe privately owned rights. Reference herein to any specific commercial product, process, or service by trade name, trademark, manufacturer, or otherwise, does not necessarily constitute or imply its endorsement, recommendation, or favoring by the United States Government or any agency thereof. The views and opinions of authors expressed herein do not necessarily state or reflect those of the United States Government or any agency thereof. 


\title{
ADDITIONAL PROTOCOL (A) PROTOCOL REPORTER VERSION 3.0 (PR3) SYSTEM REQUIREMENTS SPECIFICATION (SRS)
}

\author{
Ron Cain, Donald Kovacic, Kevin Hannan,* and Dylan Wolf*
}

*Trident Resource Corporation

Date Published: March 2014

Prepared by

OAK RIDGE NATIONAL LABORATORY

Oak Ridge, Tennessee 37831-6283

managed by

UT-BATTELLE, LLC

for the

US DEPARTMENT OF ENERGY

under contract DE-AC05-00OR22725 


\section{Contents}

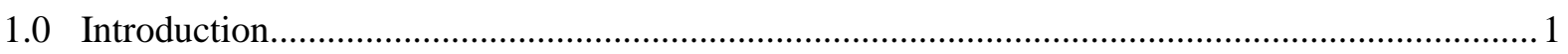

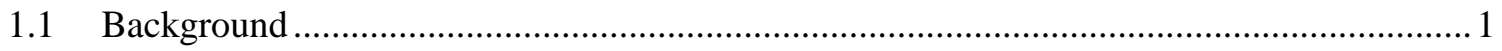

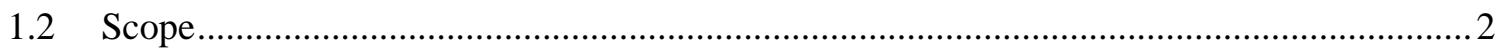

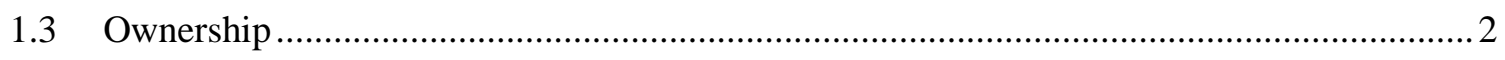

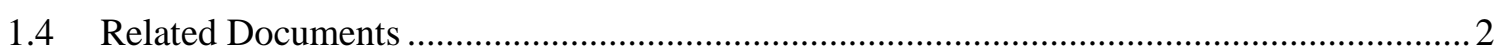

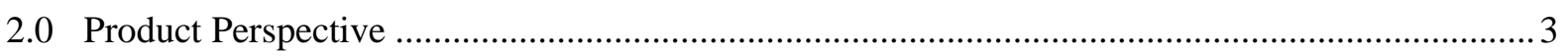

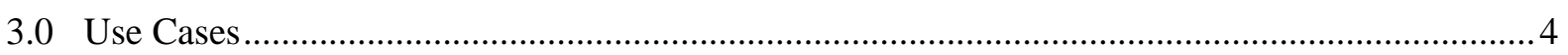

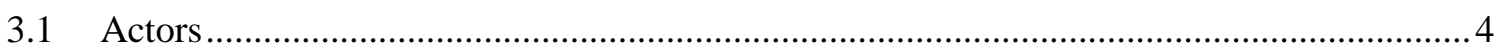

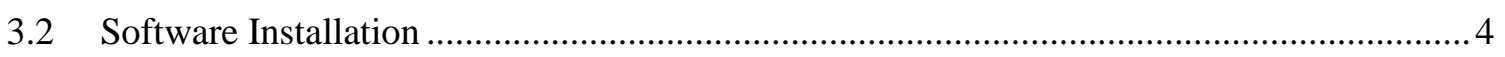

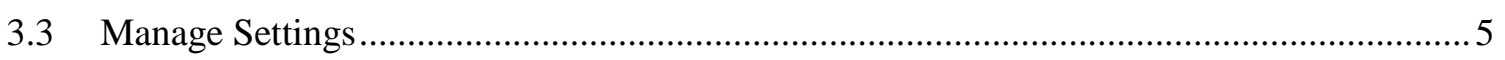

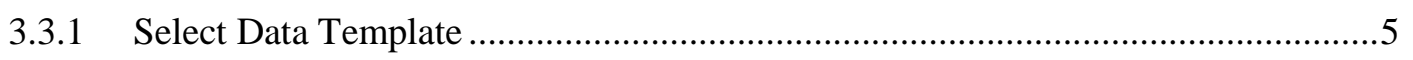

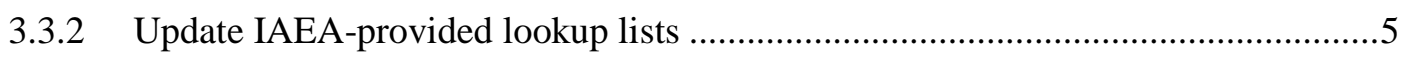

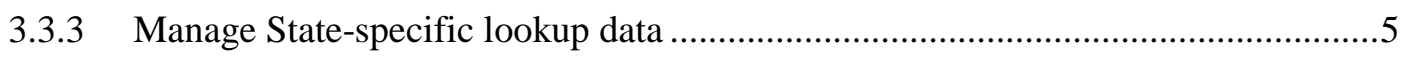

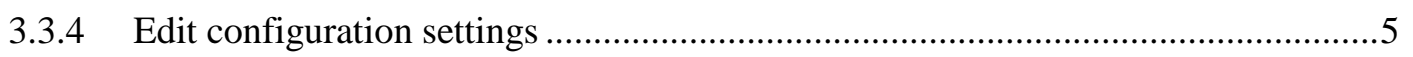

3.3.5 View or print system settings reports.............................................................

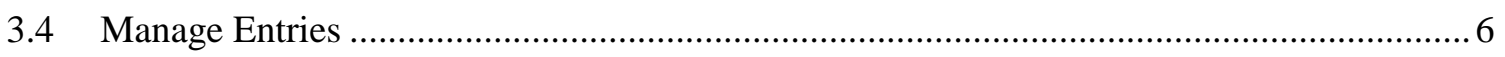

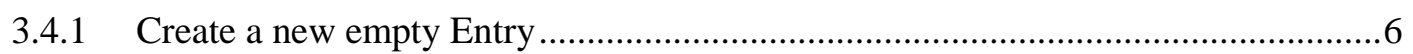

3.4.2 Create a new Entry by copying an existing Entry...................................................6

3.4.3 Create a new Entry to update a previously submitted Entry ....................................6

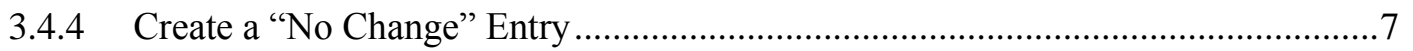

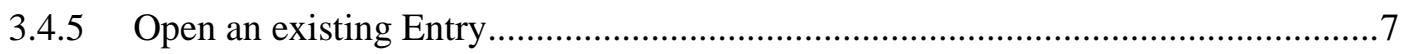

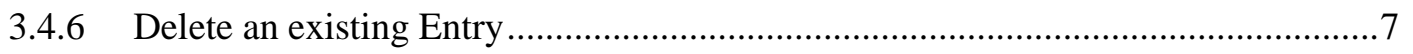

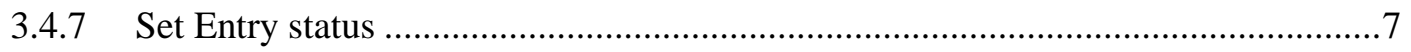

3.4.8 Validate selected Entries or validate an open Entry..............................................

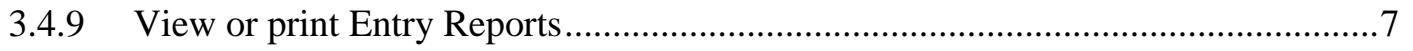

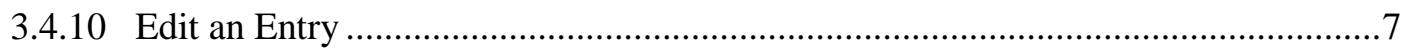

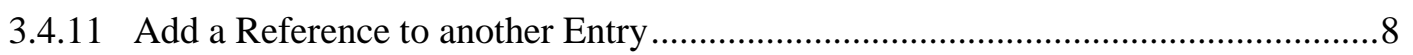

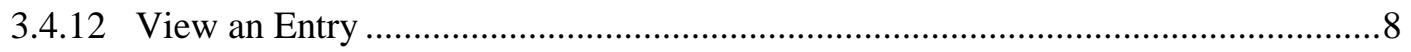

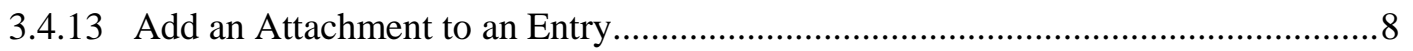

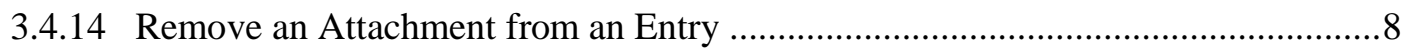

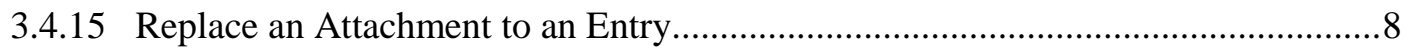

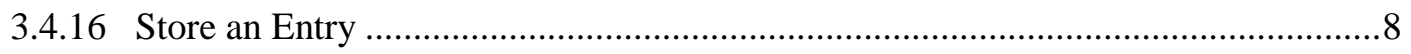

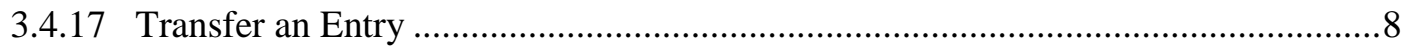


3.4.18 Create a Transfer Package of selected Entries .....................................................

3.4.19 Extract selected Entries from a Transfer Package....................................................

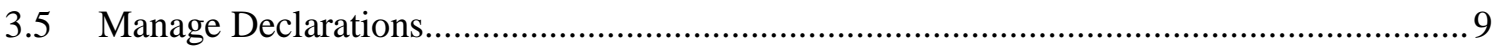

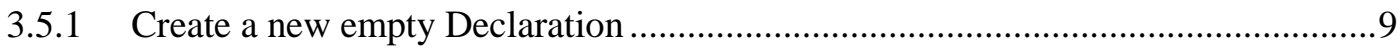

3.5.2 Create a new Declaration by copying an existing Declaration ................................9

3.5.3 Create a "No Change" Declaration ......................................................................... 10

3.5.4 Create a "Nothing to Declare" Declaration.............................................................10

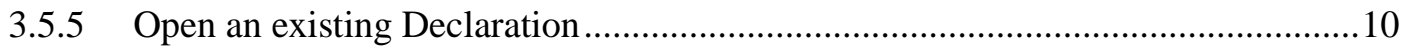

3.5.6 Delete an existing Declaration .......................................................................... 10

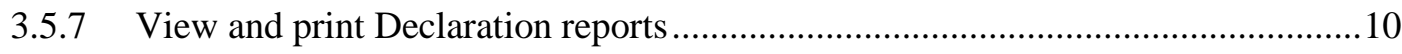

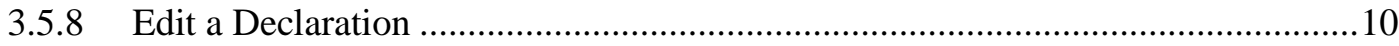

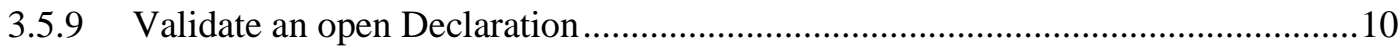

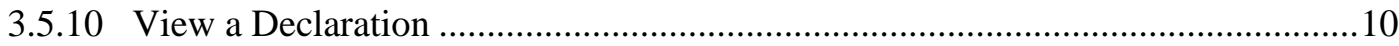

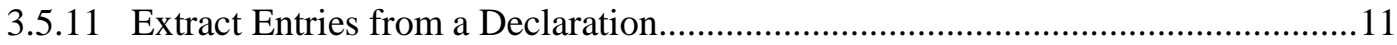

3.5.12 Add an Attachment to a Declaration..................................................................11

3.5.13 Remove an Attachment from a Declaration........................................................11

3.5.14 Replace an Attachment to a Declaration................................................................

3.5.15 Manage Entries within a Declaration..................................................................11

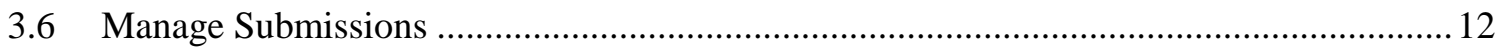

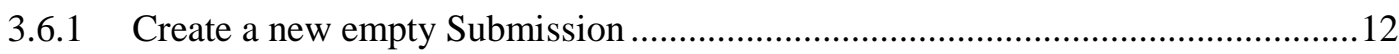

3.6.2 Create a new Submission by copying an existing Submission .............................12

3.6.3 Create a new Submission to update a previously submitted Submission ..............12

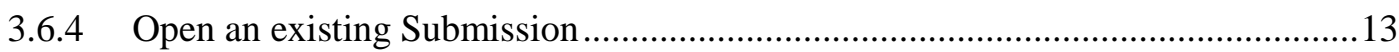

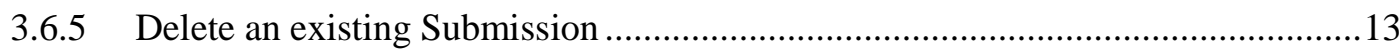

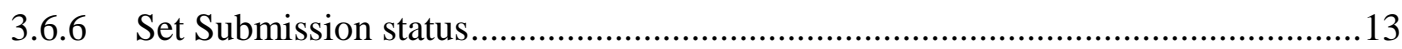

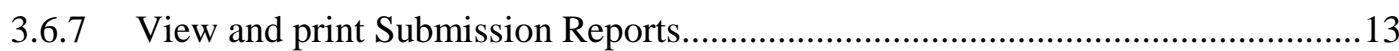

3.6.8 Validate selected Submission or validate an open Submission .............................13

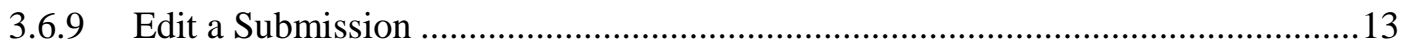

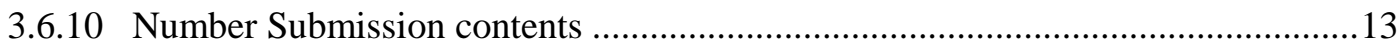

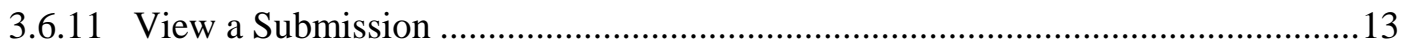

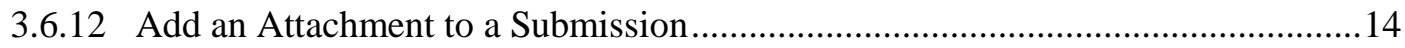

3.6.13 Remove an Attachment to a Submission ..............................................................

3.6.14 Replace an Attachment to a Submission................................................................ 14

3.6.15 Manage Declarations within a Submission ...........................................................14

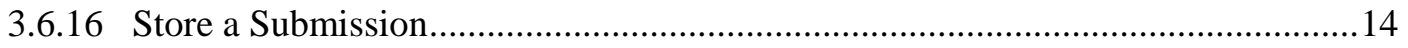


3.6.17 Transfer a Submission

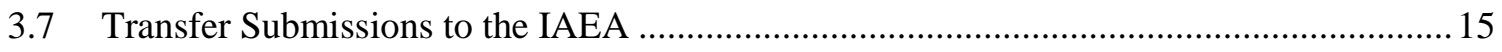

3.7.1 Export Submission for electronic transfer to IAEA ................................................15

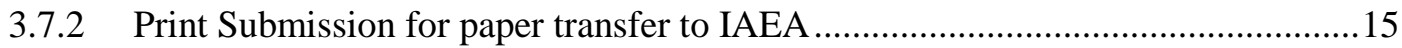

3.7.3 Transfer Submission electronically through the system ......................................15

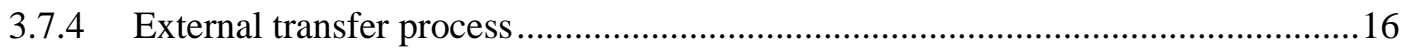

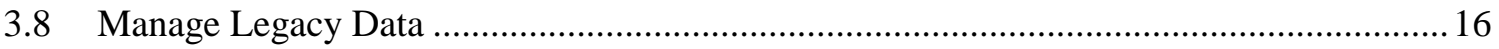

3.8.1 Import data from a PR1 text file, PR2 text file, or PR2 XML file ..........................16

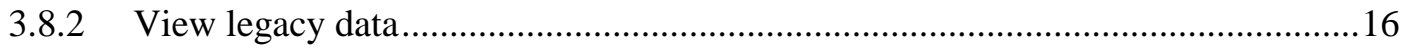

3.8.3 Store selected legacy Entries as PR3 Entries .......................................................16

3.8.4 Store a legacy submission as a PR3 Submission ................................................. 17

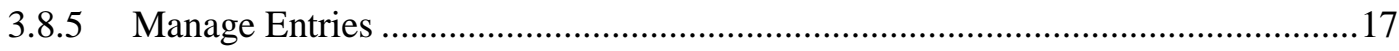

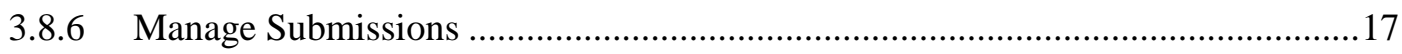

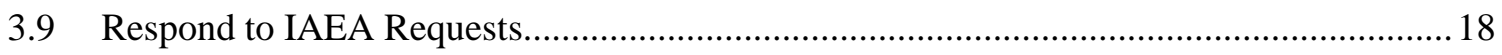

3.9.1 Create or retrieve request for amplification or clarification...................................18

3.9.2 Compile 2.c Entries, Declaration, and Submission ............................................... 18

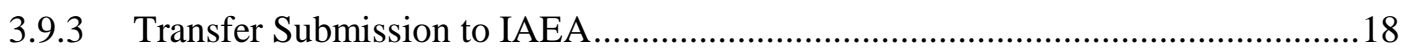

3.9.4 Upload file(s) to IAEA Document Library ......................................................... 18

3.9.5 Provide response outside of the system or IAEA website ....................................19

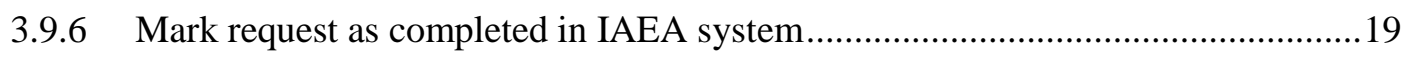

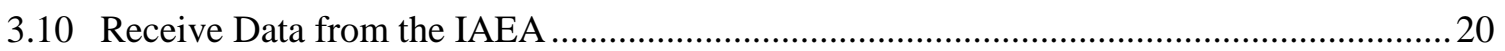

3.10.1 IAEA provides data/SRA Submitter receives data .............................................20

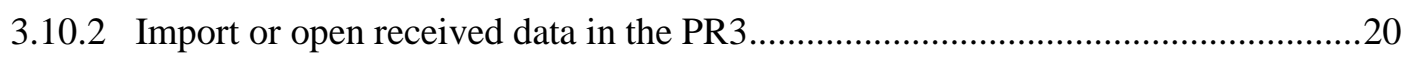

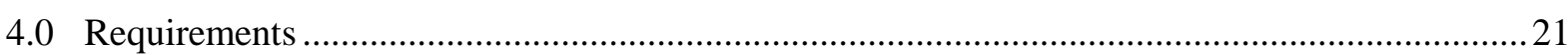

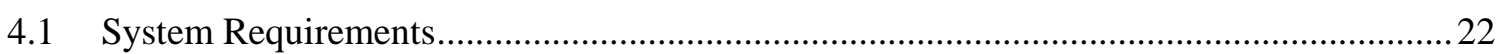

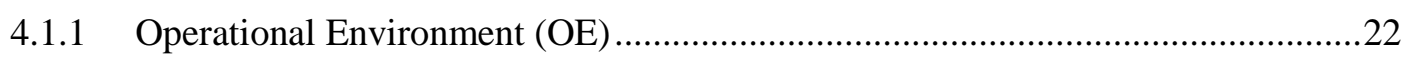

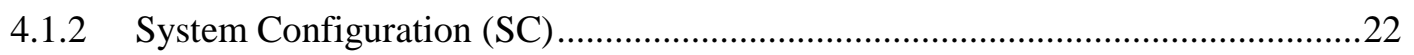

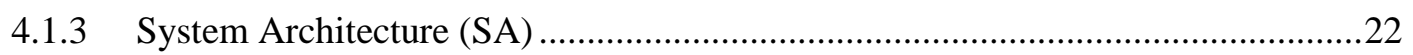

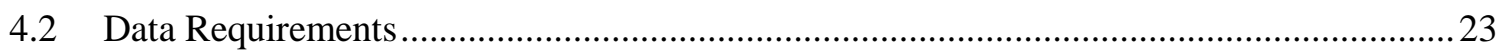

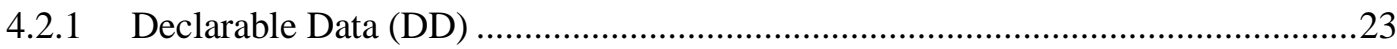

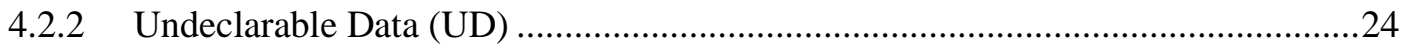

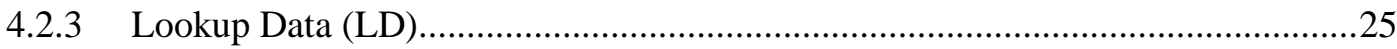

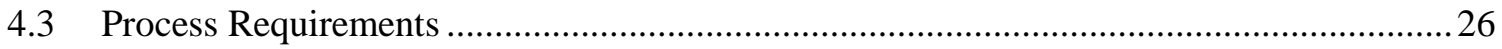

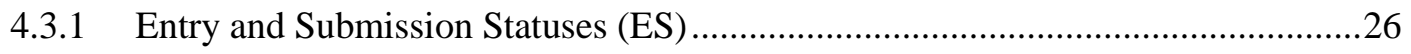

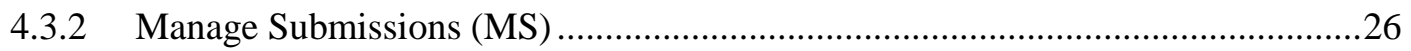




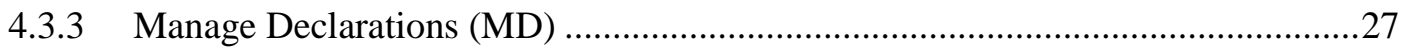

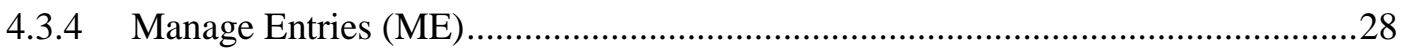

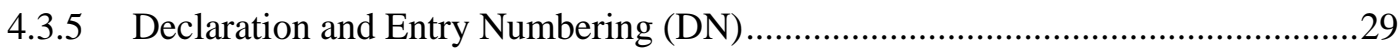

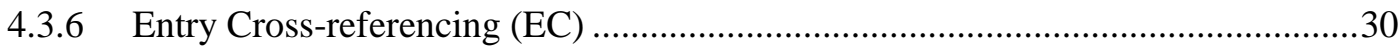

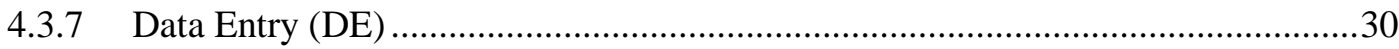

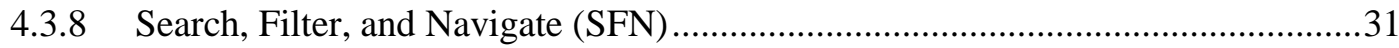

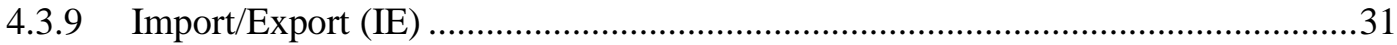

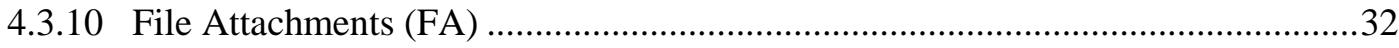

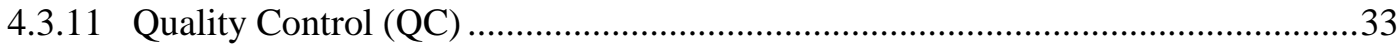

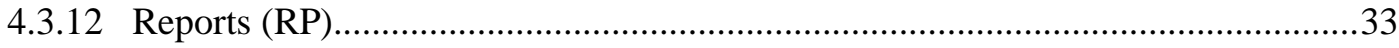

4.3.13 User Documentation (UD) ...........................................................................

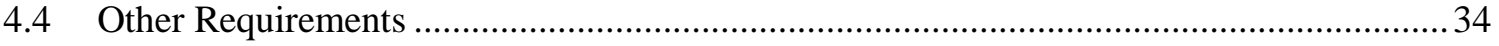

4.4.1 External Interface Requirements.........................................................................

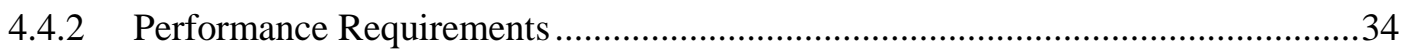

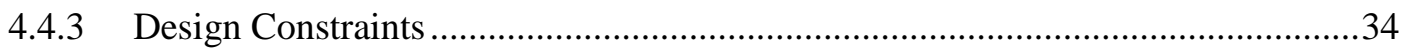

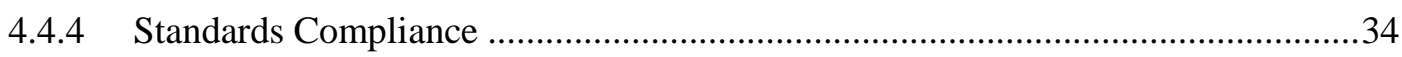

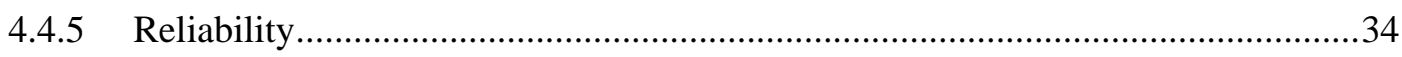

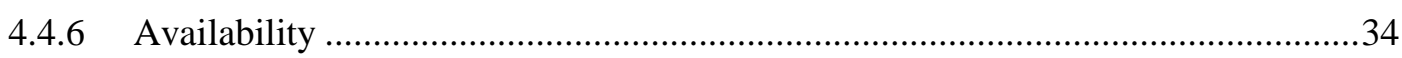

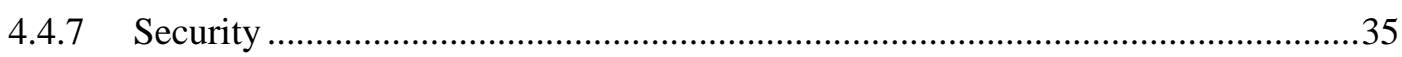

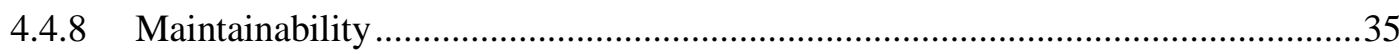

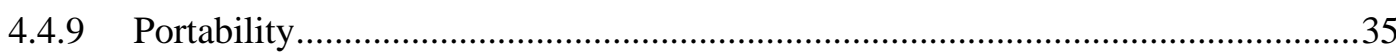

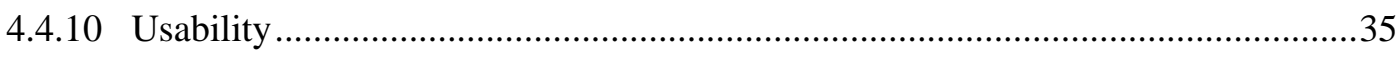

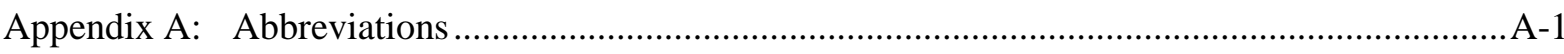

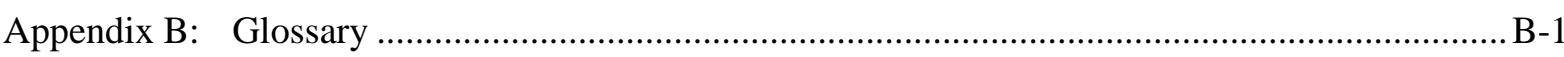

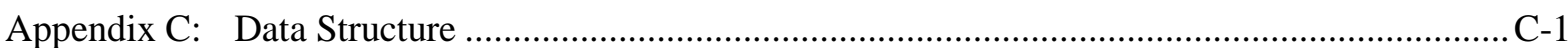

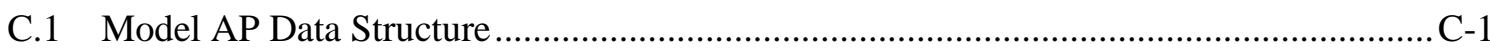

C.2 EURATOM extensions to the Model AP Data Structure …..............................................

C.3 US extensions to the Model AP Data Structure _....................................................................

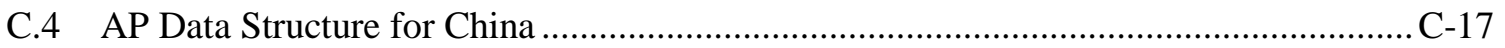

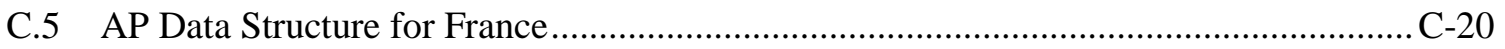

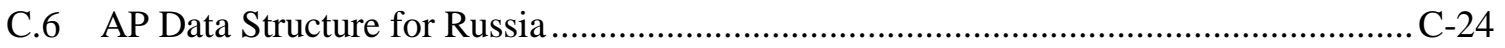

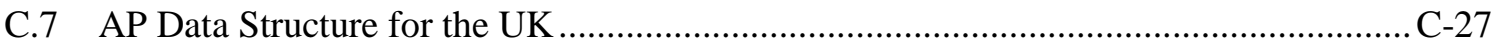

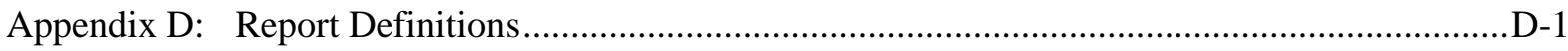

Appendix E: Protocol Reporter 1 to Protocol Reporter 3 Data Translations ..................................... E-1

Appendix F: Protocol Reporter 2 to Protocol Reporter 3 Data Translations ................................... F-1 


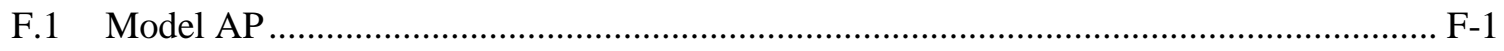

F.2 EURATOM extensions to the Model AP Data Structure ............................................. F-6

F.3 US Extensions to the Model AP Data Structure …………........................................... F-6

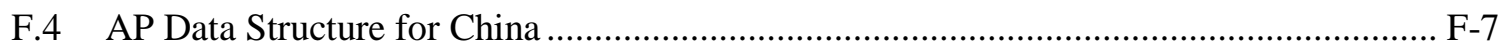

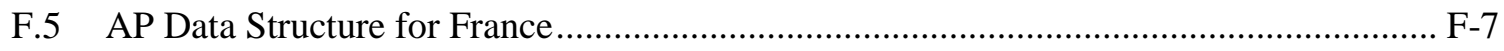

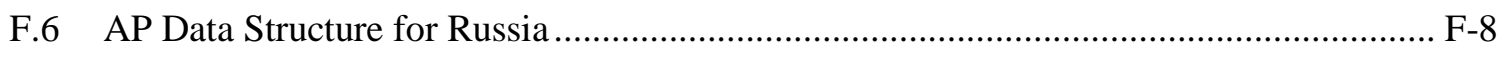

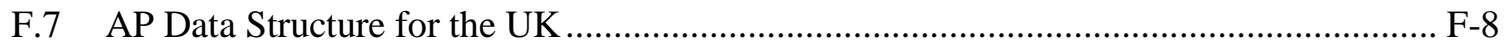




\subsection{Introduction}

\subsection{Background}

The Protocol Reporter (PR) was developed by the International Atomic Energy Agency (IAEA) to assist Member States in the creation and preparation of declarations pursuant to articles 2 and 3 of the model Additional Protocol (AP, INFCIRC/540, corrected), and was designed to be a complete tool for compiling, arranging, editing, managing, and submitting State declarations in support of the AP.

Version 1.0 (PR1) was released in 1999 and version 2.0 (PR2), the most recent version, was released in December 2008. Both are stand-alone desktop systems that allow users to systematically identify and input data on AP-declarable activities and facilities as well as to prepare a complete declaration for submission to the IAEA. The user interface is modeled similarly to that of the Microsoft Windows operating systems' File Management Module. A hierarchical structure is used to organize States (Parties), Submissions, Declarations, and Entries.

The software is currently experiencing compatibility problems with newer operating systems. Additionally, the Agency has noted shortcomings in the PR2 software and Member States have identified desirable enhancements. In this regard, Mr. Kevin Veal of the US Department of Energy (DOE) National Nuclear Security Administration (NNSA) Office of Nuclear Safeguards \& Security sent a letter dated March 26, 2013, to Mr. Herman Nackerts, Deputy Director General, Department of Safeguards, IAEA, offering DOE/NNSA's support to the Agency in upgrading the PR2 software. The IAEA accepted this offer in a May 15, 2013, letter from Mr. Nackerts to Mr. Veal.

In addition to numerous email exchanges, the following working sessions were held to facilitate documentation of the requirements specifications herein.

\section{Date}

25-26 September 2013

29-31 January 2014

11-12 March 2014

\section{Location}

IAEA, Vienna

IAEA, Vienna

IAEA, Vienna

\author{
Participants \\ SG/SGIM/ISD, IAEA \\ SG/SGIM/IFC, IAEA \\ SG/SGIM/ISI, IAEA \\ INSEP, DOE/NNSA \\ SG/SGIM/ISD, IAEA \\ SG/SGIM/IFC, IAEA \\ SG/SGIM/ISI, IAEA \\ INSEP, DOE/NNSA \\ SG/SGIM/ISD, IAEA \\ SG/SGIM/IFC, IAEA \\ SG/SGIM/ISI, IAEA \\ INSEP, DOE/NNSA
}

The intended audiences of this document are the analysts and developers tasked with designing the system to fulfill the identified requirements and the testers who must verify the requirements have been met.

Within this document, the term "the system" refers to the Protocol Reporter version 3 only. 


\subsection{Scope}

This System Requirements Specification (SRS) documents and defines the functional and data highlevel requirements for an automated information system to capture and manage data submitted to the IAEA as part of a State's AP obligations. The planned system is intended to succeed the current IAEA-developed software tools known as the IAEA Protocol Reporter versions 1.0 and 2.0.

The scope of this document is to provide the reader with discrete and verifiable software requirements for the version 3.0 of the Protocol Reporter (PR3). Section 2.0 gives a general vision of the PR3. Section 3.0 includes use-case scenarios, defining actors, system objectives, and their respective interactions. Section 4.0 decomposes the use cases into detailed functional specifications and business rules. Appendix A contains acronyms, and a glossary is included in Appendix B. Appendix C lists detailed data element requirements and their relationships, and Appendix D describes reporting requirements, including individual reports and the content of each. Appendices E and F map the legacy data elements from Protocol Reporter versions 1.0 and 2.0 into the PR3 data structure.

The SRS is not intended to capture design information. Rather, design specifications are consciously avoided to prevent injection of artificial parameters that may unintentionally constrain design options. Detailed design plans will be documented in the System Design Specification (SDS), which will cross-reference the SRS to ensure all requirements are met.

\subsection{Ownership}

This SRS was funded and developed by the United States Department of Energy National Nuclear Security Administration (DOE/NNSA) in support of, and in coordination with, the International Atomic Energy Agency (IAEA). DOE/NNSA is providing this document to the IAEA to assist the Agency in its goal of updating the Protocol Reporter software. The work is sponsored by the DOE International Nuclear Safeguards Engagement Program (INSEP). Neither the IAEA nor DOE/NNSA is bound by the specifications herein.

\subsection{Related Documents}

1. Model Protocol Additional to the Agreement(s) Between State(s) and the International Atomic Energy Agency for the Application of Safeguards (INFCIRC/540, corrected)

2. Guidelines and Format for Preparation and Submission of Declarations Pursuant to Articles 2 and 3 of the Model Protocol Additional to Safeguards Agreements, May 2004 (Service Series 11)

3. The document: Requirement specifications for PR3.0_ISD version August 2013_JI

4. The document: Idinger - Requirement specifications_Meeting_Sep2013

5. The document: Shortcomings of PR

6. The document: PR2 Requirements Document - Draft (where applicable)

7. PR3 working meeting notes: 25-26 September 2013

8. PR3 working meeting notes: $29-31$ September 2013

9. PR3 working meeting notes: $11-12$ March 2014 


\subsection{Product Perspective}

The primary functions of the PR3 are to assist States to

- create and manage entries,

- create and manage declarations and submissions, and

- transfer or transmit submissions to the IAEA.

This diagram shows how data will be passed between participants in a State's AP declaration process. A State's Safeguards Regulatory Authority (SRA) will collect declaration data from organizations within that State in the form of declaration Entries. Then, the SRA will organize them into Declarations within a Submission. Finally, the SRA will transmit only the declarable data it has collected to IAEA.

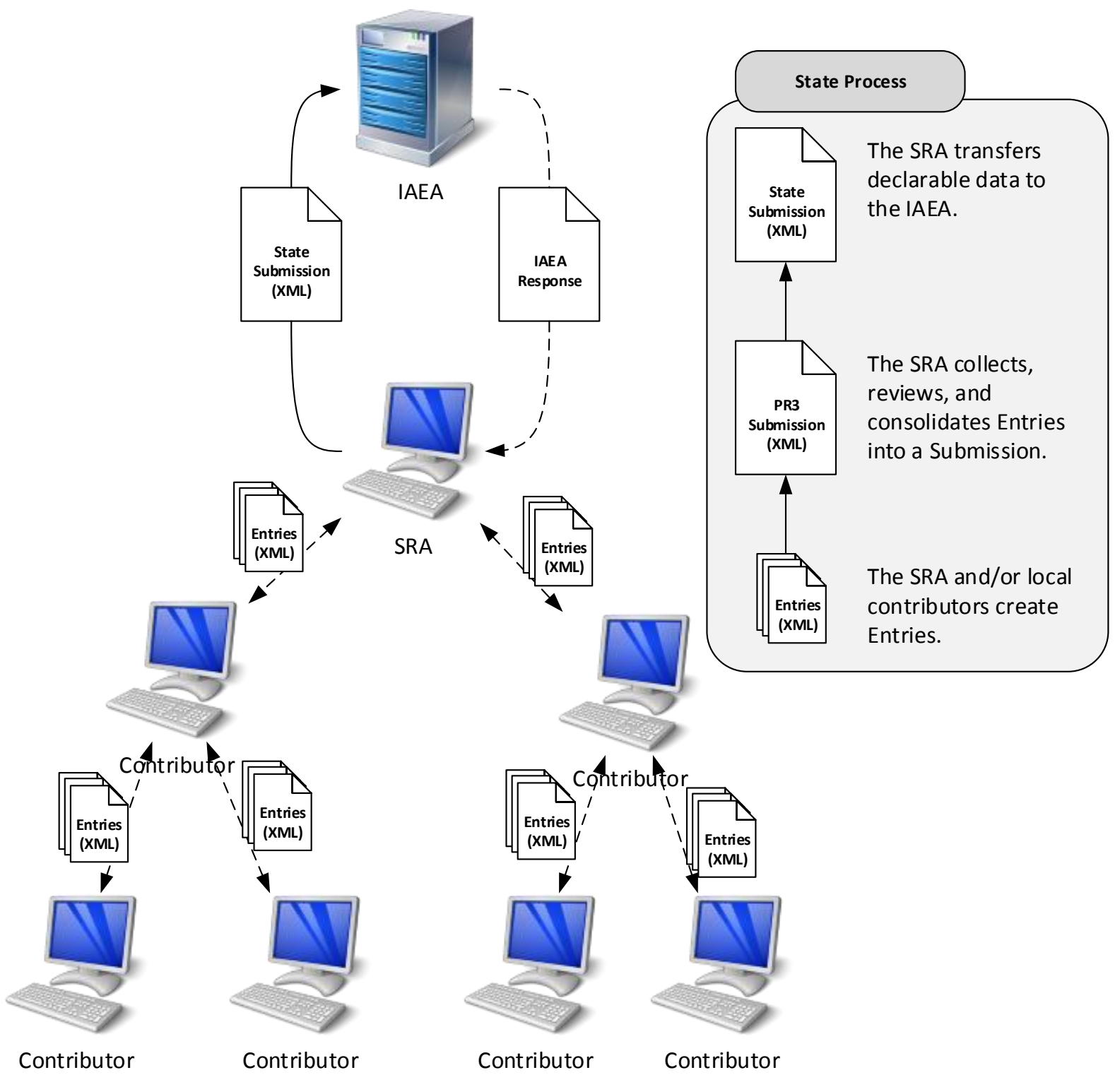




\subsection{Use Cases}

\subsection{Actors}

This section defines the roles a user may take when interacting with the Protocol Reporter 3.0, depending on the task they are performing. A user may have more than one role, or his/her role(s) may change, depending on the context.

Roles are only for the purpose of defining use cases. The system will not identify a user as a member of a particular role or restrict functionality based on roles.

\begin{tabular}{|l|l|l|l|}
\hline \multicolumn{1}{|c|}{ Actor or Role } & \multicolumn{1}{|c|}{ Type of Role } & \multicolumn{1}{|c|}{ Is a(n) } & \multicolumn{1}{|c|}{ Must be able to } \\
\hline $\begin{array}{l}\text { Contributor } \\
\text { Originator }\end{array}$ & Originator & $\begin{array}{l}\text { Field subject matter expert; may know } \\
\text { little about the AP }\end{array}$ & Create and edit entries \\
\hline $\begin{array}{l}\text { Contributor } \\
\text { Reviewer }\end{array}$ & Reviewer & Field subject matter expert & $\begin{array}{l}\text { View, review, and print } \\
\text { entries and related reports }\end{array}$ \\
\hline $\begin{array}{l}\text { Safeguards } \\
\text { Regulatory } \\
\text { Authority (SRA) } \\
\text { Originator }\end{array}$ & Originator & SRA subject matter expert & $\begin{array}{l}\text { Create and edit entries, } \\
\text { declarations, and } \\
\text { submissions }\end{array}$ \\
\hline $\begin{array}{l}\text { SRA Reviewer } \\
\text { SRA Submitter }\end{array}$ & Submitter & SRA subject matter expert & $\begin{array}{l}\text { View, review, and print } \\
\text { entries, declarations, } \\
\text { submissions, and related } \\
\text { reports }\end{array}$ \\
\hline & & & $\begin{array}{l}\text { Finalize and submit } \\
\text { completed submission to } \\
\text { the IAEA }\end{array}$ \\
\hline
\end{tabular}

\subsection{Software Installation}

Installs:

- Executable software

- Data templates available to the State

- IAEA-provided lookup file(s)

- Default values for State-specific lookup file(s)

- Electronic versions of manuals, guides, etc.

- If there is more than one data template included in the installation package, the user will select one. 


\subsection{Manage Settings}

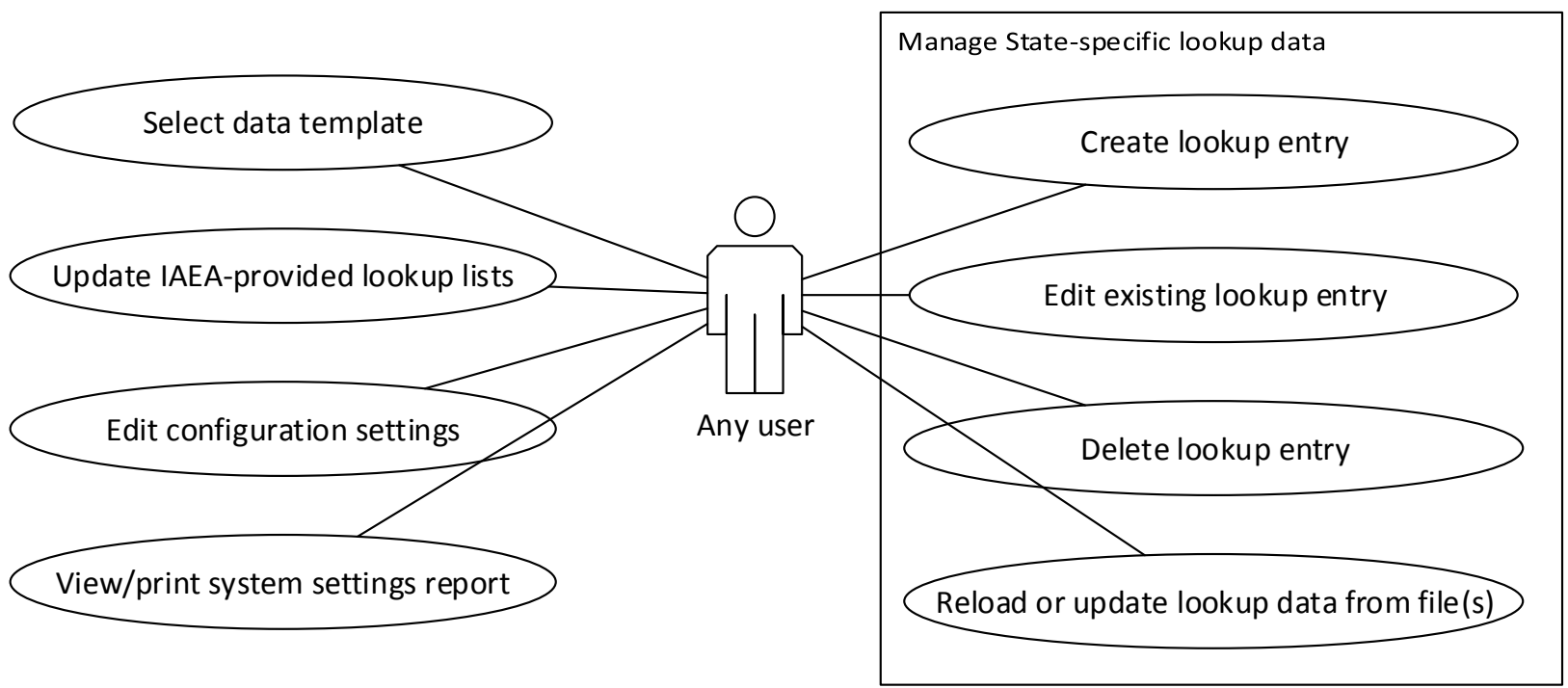

\subsubsection{Select data template}

- The user is able to view a list of all installed data templates and select the one to be the default when creating new Entries or Submissions.

\subsubsection{Update IAEA-provided lookup lists}

- These values match data specified in the Lookup section of the data model. Update data will be imported from a file provided by the IAEA.

\subsubsection{Manage State-specific lookup data}

- These values match data specified in the Lookup section of the data model.

\subsubsection{Edit configuration settings}

- Examples: default data directory, network/proxy server settings

\subsubsection{View or print system settings reports}

- A user may view a report that shows all installed data template(s), lookup list data, and lookup data. 


\subsection{Manage Entries}

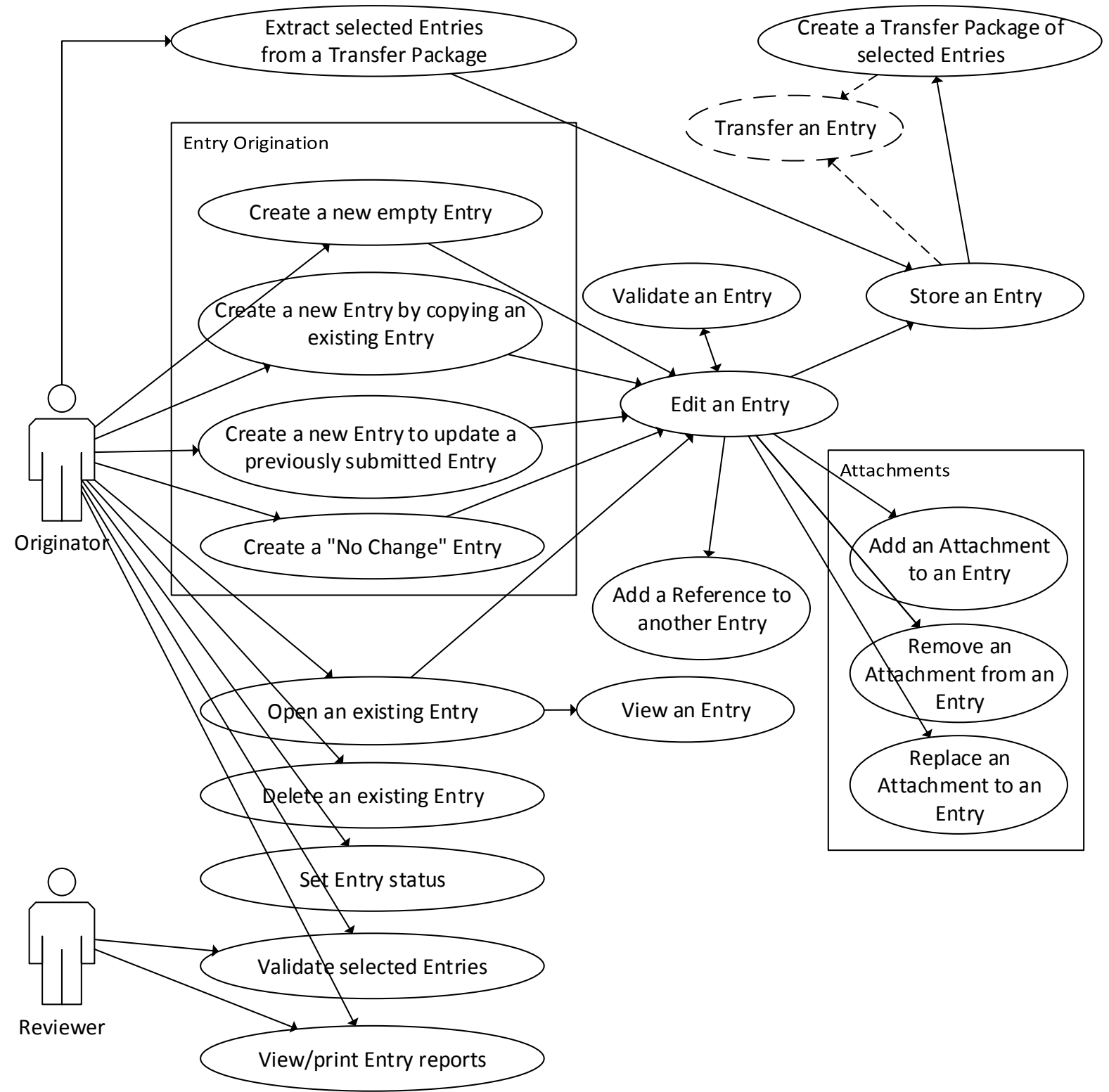

\subsubsection{Create a new empty Entry}

- Applies to: Contributor Originator or SRA Originator

- The user selects the Article for the new Entry.

\subsubsection{Create a new Entry by copying an existing Entry}

- Applies to: Contributor Originator or SRA Originator

- Data used to uniquely identify the source Entry (which will be different for the new Entry) will not be copied.

\subsubsection{Create a new Entry to update a previously submitted Entry}

- Applies to: Contributor Originator or SRA Originator

- A reference to the source Entry will be added to the new Entry. 
- Data used to uniquely identify the source Entry (which will be different for the new Entry) will not be copied.

\subsubsection{Create a "No Change" Entry}

- Applies to: Contributor Originator or SRA Originator

- The user refers to or selects a valid Entry to update (the source Entry), if available.

- A reference to the source Entry will be added to the new Entry.

- If available, data will be copied from the source Entry to the new Entry. Specific fields used to uniquely identify the source Entry (which will be different for the new Entry) will not be copied.

- Undeclarable fields such as comments may be changed, but declarable fields will not be editable.

\subsubsection{Open an existing Entry}

- Applies to: Contributor Originator or SRA Originator

- Read-only Entries will be opened for viewing rather than editing.

\subsubsection{Delete an existing Entry}

- Applies to: Contributor Originator or SRA Originator

- If the system contains a file manager, the user may delete an Entry file from the file manager.

- The system will warn the user prior to deletion if other Entries contain references to the Entry to be deleted.

- The user may delete an Entry file through Windows Explorer.

\subsubsection{Set Entry status}

- Applies to: Contributor Originator or SRA Originator

- The user may set the current status of an Entry.

- Some statuses will make the Entry read only.

\subsubsection{Validate selected Entries or validate an open Entry}

- Applies to: Contributor Originator, Contributor Reviewer, SRA Originator, or SRA Reviewer

- The user may execute validation as desired.

- Validation at this stage is a user feedback mechanism, not a constraint, and will not restrict any action.

\subsubsection{View or print Entry Reports}

- Applies to: Contributor Originator, Contributor Reviewer, SRA Originator, or SRA Reviewer

- The user may select one or more Entries (either as individual files, part of a Declaration, or part of a Submission) and view details in a printable format.

\subsubsection{Edit an Entry}

- Applies to: Contributor Originator or SRA Originator

- All undeclarable and declarable data can be edited; however, the Entry's Article or associated data template cannot be changed. 


\subsubsection{Add a Reference to another Entry}

- Applies to: Contributor Originator or SRA Originator

- The reference could indicate an update or complementary information.

- If the referenced Entry is available, the user selects it from a pick list.

- If the referenced Entry is not available, the user enters the declaration number, entry number, and (if necessary) state.

- References will be automatically resolved whenever Submissions are numbered.

\subsubsection{View an Entry}

- Applies to: Contributor Originator or SRA Originator

- This action will be used for Entries that are read only.

- The user cannot change the Entry data.

\subsubsection{Add an Attachment to an Entry}

- Applies to: Contributor Originator or SRA Originator

- The user must either select a file or enter the title of a printed document being referenced.

\subsubsection{Remove an Attachment from an Entry}

- Applies to: Contributor Originator or SRA Originator

- A selected attachment is removed from the Entry.

\subsubsection{Replace an Attachment to an Entry}

- Applies to: Contributor Originator or SRA Originator

- The user must either select a new file (or a new version of the file) or change the title of the printed document being referenced.

\subsubsection{Store an Entry}

- Applies to: Contributor Originator or SRA Originator

- Validation errors or warnings will not prevent the user from storing an Entry.

\subsubsection{Transfer an Entry}

- Applies to: Contributor Originator, Contributor Reviewer, SRA Originator, or SRA Reviewer

- Entries stored as individual files can be transferred among system users and opened per "Open an existing entry" without further processing.

- The system will not enforce or provide a method for transfer. States and sites can decide how they will transfer saved Entries internally (network file share, email, web-based collaboration software such as SharePoint, etc.).

\subsubsection{Create a Transfer Package of selected Entries}

- Applies to: Contributor Originator, Contributor Reviewer, SRA Originator, SRA Reviewer

- The user can employ an enhanced Entry management interface to select and locally store a collection of Entries that can then be transferred among system users.

- The system will not enforce a method for transfer. States and sites can decide how they will transfer saved Entries internally (network file share, email, web-based collaboration software such as SharePoint, etc.). 


\subsubsection{Extract selected Entries from a Transfer Package}

- Applies to: Contributor Originator, Contributor Reviewer, SRA Originator, SRA Reviewer

- A user can extract Entries from a Transfer Package directly in the system and manage them as they would in the case of locally created entries.

\subsection{Manage Declarations}

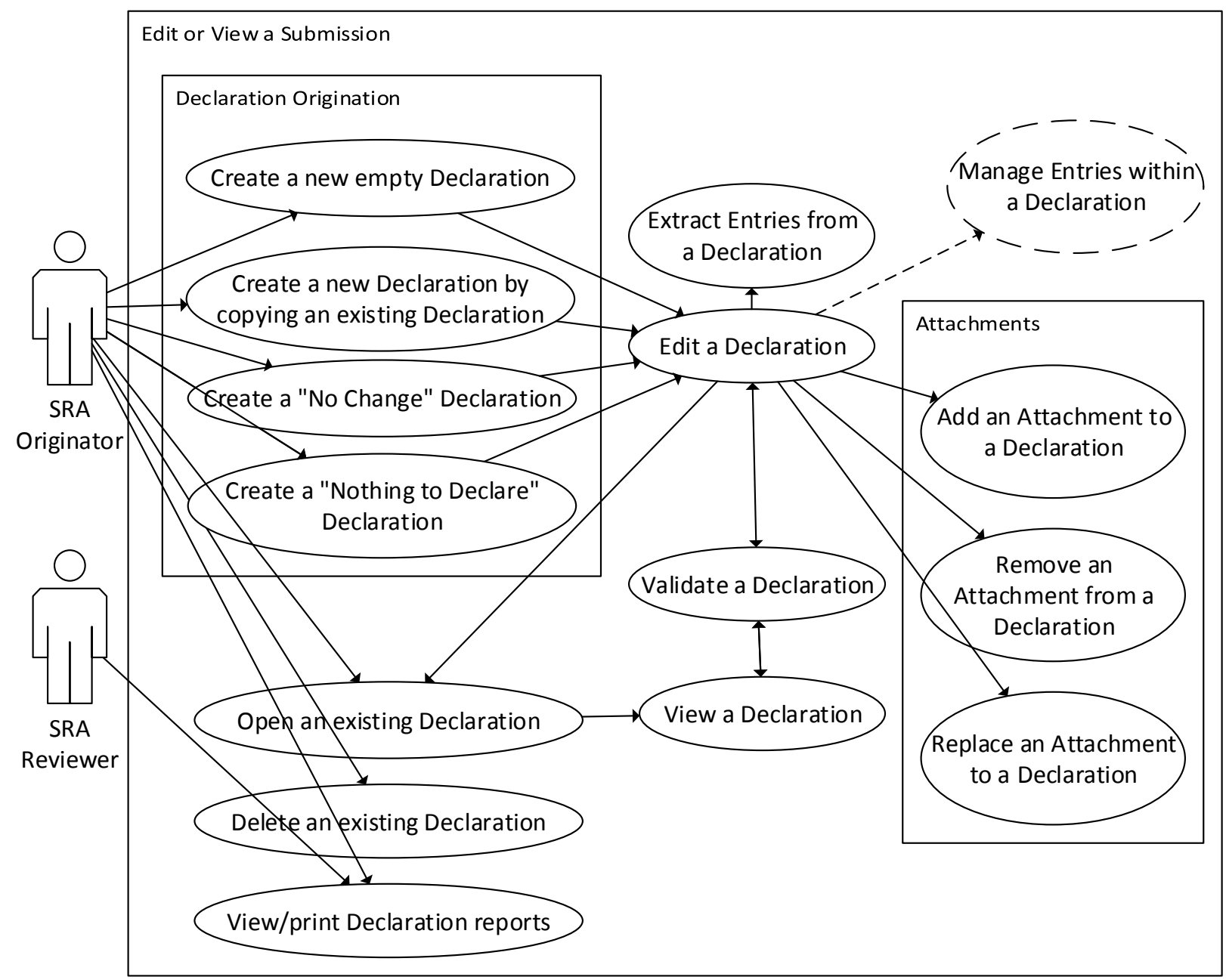

\subsubsection{Create a new empty Declaration}

- Applies to: SRA Originator

- The user selects the Article for the new Declaration from on the list of Articles allowed for the Submission.

\subsubsection{Create a new Declaration by copying an existing Declaration}

- Applies to: SRA Originator

- The source Declaration type must be valid for the Submission containing the new Declaration.

- Entries contained by the Declaration will also be copied. 
- Data used to uniquely identify the source Declaration and its Entries (which will be different for the new Declaration) will not be copied.

\subsubsection{Create a "No Change" Declaration}

- Applies to: SRA Originator

- The source Declaration type must be valid for the Submission containing the new Declaration.

- No Entries will be copied.

- Data used to uniquely identify the source Declaration and its Entries (which will be different for the new Declaration) will not be copied.

\subsubsection{Create a "Nothing to Declare" Declaration}

- Applies to: SRA Originator

- The user selects the Article for the new Declaration from the list of Articles allowed for the Submission.

- Entries may not be added to a Nothing to Declare Declaration.

\subsubsection{Open an existing Declaration}

- Applies to: SRA Originator

- Read-only Declarations will be opened for viewing rather than editing.

\subsubsection{Delete an existing Declaration}

- Applies to: SRA Originator

- The user will be warned regarding references to Entries contained by this Declaration within other Entries prior to deletion.

\subsubsection{View and print Declaration reports}

- Applies to: SRA Originator or SRA Reviewer

- The user may select one or more Declarations and view details in a printable format.

- Some reports will contain full details of the Entries contained by Declarations.

\subsubsection{Edit a Declaration}

- Applies to: SRA Originator

- All undeclarable and declarable data can be edited; however, the Declaration's Article or associated data template cannot be changed.

- Changes to the Declaration will be stored when the Submission containing it is stored.

\subsubsection{Validate an open Declaration}

- Applies to: SRA Originator or SRA Reviewer

- The user may execute validation as desired.

- Validation at this stage is a user feedback mechanism, not a constraint, and will not restrict any action.

- Both the Declaration and the Entries it contains will be validated by this action.

\subsubsection{View a Declaration}

- Applies to: SRA Originator

- This action will be used for Declarations that are read only. 
- The user cannot change any Declaration or Entry data.

\subsubsection{Extract Entries from a Declaration}

- Applies to: SRA Originator

- Entries contained in a Declaration can be copied out of the Declaration as independent Entries, or pasted into another Declaration for the same article.

\subsubsection{Add an Attachment to a Declaration}

- Applies to: SRA Originator

- The user must either select a file or enter the title of a printed document being referenced.

\subsubsection{Remove an Attachment from a Declaration}

- Applies to: SRA Originator

- A selected attachment is removed from the collection.

\subsubsection{Replace an Attachment to a Declaration}

- Applies to: SRA Originator

- The user must either select a new file (or a new version of the file) or change the title of the printed document being referenced.

\subsubsection{Manage Entries within a Declaration}

- Applies to: SRA Originator

- All operations that can be performed on Entries that exist independently can be performed on Entries contained in a Declaration. (However, some of these operations may be implemented slightly differently.)

- Entries within a Declaration are only editable if the Submission containing them is editable.

- The user will be able to perform all functions under Section 3.4, Manage Entries, for all Entries contained in a Declaration.

- The status of Entries within a Declaration is limited by that Declaration's status. For example, if the Declaration is read only, all of its contents will be read only. 


\subsection{Manage Submissions}

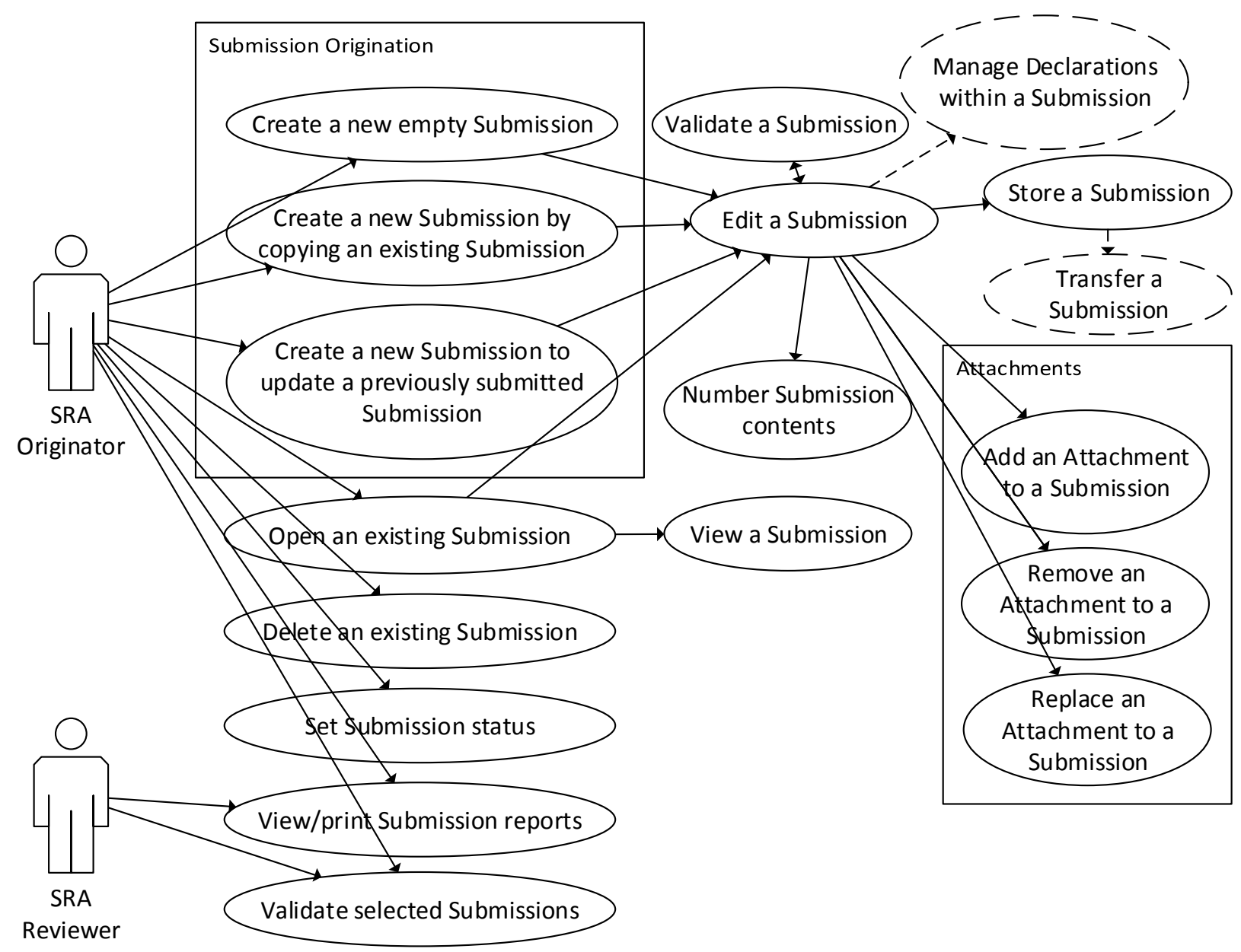

\subsubsection{Create a new empty Submission}

- Applies to: SRA Originator

- The user selects the Submission type.

\subsubsection{Create a new Submission by copying an existing Submission}

- Applies to: SRA Originator

- Declarations and Entries in the source Submission will also be copied.

- Data used to uniquely identify the source Submission and its Declarations and Entries (which will be different for the new Submission) will not be copied.

\subsubsection{Create a new Submission to update a previously submitted Submission}

- Applies to: SRA Originator

- Declarations and their Entries in the source Submission that are eligible for update will also be copied.

- A reference to the corresponding Entry in the source Submission will be added to each new update Entry as necessary.

- Data used to uniquely identify the source Submission, its Declarations, and their Entries (which will be different for the new Declaration) will not be copied. 


\subsubsection{Open an existing Submission}

- Applies to: SRA Originator

- Read-only Submissions will be opened for viewing rather than editing.

\subsubsection{Delete an existing Submission}

- Applies to: SRA Originator

- The user will be warned regarding references to Entries contained by Declarations in this Submission within other Entries prior to deletion.

\subsubsection{Set Submission status}

- Applies to: SRA Originator

- The user may set the current status of a Submission.

- Some statuses will make the Submission read only.

\subsubsection{View and print Submission Reports}

- Applies to: SRA Originator or SRA Reviewer

- The user may select one or more Submissions and view details in a printable format.

- Some reports will contain full details of the Declarations and Entries in the Submission.

\subsubsection{Validate selected Submission or validate an open Submission}

- Applies to: SRA Originator or SRA Reviewer

- The user may execute validation as desired.

- Validation at this stage is a user feedback mechanism, not a constraint, and will not restrict any action.

- The Submission and its Declarations and Entries will all be validated as part of this action.

\subsubsection{Edit a Submission}

- Applies to: SRA Originator

- All undeclarable and declarable data can be edited; however, the Submission's type or associated data template cannot be changed.

\subsubsection{Number Submission contents}

- Applies to: SRA Originator

- The Declarations and Entries in a Submission will be numbered, either automatically (sequentially, with no gaps) or explicitly.

- The first Declaration number and Entry number used in automatic numbering may be specified for each Submission.

- Numbering must occur before submission to IAEA.

- After numbering or renumbering, references will be resolved and updated accordingly.

\subsubsection{View a Submission}

- Applies to: SRA Originator

- This action will be used for Submissions that are read only.

- The user cannot change any Submission, Declaration, or Entry data. 


\subsubsection{Add an Attachment to a Submission}

- Applies to: SRA Originator

- The user must either select a file or enter the title of a printed document being referenced.

\subsubsection{Remove an Attachment to a Submission}

- Applies to: SRA Originator

- A selected attachment is removed from the collection.

\subsubsection{Replace an Attachment to a Submission}

- Applies to: SRA Originator

- The user must either select a new file (or a new version of the file) or change the title of the printed document being referenced.

\subsubsection{Manage Declarations within a Submission}

- Applies to: SRA Originator

- The user will be able to perform all functions under Section 3.5, Manage Declarations, for all Declarations contained in a Submission.

- The statuses of Declarations or Entries within a Submission are limited by that Submission's status. For example, if the Submission is read only, all of its contents will be read only.

\subsubsection{Store a Submission}

- Applies to: SRA Originator

- Validation errors or warnings will not prevent the user from storing a Submission.

\subsubsection{Transfer a Submission}

- Applies to: SRA Originator, SRA Submitter

- Submissions stored as individual files can be transferred among system users and opened per "Open an existing Submission" without any further processing.

- The system does not enforce a method for transfer. States and sites can decide how they will transfer saved data internally (network file share, email, web-based collaboration software such as SharePoint, etc.). 


\subsection{Transfer Submissions to the IAEA}

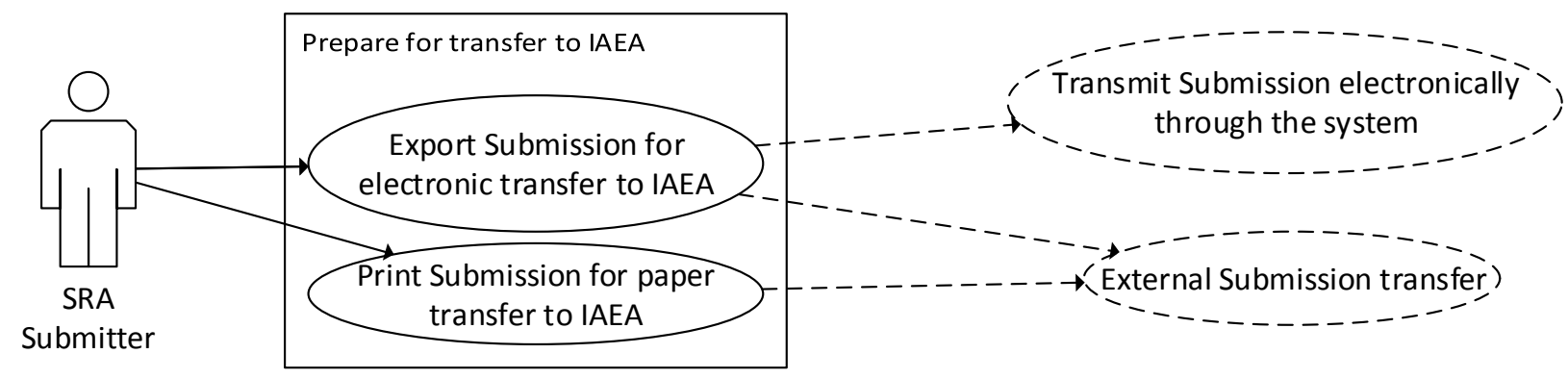

\subsubsection{Export Submission for electronic transfer to IAEA}

- Applies to: SRA Submitter

- Validation will be automatically triggered prior to exporting. If the Submission is not complete, appropriate warnings will be shown but will not prevent the user from exporting.

- Only declarable information will be included in the exported file. Undeclarable data entered for State use only will not be included.

- The Submission being exported will have its status changed to "prepared for submission", and will become read only.

\subsubsection{Print Submission for paper transfer to IAEA}

- Applies to: SRA Submitter

- Validation will be automatically triggered prior to printing. If the Submission is not complete, appropriate warnings will be shown but will not prevent the user from printing.

- The printed Submission will match format and submission guidelines.

- Only declarable information will be included in the report. Undeclarable data entered for State use only will not be included.

- The Submission being printed will have its status changed to "prepared for submission", and will become read only.

\subsubsection{Transfer Submission electronically through the system}

- Applies to: SRA Submitter

- A possible use case; not required. This would require cooperation between developers of the PR3 and developers of the IAEA's internal AP system.

- This could be a separate application from the system.

- The user must provide credentials before upload is allowed.

- IAEA's receiving system would immediately report the success or failure of reading, validating, and importing the file.

- The export format would be the same as that produced by "Export Submission for electronic transfer to IAEA," discussed in Section 3.7.1.

- The system would update the status of the Submission based on the response.

- This function should employ appropriate error-checking and security techniques based on requirements to be defined. 


\subsubsection{External transfer process}

- Applies to: SRA Submitter

- A State may transfer its exported or printed Submission to the IAEA outside the system (courier, email, hard copy, disk, flash drive, file upload, etc.).

- This process cannot be tracked by the system.

- Other software or manual processes at the IAEA will be necessary to report the success or failure of reading, validating, and importing the file into the IAEA's internal system to the State.

- The State is responsible for following up if necessary.

\subsection{Manage Legacy Data}

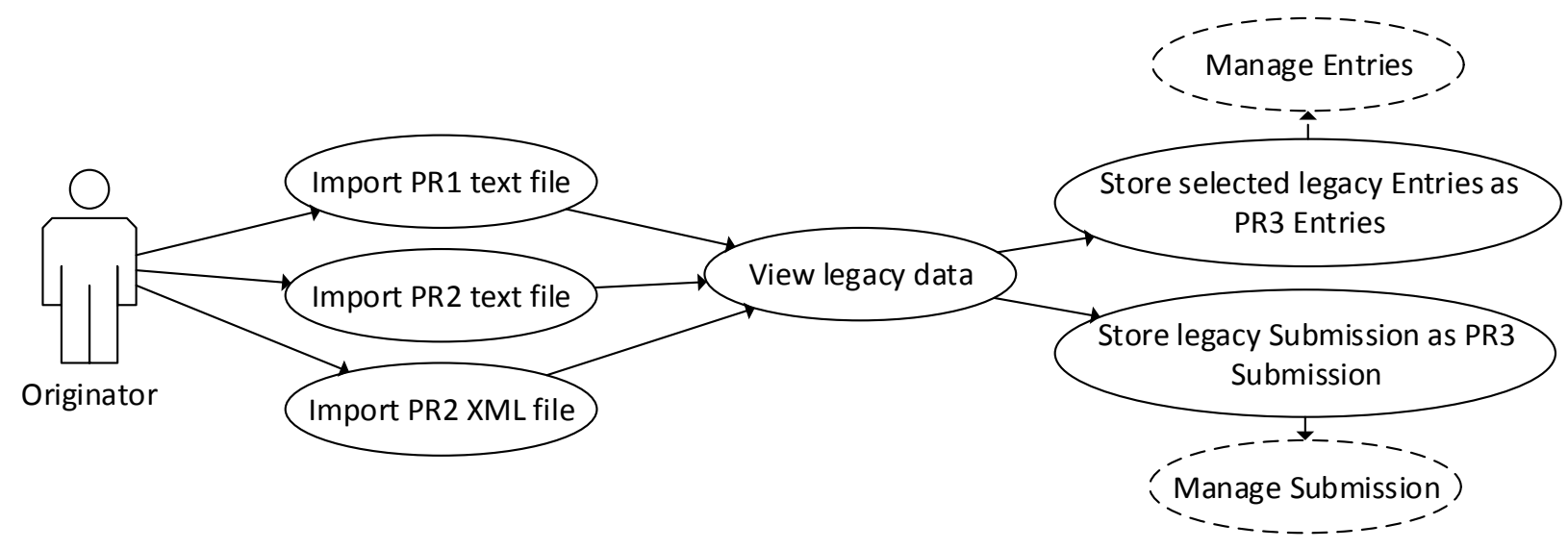

\subsubsection{Import data from a PR1 text file, PR2 text file, or PR2 XML file}

- Applies to: Contributor Originator or SRA Originator

- Loads data from PR1 or PR2 format, based on the current data template.

- Submission data to be imported must be in a valid format that matches an installed data template.

\subsubsection{View legacy data}

- Applies to: Contributor Originator or SRA Originator

- Displays the loaded PR1 or PR2 file in the legacy format (with fields as they existed in the earlier version).

- Legacy data is read only.

\subsubsection{Store selected legacy Entries as PR3 Entries}

- Applies to: Contributor Originator or SRA Originator

- Imports selected Entries from the legacy Submission in the current format, based on the selected data template.

- Two purposes:

- Allows users to import data initially created in the PR1 or PR2.

- Allows a State's previous submissions to be used for validating references in the system.

- Where the system uses a more granular structure than previous PR versions:

○ The PR3 Entry will be incomplete. 
- Combined fields will be stored into general description or declarable comments fields (depending on the Entry Article).

- A user must manually copy and paste data from the legacy Entries into the PR3's structure to meet validation requirements if it is to be submitted later.

\subsubsection{Store a legacy submission as a PR3 Submission}

- Applies to: SRA Originator

- Saves the legacy data in the current format, based on the selected data template.

- Two purposes:

- Allows users to enter data initially created in the PR1 or PR2.

- Allows a State's previous submissions to be used for validating references in the system.

- Where the system uses a more granular structure than previous PR versions:

- The PR3 Submission will be incomplete.

- Combined fields will be stored into general description or declarable comments fields (depending on the Entry Article).

- A user must manually copy and paste data from the legacy Submission into the PR3's structure to meet validation requirements if it is to be submitted later.

\subsubsection{Manage Entries}

- Applies to: Contributor Originator, Contributor Reviewer, SRA Originator, or SRA Reviewer

- PR3 Entries created from legacy data can be managed just like independent Entries created in the system.

\subsubsection{Manage Submissions}

- Applies to: SRA Originator or SRA Reviewer

- A PR3 Submission created from legacy data can be managed just like a Submission created in the system.

- Declarations or Entries in the imported Submission can be extracted into individual Declarations and Entries, and transferred to other users, either at sites or the SRA. 


\subsection{Respond to IAEA Requests}

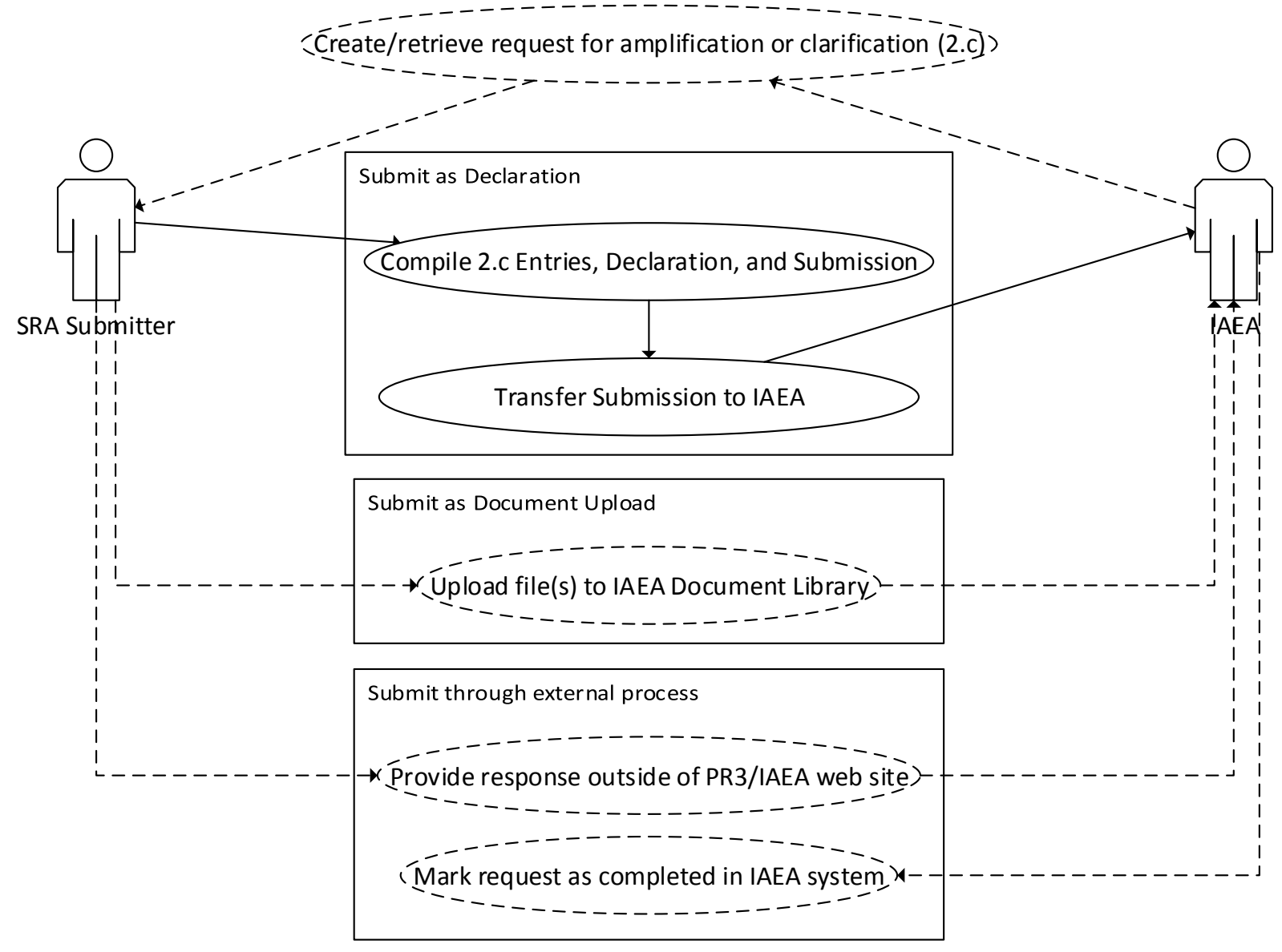

\subsubsection{Create or retrieve request for amplification or clarification}

- Applies to: IAEA and SRA Submitter

- The IAEA requests additional information from the State per Model AP article 2.c (or equivalent article in a State-specific AP).

\subsubsection{Compile 2.c Entries, Declaration, and Submission}

- Applies to: SRA Submitter

- If the request is received as a file in a standard format, the system may be able to automatically generate 2.c Entries or Submissions to be filled in.

- A Submission containing 2.c Declarations and Entries should be created as described in other use cases.

\subsubsection{Transfer Submission to IAEA}

- Applies to: SRA Submitter

- A Submission containing 2.c Declarations can be exported and submitted to IAEA as described in other use cases.

\subsubsection{Upload file(s) to IAEA Document Library}

- Applies to: SRA Submitter 
- A possible use case; the IAEA may provide a web site to serve as a portal to a document repository so States can upload files directly rather than submit responses through the PR3.

- This option would only be available for requests under article 2.c. Responses to Article 2.a.(ii) requests must still be submitted as Declarations.

\subsubsection{Provide response outside of the system or IAEA website}

- Applies to: SRA Submitter, IAEA

- A State should be able to respond to an Agency request without using an IAEA-provided web site or a Submission.

- This option would only be available for requests under article 2.c. Responses to Article 2.a.(ii) requests must still be submitted as Declarations.

\subsubsection{Mark request as completed in IAEA system}

- Applies to: IAEA

- If a State responds to an Agency request outside of an IAEA-provided web site or a Submission, the IAEA should have a way to mark the request as completed within its system. 


\subsection{Receive Data from the IAEA}

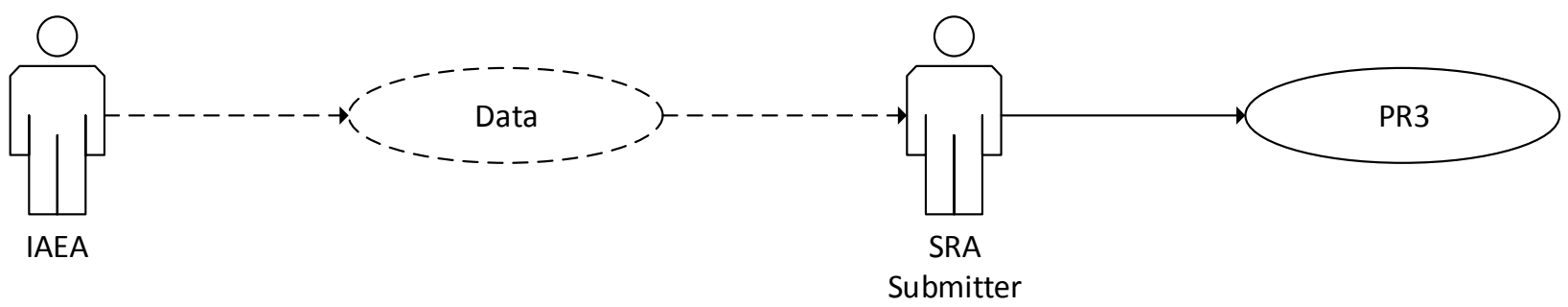

\subsubsection{IAEA provides data/SRA Submitter receives data}

- Applies to: IAEA and SRA Submitter

- A possible use case; not required. This would require cooperation between developers of the PR3 and developers of the IAEA's internal AP system.

- Data could be downloaded into the system directly or could be received via external means. The latter would require the SRA to enter the data into the system, if necessary.

- The IAEA could allow States to retrieve:

- Responses to Submissions with any feedback, identification, or notes added by the IAEA

- Requests for additional information from the IAEA (i.e., Article 2.c)

- Lists of declarations and entries currently on file and expected to be updated

○ Previously submitted State Submissions

\subsubsection{Import or open received data in the PR3}

- Applies to: Contributor Originator or SRA Originator

- The actions available in the system will be developed based on the type of data that may be provided by the IAEA. 


\subsection{Requirements}

This section describes detail requirements of the PR3.

The requirement tables include several items of information concerning each individual requirement:

- The requirement identifier

- The actual text of the requirement

- The test method to be used for the requirement

A valid requirement identifier is of the format $a a-n n n$, where $a a$ signifies the topical area (such as "OE" for Operational Environment) and nnn is a number unique to the given topical area. The requirement number will stay with the requirement for the life of the project to ensure proper traceability.

In regards to Test Method, the following are used.

- Interview (I): The testing process includes an interview of someone (e.g., an authenticated user, system administrator, cyber security officer, system owner, etc.) to confirm that part or the entire requirement has been implemented.

- Observation $(\mathrm{O})$ : The testing process includes observing an operation (e.g., system accepts/rejects the data, user initiates help, etc.) to confirm that part or the entire requirement has been implemented.

- Technical Testing (T): The testing process includes technically testing an operation (e.g., upload/download of data, the system generates correct reports, etc.) to confirm that part or the entire requirement has been implemented.

- Documentation (D): The testing process includes verifying that documentation exists and includes the required information (e.g., data management procedures are in place, user/administrators guidance is available, etc.) to confirm that part or the entire requirement has been implemented.

The SRS is a living document that evolves with the project. Additions and modifications will occur as significant new functionality is identified or substantive changes are required. 


\subsection{System Requirements}

\subsubsection{Operational Environment (OE)}

\begin{tabular}{|l|l|c|}
\hline Reqmt-ID & Requirement & $\begin{array}{c}\text { Test } \\
\text { Method }\end{array}$ \\
\hline OE-001 & The system shall be able to operate on a single Windows-based computer. & T \\
\hline OE-002 & $\begin{array}{l}\text { The system shall be capable of running on either 32-bit or 64-bit computing } \\
\text { platforms. }\end{array}$ & $\mathrm{T}$ \\
\hline OE-003 & $\begin{array}{l}\text { The system shall be capable of running under Microsoft Windows XP } \\
\text { operating system and later versions of Windows through Windows 8.1. }\end{array}$ & $\mathrm{T}$ \\
\hline OE-004 & $\begin{array}{l}\text { Installation and operation of the system shall not require additional software } \\
\text { or special environments that lead to the need for supplementary software } \\
\text { licenses. }\end{array}$ & O,D \\
\hline
\end{tabular}

\subsubsection{System Configuration (SC)}

\begin{tabular}{|l|l|c|}
\hline Reqmi-ID & Requirement & $\begin{array}{c}\text { Test } \\
\text { Method }\end{array}$ \\
\hline SC-001 & $\begin{array}{l}\text { The system and all associated components (including help files) shall be } \\
\text { written in the English language. }\end{array}$ & O \\
\hline SC-002 & $\begin{array}{l}\text { At a minimum, the system shall support a single-user stand-alone installation } \\
\text { with no network connection. }\end{array}$ & $\mathrm{T}$ \\
\hline SC-003 & $\begin{array}{l}\text { The system shall not require user authentication to operate. This requirement } \\
\text { does not apply to any function that electronically transmits or receives } \\
\text { Submission data from Agency systems. }\end{array}$ & $\mathrm{T}$ \\
\hline SC-004 & $\begin{array}{l}\text { Installation and use of the system shall not require reconfiguration (i.e., } \\
\text { changing the default date format) of the target computer. }\end{array}$ & $\mathrm{T}$ \\
\hline SC-005 & $\begin{array}{l}\text { The system shall be built such that it can be translated into different } \\
\text { languages. }\end{array}$ & $\mathrm{T}$ \\
\hline
\end{tabular}

\subsubsection{System Architecture (SA)}

\begin{tabular}{|l|l|c|}
\hline Reqmt-ID & Requirement & $\begin{array}{c}\text { Test } \\
\text { Method }\end{array}$ \\
\hline SA-001 & $\begin{array}{l}\text { The system's web components (if any) shall operate on computers running } \\
\text { appropriate popular browsers with a secure transmission protocol. }\end{array}$ & $\mathrm{T}$ \\
\hline SA-002 & $\begin{array}{l}\text { The system shall support two user levels of Entry and Submission } \\
\text { development: }\end{array}$ & O,T \\
\hline SA-002.1 & $\begin{array}{l}\text { Entry preparation by Contributors (for example, at the operator or } \\
\text { site level). }\end{array}$ & O,T \\
\hline SA-002.2 & $-\quad$ Submission preparation at the SRA level. & O,T \\
\hline
\end{tabular}




\begin{tabular}{|l|l|c|}
\hline Reqmi-ID & Requirement & $\begin{array}{c}\text { Test } \\
\text { Method }\end{array}$ \\
\hline SA-003 & $\begin{array}{l}\text { The system shall be able to accommodate and apply different data structures } \\
\text { for different states in accordance with the requirements of their specific AP } \\
\text { agreements. }\end{array}$ & $\mathrm{T}$ \\
\hline SA-003.1 & $-\quad$ Model Additional Protocol & $\mathrm{T}$ \\
\hline SA-003.2 & $-\quad$ United Kingdom & $\mathrm{T}$ \\
\hline SA-003.3 & $-\quad$ France & $\mathrm{T}$ \\
\hline SA-003.4 & $-\quad$ People's Republic of China & $\mathrm{T}$ \\
\hline SA-003.5 & $-\quad$ Russia & $\mathrm{T}$ \\
\hline SA-003.6 & $-\quad$ Other TBD structures based upon future Agency agreements. & $\mathrm{T}$ \\
\hline SA-004 & $\begin{array}{l}\text { The system shall allow the user to select which data template the system will } \\
\text { use when creating Entries, Declarations, and Submissions. }\end{array}$ & $\mathrm{T}$ \\
\hline SA-005 & The system shall not require installation of a separate database server. \\
\hline
\end{tabular}

\subsection{Data Requirements}

\subsubsection{Declarable Data (DD)}

Declarable Data is any data that will be provided to the IAEA via the system as part of or in connection with a submission.

\begin{tabular}{|l|l|c|}
\hline Reqmt-ID & Requirement & $\begin{array}{c}\text { Test } \\
\text { Method }\end{array}$ \\
\hline DD-001 & $\begin{array}{l}\text { The system shall support the creation and management of information that } \\
\text { meets the requirements set forth in Article 2 and Article 3 of the AP with file } \\
\text { attachments. }\end{array}$ & O,T \\
\hline DD-002 & $\begin{array}{l}\text { A valid Entry is a collection of specific information in a format that meets the } \\
\text { requirements of the AP article to which the Entry applies. The required data } \\
\text { structure for each type of Entry is listed in Appendix C of this document. }\end{array}$ & $\mathrm{T}$ \\
\hline DD-003 & $\begin{array}{l}\text { An Entry can exist independently, without a relationship or reference to any } \\
\text { Declaration or Submission. }\end{array}$ & $\mathrm{T}$ \\
\hline DD-004 & $\begin{array}{l}\text { A Declaration consists of header information and a collection of zero or more } \\
\text { entries that apply to a specific AP article, in a format that meets the } \\
\text { requirements of that article. The required data structure for each type of } \\
\text { Declaration is listed in Appendix C. }\end{array}$ & $\mathrm{T}$ \\
\hline
\end{tabular}




\begin{tabular}{|c|c|c|}
\hline Reqmt-ID & Requirement & $\begin{array}{c}\text { Test } \\
\text { Method }\end{array}$ \\
\hline DD-005 & $\begin{array}{l}\text { A valid Declaration is one that contains all required header information (as } \\
\text { defined in Appendix C) and contains one and only one of the following. } \\
\text { - An affirmative indication that it is a "No Change" declaration, indicating } \\
\text { that the information provided in the previously submitted active } \\
\text { declaration for the corresponding article still stands, or } \\
\text { - An affirmative indication that there is "Nothing to Declare" for the } \\
\text { - Associated article, or } \\
\text { A collection or list of one or more valid Entries for the associated article. }\end{array}$ & $\mathrm{T}$ \\
\hline DD-006 & $\begin{array}{l}\text { A Submission is a collection of one or more Declarations that apply to a } \\
\text { specific Submission Type as defined in AP Article 3, along with header } \\
\text { information in a format that meets the requirements of that Submission Type. } \\
\text { The required data structure for each type of Submission is listed in } \\
\text { Appendix C of this document. }\end{array}$ & $\mathrm{T}$ \\
\hline DD-007 & $\begin{array}{l}\text { A Submission can exist independently, without a relationship to or } \\
\text { "knowledge" of any Declaration or Entry. }\end{array}$ & $\mathrm{T}$ \\
\hline DD-008 & $\begin{array}{l}\text { Submission content is identified in terms of Article } 3 \text { of the Protocol } \\
\text { Additional to the Agreement(s) Between State(s) and the International Atomic } \\
\text { Energy Agency for the Application of Safeguards. For example, 3.a type } \\
\text { Submission will expect only Declarations identified under Article 3.a and } \\
\text { Notes. A detailed description is provided in Appendix C of this document. }\end{array}$ & $\mathrm{O}, \mathrm{T}$ \\
\hline DD-009 & $\begin{array}{l}\text { A valid Submission contains all required header information (as defined in } \\
\text { Appendix C) and contains a collection of one or more Declarations that meet } \\
\text { the requirements of Article } 3 \text { for that Submission Type. }\end{array}$ & $\mathrm{O}, \mathrm{T}$ \\
\hline DD-010 & $\begin{array}{l}\text { Unless prescribed otherwise by a Submission template, Declaration content is } \\
\text { identified in terms of Article } 2 \text { of the Protocol Additional to the Agreement(s) } \\
\text { Between State(s) and the International Atomic Energy Agency for the } \\
\text { Application of Safeguards. This includes Article 2.c. A detailed description is } \\
\text { provided in Appendix C of this document. }\end{array}$ & $\mathrm{O}, \mathrm{T}$ \\
\hline DD-011 & $\begin{array}{l}\text { The system shall be capable of tracking Article 2.c support files, such as } \\
\text { letters, maps, and copies of correspondence (see File Attachments for related } \\
\text { requirements). }\end{array}$ & $\mathrm{T}$ \\
\hline DD-012 & $\begin{array}{l}\text { Data entry fields shall be displayed in such a way as to easily distinguish } \\
\text { between declarable data fields that will be submitted to the IAEA, and } \\
\text { undeclarable data fields that will not be submitted to the IAEA and is reserved } \\
\text { for State use. }\end{array}$ & $\mathrm{O}$ \\
\hline
\end{tabular}

\subsubsection{Undeclarable Data (UD)}

Undeclarable Data is information that will not be submitted to the IAEA via the system as part of or in connection with a Submission. 


\begin{tabular}{|l|l|c|}
\hline Reqmt-ID & Requirement & $\begin{array}{c}\text { Test } \\
\text { Method }\end{array}$ \\
\hline UD-001 & $\begin{array}{l}\text { The system shall generate an internal unique identifier for each Entry, } \\
\text { Declaration, and Submission. }\end{array}$ & T \\
\hline UD-002 & $\begin{array}{l}\text { The system shall allow status information to be tracked for Entry, Declaration, } \\
\text { and Submission (see Entry and Submission Status section for related } \\
\text { requirements). }\end{array}$ & O,T \\
\hline UD-003 & $\begin{array}{l}\text { The system shall support the entry of undeclarable data at the Submission } \\
\text { level. These undeclarable data are for use by State authorities and are not } \\
\text { included in the submission to the IAEA. A detailed description is provided in } \\
\text { Appendix C of this document. }\end{array}$ & O,T \\
\hline UD-005 & $\begin{array}{l}\text { The system shall support the entry of undeclarable data at the Declaration } \\
\text { level. These undeclarable data are for use by State authorities and are not } \\
\text { included in the submission to the IAEA. A detailed description is provided in } \\
\text { Appendix C of this document. }\end{array}$ & O,T \\
\hline $\begin{array}{l}\text { The system shall support the entry of undeclarable data at the Entry level. } \\
\text { These undeclarable data are for use by State authorities and are not included } \\
\text { in the Submission to the IAEA. A detailed description is provided in } \\
\text { Appendix C of this document. }\end{array}$ & O,T \\
\hline
\end{tabular}

\subsubsection{Lookup Data (LD)}

This can include any fixed lookup data in the lookup file provided by the IAEA, as well as any lookup data created within the State. The latter may include fields such as Contributor.

\begin{tabular}{|l|l|c|}
\hline Reqmt-ID & Requirement & $\begin{array}{c}\text { Test } \\
\text { Method }\end{array}$ \\
\hline LD-001 & $\begin{array}{l}\text { The system shall load lookup files containing choices for enumerated fields } \\
\text { provided by both the IAEA and the State. }\end{array}$ & $\mathrm{O}, \mathrm{T}$ \\
\hline LD-002 & $\begin{array}{l}\text { The system shall allow the user to manually update lookup tables not provided } \\
\text { by the IAEA. }\end{array}$ & $\mathrm{O}, \mathrm{T}$ \\
\hline LD-003 & $\begin{array}{l}\text { The system shall allow the user to export State-maintained lookup tables to a } \\
\text { file that can be loaded into another instance of the system. }\end{array}$ & $\mathrm{O}, \mathrm{T}$ \\
\hline LD-004 & $\begin{array}{l}\text { A user shall be able to merge State-maintained lookup data from a file with } \\
\text { existing local lookup data. }\end{array}$ & $\mathrm{O}, \mathrm{T}$ \\
\hline LD-005 & $\begin{array}{l}\text { The system shall allow users to view the contents of lookup files and relevant } \\
\text { revision information. }\end{array}$ & $\mathrm{O}$ \\
\hline
\end{tabular}




\subsection{Process Requirements}

\subsubsection{Entry and Submission Statuses (ES)}

\begin{tabular}{|c|c|c|}
\hline Reqmt-ID & Requirement & $\begin{array}{c}\text { Test } \\
\text { Method }\end{array}$ \\
\hline ES-001 & $\begin{array}{l}\text { Entries shall have a Status field representing their current state in the } \\
\text { declaration development process. }\end{array}$ & $\mathrm{O}, \mathrm{T}$ \\
\hline ES-002 & $\begin{array}{l}\text { Submissions shall have a Status field representing their current state in the } \\
\text { declaration development process. }\end{array}$ & $\mathrm{O}, \mathrm{T}$ \\
\hline ES-003 & There shall be at least two categories of statuses: & $\mathrm{O}$ \\
\hline ES-003.1 & $\begin{array}{l}\text { - Statuses representing in-development declaration data, which are } \\
\text { fully editable. }\end{array}$ & $\mathrm{O}$ \\
\hline ES-003.2 & $\begin{array}{l}\text { - Statuses representing completed or submitted declaration data, which } \\
\text { are read only. }\end{array}$ & $\mathrm{O}$ \\
\hline ES-004 & $\begin{array}{l}\text { Users may change the status of an Entry or Submission, since the purpose of } \\
\text { the status field is for users to track their own progress. }\end{array}$ & $\mathrm{O}, \mathrm{T}$ \\
\hline ES-004.1 & $\begin{array}{l}\text { - Validation or other process requirements shall not restrict status } \\
\text { changes. }\end{array}$ & $\mathrm{O}, \mathrm{T}$ \\
\hline ES-004.2 & $\begin{array}{l}\text { - Status may be changed automatically by certain actions within the } \\
\text { system. }\end{array}$ & $\mathrm{O}, \mathrm{T}$ \\
\hline ES-004.3 & $\begin{array}{l}\text { - If a Submission has a completed or submitted status, its Entries must } \\
\text { also be completed or submitted. }\end{array}$ & $\mathrm{O}, \mathrm{T}$ \\
\hline
\end{tabular}

\subsubsection{Manage Submissions (MS)}

\begin{tabular}{|l|l|c|}
\hline Reqmt-ID & Requirement & \multicolumn{1}{c|}{$\begin{array}{c}\text { Test } \\
\text { Method }\end{array}$} \\
\hline MS-001 & $\begin{array}{l}\text { The system shall provide the capability to create a new Submission. } \\
\text { Submission contents and properties are described in Appendix C of this } \\
\text { document. }\end{array}$ & O,T \\
\hline MS-002 & $\begin{array}{l}\text { The system shall provide the capability to create a new Submission by } \\
\text { copying an existing Submission. }\end{array}$ & O,T \\
\hline MS-003 & $\begin{array}{l}\text { The user shall be able to manage Declarations as part of a Submission (see } \\
\text { Manage Declarations for related requirements) }\end{array}$ & O,T \\
\hline MS-004 & $\begin{array}{l}\text { The system shall provide the capability to import a Submission (see } \\
\text { Import/Export for related requirements) from legacy formats. }\end{array}$ & T \\
\hline MS-005 & The system shall provide the capability to edit the properties of a Submission. & O,T \\
\hline MS-006 & The system shall provide a warning to the user before deleting a Submission. & O,T
\end{tabular}




\begin{tabular}{|l|l|c|}
\hline Reqmi-ID & Requirement & $\begin{array}{c}\text { Test } \\
\text { Method }\end{array}$ \\
\hline MS-007 & $\begin{array}{l}\text { The system shall be capable of exporting a Submission to a format that can be } \\
\text { submitted to the IAEA (see Import/Export and Quality Control for related } \\
\text { requirements). }\end{array}$ & T \\
\hline MS-008 & $\begin{array}{l}\text { The system shall allow a Submission to be created based on the previous } \\
\text { Submission, with the possibility to denote each declaration as "Update" or } \\
\text { "No Change." }\end{array}$ & O,T \\
\hline MS-009 & $\begin{array}{l}\text { When creating a new Submission to update a previous Submission, the default } \\
\text { reporting period dates shall be generated automatically. }\end{array}$ & O,T \\
\hline
\end{tabular}

\subsubsection{Manage Declarations (MD)}

\begin{tabular}{|c|c|c|}
\hline Reqmi-ID & Requirement & $\begin{array}{c}\text { Test } \\
\text { Method }\end{array}$ \\
\hline MD-001 & $\begin{array}{l}\text { The system shall provide the capability to create a Declaration. Declaration } \\
\text { contents and properties are described in Appendix } \mathrm{C} \text { of this document. }\end{array}$ & $\mathrm{O}, \mathrm{T}$ \\
\hline MD-002 & $\begin{array}{l}\text { The system shall allow a Declaration to be created based on a previous } \\
\text { Declaration, with the possibility to denote it as "No Change," or its Entries as } \\
\text { "Update." }\end{array}$ & $\mathrm{O}, \mathrm{T}$ \\
\hline MD-003 & $\begin{array}{l}\text { The user shall be able to manage Entries as part of a Declaration (see Manage } \\
\text { Entries for related requirements). }\end{array}$ & $\mathrm{O}, \mathrm{T}$ \\
\hline MD-004 & $\begin{array}{l}\text { A user shall be able to add existing Entries for a given Article to a Declaration } \\
\text { for the same Article. }\end{array}$ & $\mathrm{O}, \mathrm{T}$ \\
\hline MD-005 & $\begin{array}{l}\text { The user shall be able to extract Entries from a Declaration, either to save } \\
\text { independently or insert into another Declaration. }\end{array}$ & $\mathrm{O}, \mathrm{T}$ \\
\hline MD-006 & $\begin{array}{l}\text { A Declaration shall not be considered valid unless it includes at least one } \\
\text { Entry for the associated Article or is marked as either "No Change" or } \\
\text { "Nothing to Declare." }\end{array}$ & $\mathrm{T}$ \\
\hline MD-007 & $\begin{array}{l}\text { A Declaration marked as "No Change" or "Nothing to Declare" shall not } \\
\text { contain Entries. }\end{array}$ & $\mathrm{T}$ \\
\hline MD-008 & $\begin{array}{l}\text { The system shall provide the capability of entering Declaration data as } \\
\text { described in Appendix } \mathrm{C} \text { of this document. }\end{array}$ & $\mathrm{O}, \mathrm{T}$ \\
\hline MD-009 & The system shall provide the capability to edit an existing Declaration. & $\mathrm{O}, \mathrm{T}$ \\
\hline MD-010 & The system shall provide the capability to delete a Declaration. & $\mathrm{O}, \mathrm{T}$ \\
\hline MD-011 & $\begin{array}{l}\text { Where practical, the system shall use structured fields in place of general text } \\
\text { fields that cannot be easily validated. }\end{array}$ & $\mathrm{O}, \mathrm{T}$ \\
\hline MD-012 & $\begin{array}{l}\text { The system shall provide the capability of attaching any number of files to a } \\
\text { Declaration (see File Attachments for related requirements). }\end{array}$ & $\mathrm{O}, \mathrm{T}$ \\
\hline
\end{tabular}




\begin{tabular}{|c|c|c|}
\hline Reqmt-ID & Requirement & $\begin{array}{c}\text { Test } \\
\text { Method }\end{array}$ \\
\hline MD-013 & $\begin{array}{l}\text { Where practical, the layout of the primary Declaration view shall resemble } \\
\text { that depicted in Guidelines and Format for Preparation and Submission of } \\
\text { Declarations Pursuant to Articles } 2 \text { and } 3 \text { of the Model Protocol Additional to } \\
\text { Safeguards Agreements (May 2004). }\end{array}$ & $\mathrm{O}$ \\
\hline MD-013.1 & $\begin{array}{l}\text { - The system shall provide the capability of displaying sorted Entries } \\
\text { within a Declaration by Entry number or by another column selected } \\
\text { by the user. }\end{array}$ & $\mathrm{O}$ \\
\hline MD-014 & $\begin{array}{l}\text { The system shall provide methods for validating a Declaration for correctness } \\
\text { and completeness, and the user shall be able to execute validation when } \\
\text { editing or viewing a Declaration. }\end{array}$ & $\mathrm{O}, \mathrm{T}$ \\
\hline MD-015 & The process of validating a Declaration shall also validate its Entries. & $\mathrm{O}, \mathrm{T}$ \\
\hline MD-016 & $\begin{array}{l}\text { To avoid re-entry of the same data, the system shall automatically generate } \\
\text { default reporting period and "as-of" dates where practical. }\end{array}$ & $\mathrm{O}, \mathrm{T}$ \\
\hline MD-017 & $\begin{array}{l}\text { Default reporting periods and "as-of" dates should be easily changeable by the } \\
\text { user. }\end{array}$ & $\mathrm{O}, \mathrm{T}$ \\
\hline MD-018 & $\begin{array}{l}\text { If there are multiple Declarations in an Initial Submission or the first update } \\
\text { for a given Article, then those Declarations may have different "as-of" dates. }\end{array}$ & $\mathrm{T}$ \\
\hline
\end{tabular}

\subsubsection{Manage Entries (ME)}

\begin{tabular}{|c|c|c|}
\hline Reqmt-ID & Requirement & $\begin{array}{c}\text { Test } \\
\text { Method }\end{array}$ \\
\hline ME-001 & $\begin{array}{l}\text { The system shall provide the capability to create Entries. Entry data structure } \\
\text { is described in Appendix } \mathrm{C} \text { of this document. }\end{array}$ & $\mathrm{O}, \mathrm{T}$ \\
\hline ME-002 & $\begin{array}{l}\text { The system shall provide the capability to create a new Entry by copying an } \\
\text { existing Entry. }\end{array}$ & $\mathrm{O}, \mathrm{T}$ \\
\hline ME-003 & $\begin{array}{l}\text { The system shall allow the user to include any number of Entries in a } \\
\text { Declaration. }\end{array}$ & $\mathrm{O}, \mathrm{T}$ \\
\hline ME-004 & The system shall provide the capability to edit an existing Entry. & $\mathrm{O}, \mathrm{T}$ \\
\hline ME-005 & $\begin{array}{l}\text { The system shall provide the capability to edit a previously submitted Entry } \\
\text { by changing the status of the Entry (or the Submission containing it) to one } \\
\text { that allows editing. }\end{array}$ & $\mathrm{O}, \mathrm{T}$ \\
\hline ME-006 & $\begin{array}{l}\text { The system shall allow an Entry to be created based on a previous Entry, with } \\
\text { the possibility to denote it as "Update" or "No Change." }\end{array}$ & $\mathrm{O}, \mathrm{T}$ \\
\hline ME-006.1 & $\begin{array}{l}\text { - The system shall display a warning before allowing the user to create } \\
\text { an Update Entry for a previously submitted Final Entry. }\end{array}$ & $\mathrm{O}, \mathrm{T}$ \\
\hline ME-007 & The system shall provide the capability to delete an Entry. & $\mathrm{O}, \mathrm{T}$ \\
\hline
\end{tabular}




\begin{tabular}{|c|c|c|}
\hline Reqmt-ID & Requirement & $\begin{array}{c}\text { Test } \\
\text { Method }\end{array}$ \\
\hline ME-008 & $\begin{array}{l}\text { The system shall provide the capability of displaying Entries sorted by a } \\
\text { column selected by the user. }\end{array}$ & $\mathrm{O}, \mathrm{T}$ \\
\hline ME-009 & $\begin{array}{l}\text { Where practical, the system shall use structured fields in place of general text } \\
\text { fields that cannot be easily validated. }\end{array}$ & $\mathrm{O}, \mathrm{T}$ \\
\hline ME-010 & $\begin{array}{l}\text { The system shall provide the capability of attaching any number of files to an } \\
\text { Entry (see File Attachments for related requirements). }\end{array}$ & $\mathrm{O}, \mathrm{T}$ \\
\hline ME-011 & $\begin{array}{l}\text { The system shall provide the same functions for managing an Entry whether } \\
\text { or not it is part of a Declaration. }\end{array}$ & $\mathrm{O}, \mathrm{T}$ \\
\hline ME-012 & $\begin{array}{l}\text { The system shall provide methods for validating an Entry for correctness and } \\
\text { completeness, and the user shall be able to execute validation when editing or } \\
\text { viewing an Entry. }\end{array}$ & $\mathrm{O}, \mathrm{T}$ \\
\hline ME-013 & It shall be possible to transfer Entries to other users. & $\mathrm{T}$ \\
\hline ME-014 & $\begin{array}{l}\text { If Entries are not stored in individual files by default, it shall be possible to } \\
\text { export and import them to and from the file system. }\end{array}$ & $\mathrm{T}$ \\
\hline ME-015 & $\begin{array}{l}\text { The system shall allow input of multiple fuel cycle stages for Article 2.a.(i), } \\
\text { 2.a.(x), and 2.b.(i) Entries. }\end{array}$ & $\mathrm{O}, \mathrm{T}$ \\
\hline ME-016 & $\begin{array}{l}\text { For Article 2.a.(ix) Entries, the system shall allow only the year or only the } \\
\text { year and month to be entered in case the exact export date is not available. }\end{array}$ & $\mathrm{T}$ \\
\hline
\end{tabular}

\subsubsection{Declaration and Entry Numbering (DN)}

\begin{tabular}{|l|l|c|}
\hline Reqmt-ID & Requirement & \multicolumn{1}{|c|}{$\begin{array}{c}\text { Test } \\
\text { Method }\end{array}$} \\
\hline DN-001 & $\begin{array}{l}\text { By default, the first declaration created in the system shall be numbered "1". } \\
\text { Subsequent declarations shall be numbered sequentially within each } \\
\text { submission and shall continue sequentially from one submission to the next. }\end{array}$ & O,T \\
\hline DN-002 & $\begin{array}{l}\text { By default, the system shall automatically renumber Declarations as they are } \\
\text { added to, removed from, or re-ordered within a Submission to achieve } \\
\text { sequential numbering with no gaps. }\end{array}$ & O,T \\
\hline DN-003 & $\begin{array}{l}\text { It shall be possible to specify the starting number for automatically numbering } \\
\text { declarations within a submission. This may be used to specify a number other } \\
\text { than "1" for the first Declaration in the first Submission. }\end{array}$ & O,T \\
\hline DN-004 & $\begin{array}{l}\text { By default, the system shall automatically renumber Entries as they are added } \\
\text { to, removed from, or re-ordered within a Declaration to achieve sequential } \\
\text { numbering with no gaps. }\end{array}$ & $\begin{array}{l}\text { The system shall provide the capability to reserve a particular number for a } \\
\text { particular Declaration or Entry, so that missing Declarations or Entries can be } \\
\text { included in a later Submission, while preserving numbering. }\end{array}$ \\
\hline DN-005 & O,T \\
\hline
\end{tabular}




\subsubsection{Entry Cross-referencing (EC)}

\begin{tabular}{|c|c|c|}
\hline Reqmt-ID & Requirement & $\begin{array}{c}\text { Test } \\
\text { Method }\end{array}$ \\
\hline EC-001 & $\begin{array}{l}\text { The system shall provide the capability for an Entry to cross-reference any } \\
\text { number of other Entries, either within the same and/or another Submission. }\end{array}$ & $\mathrm{O}, \mathrm{T}$ \\
\hline EC-002 & $\begin{array}{l}\text { The system shall provide the capability for an Entry to cross-reference any } \\
\text { number of Declarations within the same and/or another Submission. }\end{array}$ & $\mathrm{O}, \mathrm{T}$ \\
\hline EC-003 & $\begin{array}{l}\text { A cross-reference shall consist of the Declaration and Entry Number of the } \\
\text { related entry. }\end{array}$ & $\mathrm{O}, \mathrm{T}$ \\
\hline EC-004 & $\begin{array}{l}\text { Within the same Submission, if Entry "A" refers to Entry "B," then Entry "B" } \\
\text { shall automatically refer to Entry "A." }\end{array}$ & $\mathrm{O}, \mathrm{T}$ \\
\hline EC-005 & $\begin{array}{l}\text { Where applicable, the system shall perform quality check to ensure that if } \\
\text { Entry "A" references Entry "B", Entry "B" references Entry "A" as well. }\end{array}$ & $\mathrm{T}$ \\
\hline EC-006 & $\begin{array}{l}\text { The system shall support viewing the referenced Entry from the referencing } \\
\text { Entry if the referenced Entry is available. }\end{array}$ & $\mathrm{O}, \mathrm{T}$ \\
\hline EC-007 & It shall be possible to delete a Reference. & $\mathrm{O}, \mathrm{T}$ \\
\hline EC-008 & $\begin{array}{l}\text { If Declarations or Entries within a Submission are renumbered, all References } \\
\text { within that Submission shall be updated to reflect the new numbers. }\end{array}$ & $\mathrm{O}, \mathrm{T}$ \\
\hline
\end{tabular}

\subsubsection{Data Entry (DE)}

\begin{tabular}{|l|l|c|}
\hline Reqmt-ID & Requirement & \multicolumn{1}{|c|}{$\begin{array}{c}\text { Test } \\
\text { Method }\end{array}$} \\
\hline DE-001 & $\begin{array}{l}\text { Data validation shall be available where practical on all entry screens (see } \\
\text { Quality Control (QC) for related requirements). }\end{array}$ & O,T \\
\hline DE-002 & $\begin{array}{l}\text { Data entry fields shall be displayed in such a way as to easily distinguish } \\
\text { between which elements the IAEA considers mandatory and those considered } \\
\text { optional. }\end{array}$ & O \\
\hline DE-003 & $\begin{array}{l}\text { Printable output of Declarations or Submissions not intended for paper } \\
\text { transfer to the IAEA shall include the designation, "Not valid for submission } \\
\text { to the IAEA until certified by the State." }\end{array}$ & O \\
\hline DE-005 & $\begin{array}{l}\text { Where appropriate (such as for authorities and addresses), the system shall } \\
\text { provide a means for States to manage their own validation lists. }\end{array}$ & O,T \\
\hline
\end{tabular}




\subsubsection{Search, Filter, and Navigate (SFN)}

\begin{tabular}{|c|c|c|}
\hline Reqmt-ID & Requirement & $\begin{array}{l}\text { Test } \\
\text { Method }\end{array}$ \\
\hline SFN-001 & $\begin{array}{l}\text { At a minimum, the system shall provide the capability of searching } \\
\text { Declaration data using the following criteria: }\end{array}$ & $\mathrm{O}, \mathrm{T}$ \\
\hline SFN-001.1 & - Declaration number & $\mathrm{O}, \mathrm{T}$ \\
\hline SFN-001.2 & - $\quad$ AP Article & $\mathrm{O}, \mathrm{T}$ \\
\hline SFN-001.3 & - $\quad$ Declaration date(s) & $\mathrm{O}, \mathrm{T}$ \\
\hline SFN-001.4 & - Cross-reference & $\mathrm{O}, \mathrm{T}$ \\
\hline SFN-002 & $\begin{array}{l}\text { The system shall include the capability of performing a full-text search } \\
\text { (including Boolean operators and wildcards) across all data that is accessible } \\
\text { by the system. }\end{array}$ & $\mathrm{O}, \mathrm{T}$ \\
\hline SFN-003 & $\begin{array}{l}\text { It shall be possible to easily filter, navigate, and browse Declaration and Entry } \\
\text { data throughout a Submission. }\end{array}$ & $\mathrm{T}$ \\
\hline
\end{tabular}

\subsubsection{Import/Export (IE)}

\begin{tabular}{|c|c|c|}
\hline Reqmt-ID & Requirement & $\begin{array}{c}\text { Test } \\
\text { Method }\end{array}$ \\
\hline IE-001 & $\begin{array}{l}\text { The system shall be capable of importing files of text-delimited Submissions } \\
\text { as defined in Protocol Reporter } 1.0 \text { export format even if the file to be } \\
\text { imported includes validation errors. }\end{array}$ & $\mathrm{T}$ \\
\hline IE-002 & $\begin{array}{l}\text { The system shall be capable of importing files of text-delimited Submissions } \\
\text { as defined in Protocol Reporter } 2.0 \text { export format even if the file to be } \\
\text { imported includes validation errors. }\end{array}$ & $\mathrm{T}$ \\
\hline IE-003 & $\begin{array}{l}\text { The system shall be capable of importing files of .xml Submissions as defined } \\
\text { in Protocol Reporter } 2.0 \text { export format even if the file to be imported includes } \\
\text { validation errors. }\end{array}$ & $\mathrm{T}$ \\
\hline IE-004 & $\begin{array}{l}\text { The system must be capable of importing previously submitted Declaration } \\
\text { data provided by the Agency in PR1, PR2, or PR3 format. }\end{array}$ & $\mathrm{T}$ \\
\hline IE-005 & By default, legacy data shall be imported in read-only format. & $\mathrm{T}$ \\
\hline IE-006 & A user may opt to convert legacy data into an editable format. & $\mathrm{T}$ \\
\hline IE-007 & $\begin{array}{l}\text { The system shall notify the user and provide details if an import or export } \\
\text { fails. }\end{array}$ & $\mathrm{T}$ \\
\hline
\end{tabular}




\begin{tabular}{|l|l|c|}
\hline Reqmi-ID & Requirement & $\begin{array}{c}\text { Test } \\
\text { Method }\end{array}$ \\
\hline IE-008 & The system must be capable of deleting any imported data. & O,T \\
\hline IE-009 & $\begin{array}{l}\text { The ability to import and export files shall be a standard feature of the system } \\
\text { and not require special activation to enable. }\end{array}$ & O,T \\
\hline IE-010 & The system shall be capable of importing any output exported by the system. & T \\
\hline IE-011 & All data exported by the system shall be in human-readable format. & T \\
\hline IE-012 & The system shall support export in UTF-8 text format. & T \\
\hline IE-013 & Data shall be exported without adding to or changing its content. & T \\
\hline IE-014 & $\begin{array}{l}\text { Where applicable, exported data shall include all attached files (see File } \\
\text { Attachments (FA) for related requirements). }\end{array}$ & T \\
\hline IE-015 & $\begin{array}{l}\text { Where applicable, exported Submissions shall provide dates formatted as } \\
\text { YYYY-MM-DD. }\end{array}$ & $\begin{array}{l}\text { All data shall be validated prior to export. The user shall be notified of any } \\
\text { errors and warnings, but may choose to continue the export. }\end{array}$ \\
\hline IE-016 & & O,T \\
\hline
\end{tabular}

\subsubsection{File Attachments (FA)}

\begin{tabular}{|l|l|c|}
\hline Reqmt-ID & Requirement & $\begin{array}{c}\text { Test } \\
\text { Method }\end{array}$ \\
\hline FA-001 & $\begin{array}{l}\text { The system shall include the capability to attach any number of files at the } \\
\text { Submission level. }\end{array}$ & O,T \\
\hline FA-002 & $\begin{array}{l}\text { The system shall include the capability to attach any number of files at the } \\
\text { Declaration level. }\end{array}$ & O,T \\
\hline FA-003 & $\begin{array}{l}\text { The system shall include the capability to attach any number of files at the } \\
\text { Entry level. }\end{array}$ & O,T \\
\hline FA-004 & $\begin{array}{l}\text { The system shall include the capability of removing attached files. } \\
\text { FA-005 }\end{array}$ & $\begin{array}{l}\text { The system shall enable the user to open attachments with associated } \\
\text { applications defined in the operating system. }\end{array}$ \\
\hline
\end{tabular}




\subsubsection{Quality Control (QC)}

\begin{tabular}{|c|c|c|}
\hline Reqmt-ID & Requirement & $\begin{array}{c}\text { Test } \\
\text { Method }\end{array}$ \\
\hline QC-001 & $\begin{array}{l}\text { The system shall employ validation checks and user feedback mechanisms } \\
\text { wherever necessary to help ensure all Entry, Declaration, and Submission } \\
\text { data meet the format and content requirements specified in the Detail } \\
\text { Requirements and Appendix C. }\end{array}$ & $\mathrm{O}, \mathrm{T}$ \\
\hline QC-002 & $\begin{array}{l}\text { Each validation feedback message shall be identified as an error, warning, or } \\
\text { informational message to indicate the severity of the problem. }\end{array}$ & $\mathrm{O}$ \\
\hline QC-003 & $\begin{array}{l}\text { Validation feedback shall contain sufficient detail to help the user correct the } \\
\text { problem. }\end{array}$ & $\mathrm{O}$ \\
\hline QC-004 & $\begin{array}{l}\text { The system shall not prevent the use of any functionality in the system as a } \\
\text { result of failed validation. }\end{array}$ & $\mathrm{T}$ \\
\hline QC-005 & $\begin{array}{l}\text { Where applicable, the system shall perform quality checks on dates to ensure } \\
\text { consistency and correct chronology. }\end{array}$ & $\mathrm{O}, \mathrm{T}$ \\
\hline QC-006 & $\begin{array}{l}\text { Where applicable, the system shall perform quality checks on Entry cross- } \\
\text { references and other data to ensure consistency and accuracy. }\end{array}$ & $\mathrm{O}, \mathrm{T}$ \\
\hline QC-007 & $\begin{array}{l}\text { If applicable, the system shall provide the user with details of any errors or } \\
\text { messages returned from IAEA following electronic transmission of a } \\
\text { Submission. }\end{array}$ & $\mathrm{O}, \mathrm{T}$ \\
\hline
\end{tabular}

\subsubsection{Reports (RP)}

\begin{tabular}{|l|l|c|}
\hline Reqmt-ID & Requirement & \multicolumn{1}{|c|}{$\begin{array}{c}\text { Test } \\
\text { Rethod }\end{array}$} \\
\hline RP-001 & $\begin{array}{l}\text { The system shall provide the capability to generate a viewable and printable } \\
\text { report of any Submission, including its Declarations and Entries (or any user- } \\
\text { selected subset). Detailed descriptions of such reports are provided in } \\
\text { Appendix D of this document. }\end{array}$ & O,T \\
\hline RP-002 & $\begin{array}{l}\text { The system shall provide the capability to generate a viewable and printable } \\
\text { report of Submission due dates. A detailed description of the report is } \\
\text { provided in Appendix D of this document. }\end{array}$ & O,T \\
\hline RP-003 & $\begin{array}{l}\text { The system shall support multiple print layouts. } \\
\text { RP-004 }\end{array}$ & $\begin{array}{l}\text { Where applicable, the system shall clearly differentiate Declarable Data from } \\
\text { Undeclarable Data in reports. }\end{array}$ \\
\hline RP-005 & $\begin{array}{l}\text { The system shall provide the capability to generate a viewable and printable } \\
\text { report of a user-selected collection of one or more Entries. A detailed } \\
\text { description of the report is provided in Appendix D of this document. }\end{array}$ & $\mathrm{O}$ \\
\hline
\end{tabular}




\subsubsection{User Documentation (UD)}

\begin{tabular}{|l|l|c|}
\hline Reqmi-ID & Requirement & $\begin{array}{c}\text { Test } \\
\text { Method }\end{array}$ \\
\hline UD-001 & $\begin{array}{l}\text { System help shall include thorough documentation, explanation of major } \\
\text { system functions, and reference documents. }\end{array}$ & T,D \\
\hline UD-001.1 & $\begin{array}{l}\text { System help shall include a copy of the IAEA document, Model } \\
\text { Protocol Additional to the Agreement(s) Between State(s) and the } \\
\text { International Atomic Energy Agency for the Application of } \\
\text { Safeguards (INFCIRC/540, corrected). }\end{array}$ & D \\
\hline UD-001.3 & $\begin{array}{l}\text { System help shall include a copy of the IAEA document, Guidelines } \\
\text { and Format for Preparation and Submission of Declarations } \\
\text { Pursuant to Articles 2 and 3 of the Model Protocol Additional to } \\
\text { Safeguards Agreements (or equivalent document) }\end{array}$ & D \\
\hline UD-002 & $\begin{array}{l}\text { System help shall include an explanation of the determination of } \\
\text { due dates, including the significance of the Entry Into Force and As- } \\
\text { Of dates. }\end{array}$ & D \\
\hline UD-003 & $\begin{array}{l}\text { Where applicable, access to system help topics shall be context-sensitive. } \\
\text { Where necessary, help topics shall include examples of Entry, Declaration, } \\
\text { and Submission data. }\end{array}$ & O,T \\
\hline
\end{tabular}

\subsection{Other Requirements}

\subsubsection{External Interface Requirements}

At the time of this writing, specific external interface requirements were dependent upon factors outside the scope of this effort. As these factors become better defined, detailed external interface requirements will be identified and documented.

\subsubsection{Performance Requirements}

There are no special performance requirements for this system.

\subsubsection{Design Constraints}

The system shall adhere to the scope, terminology, obligations, and specifications of the Model Protocol Additional to the Agreement(s) Between State(s) and the International Atomic Energy Agency for the Application of Safeguards (INFCIRC/540, corrected).

\subsubsection{Standards Compliance}

There are no special standards compliance requirements for this system.

\subsubsection{Reliability}

There are no special reliability requirements for this system.

\subsubsection{Availability}

There are no special availability requirements for this system. 


\subsubsection{Security}

At the time of this writing, specific security requirements were dependent upon factors outside the scope of this effort. As these factors become better defined, detailed security requirements will be identified and documented.

\subsubsection{Maintainability}

There are no special maintainability requirements for this system.

\subsubsection{Portability}

There are no special portability requirements for this system.

\subsubsection{Usability}

There are no special usability requirements for this system. 


\section{Appendix A: Abbreviations}

AP

DOE

IAEA

INSEP

ISD

NNSA

PR1

PR2

PR3

SDS

SG

SGIM

SRA

SRS

SSAC

The Agency
Additional Protocol

US Department of Energy

International Atomic Energy Agency

International Nuclear Safeguards Engagement Program

IAEA Declared and Statistical Information Analysis Section

National Nuclear Security Administration

Protocol Reporter version 1.0

Protocol Reporter version 2.0

Protocol Reporter version 3.0

System Design Specification

IAEA Department of Safeguards

IAEA Safeguards Information Management

Safeguards Regulatory Authority

System Requirements Specification

State System of Accounting for and Control of Nuclear Material

The International Atomic Energy Agency 


\section{Appendix B: Glossary}

Additional Protocol (AP)

Article 2

Article 3

Contributor

Declarable Data

Declaration

Entry

Entry Into Force (EIF) Date

Final Entry
Refers to the additional reporting agreements following the "Model Protocol Additional to the Agreement( $(s)$ between State( $s)$ and the International Atomic Energy Agency for the Application of Safeguards" (INFCIRC/540) document

That section of an Additional Protocol that defines the types of information that a State must provide to the IAEA.

That section of an Additional Protocol that defines the frequencies at which different types of information defined in Article 2 must be provided to the IAEA.

An organization or individual in a Member State that is responsible for preparing and submitting a portion of the State's declaration data to the SRA or to another Contributor or reviewer for eventual submission to the SRA.

Data in fields that are intended to be transmitted to the IAEA as part of the declaration process. When the PR3 prepares a Submission to be transferred to the IAEA, it will contain only Declarable data.

Information submitted to the IAEA by a State about its nuclear program and related activities pursuant to an AP agreement. A Declaration consists of header information and a collection of zero or more entries that apply to a specific paragraph of AP Article 2, in a format that meets the requirements of that article.

An Entry is a description of a specific activity and/or location for a specific reporting period that is reported to the IAEA pursuant to a specific paragraph of AP Article 2.

The date on which the Agency receives from a State written notification that the State's statutory and constitutional requirements for entry into force have been met. A State may, at any date before its AP enters into force, declare that it will apply the AP provisionally.

An Entry reporting an activity or location that is completed or closed, for which future updates are not expected to be submitted to the IAEA. 
Format Guidelines

Legacy Data

No Change Declaration

No Change Entry

Nothing to Declare Declaration

Safeguards Regulatory Authority (SRA)

Submission
An IAEA publication entitled "Guidelines and Format for the Preparation and Submission of the Declarations Pursuant to Article $2 \& 3$ of the Model Protocol Additional to Safeguards Agreements (May 2004)".

For the purposes of this document, legacy data refers to any Declaration data created in Protocol Reporter 1.0 or Protocol Reporter 2.0 format.

A Declaration indicating that the information previously submitted under the associated AP Article remains accurate for the indicated reporting period. In a Submission, this indicates that the absence of new information related to that Article is intended.

No Change Declarations may include No Change Entries for each activity or location that was previously declared, but this is not required.

A special case of Update Entry indicating that the information previously submitted for an activity or location remains accurate for the indicated reporting period. In a Declaration, this indicates that the absence of new information related to that activity or location is intended.

A Declaration indicating that no activities or locations are declarable under the associated AP Article for the indicated reporting period. In a Submission, this indicates that the absence of Declaration data related to that AP Article is intended.

If a State has declarable activities or locations, but they have not changed since the last Submission, use a No Change Declaration instead.

The organization in a Member State responsible for preparing, certifying, and submitting declarations to the IAEA.

A set of one or more Declarations that are compiled by a State to be provided to the IAEA in accordance with AP Article 3. 
Undeclarable Data

Update Entry
Data in fields that are intended to be withheld from the IAEA and used only for internal State recordkeeping or for tracking the declaration development process. When the PR3 prepares a Submission to be transferred to the IAEA, it will contain no Undeclarable Data.

An Entry that provides information related to a specific activity or location reported in a previously submitted Entry. The Update Entry shall include a reference to the previous Entry. 


\section{Appendix C: Data Structure}

\section{C.1 Model AP Data Structure \\ Entry Data Structures}

\section{Base Entry Data Structure}

All Entries, no matter the article type, should contain the following fields.

\begin{tabular}{|c|c|c|}
\hline Name & Type & Notes \\
\hline Internal ID & String & $\begin{array}{l}\text { Will be automatically generated (i.e., GUID) by the } \\
\text { PR3. }\end{array}$ \\
\hline Undeclarable Comments & String & \\
\hline Contributor & $\begin{array}{l}\text { Contributor } \\
\text { (see Lookups) }\end{array}$ & Must contain one. \\
\hline State & $\begin{array}{l}\text { State } \\
\text { (see Lookups) }\end{array}$ & Must contain one. \\
\hline INFCIRC \# & $\begin{array}{l}\text { INFCIRC \# } \\
\text { (see Lookups) }\end{array}$ & Must contain one. \\
\hline Data Template & $\begin{array}{l}\text { Data Template } \\
\text { (see Lookups) }\end{array}$ & Must contain one. \\
\hline AP Article & $\begin{array}{l}\text { AP Article } \\
\text { (see Lookups) }\end{array}$ & $\begin{array}{l}\text { Chosen as part of the creation process. Cannot be } \\
\text { changed. }\end{array}$ \\
\hline References & $\begin{array}{l}\text { Set of References } \\
\text { (see Data Types) }\end{array}$ & May contain zero, one, or many. \\
\hline Document References & $\begin{array}{l}\text { Set of Documents } \\
\text { (see Data Types) }\end{array}$ & May contain zero, one, or many. \\
\hline Declarable Comments & String & \\
\hline Local ID & String & $\begin{array}{l}\text { Undeclarable field used for the Contributor's local } \\
\text { identifier for the activity. }\end{array}$ \\
\hline Entry Number & Integer & Only assigned as part of a Submission. \\
\hline Entry Title & String & $\begin{array}{l}\text { To be used as identification to SRA or Contributor } \\
\text { users until the Entry is numbered as part of a } \\
\text { Submission. }\end{array}$ \\
\hline Entry Type & $\begin{array}{l}\text { Entry Type } \\
\text { (see Lookups) }\end{array}$ & \\
\hline Reporting Period Start & Date & $\begin{array}{l}\text { Used by SRA to build Submission. Must contain a date } \\
\text { value to validate. }\end{array}$ \\
\hline Reporting Period End & Date & $\begin{array}{l}\text { Used by SRA to build Submission. Must contain a date } \\
\text { value to validate. }\end{array}$ \\
\hline Final Entry & Boolean & $\begin{array}{l}\text { If True, this entry represents the final update for this } \\
\text { activity. (Used for IAEA analysis. This does not affect } \\
\text { any actions the user could take on this entry.) }\end{array}$ \\
\hline
\end{tabular}

Additional Entry fields will also be provided for internal State use. These fields may be labeled by users and their contents will not be included in any submission to IAEA.

Entry 2.a.(i)

\begin{tabular}{|l|l|l|}
\hline Name & Type & Notes \\
\hline Fuel Cycle Stages & $\begin{array}{l}\text { Set of Fuel Cycle } \\
\text { Stages (see Lookups) }\end{array}$ & $\begin{array}{l}\text { May contain zero, one, or many. Must contain at least } \\
\text { one to validate for submission. }\end{array}$ \\
\hline Location & $\begin{array}{l}\text { Location } \\
\text { (see Data Types) }\end{array}$ & $\begin{array}{l}\text { May contain zero or one. Must contain one to validate } \\
\text { for submission. }\end{array}$ \\
\hline Project Title & String & \\
\hline Project ID & String & \\
\hline
\end{tabular}




\begin{tabular}{|l|l|l|}
\hline Name & Type & Notes \\
\hline Relationship to State & String & \\
\hline Description & String & Must contain a value to validate for submission. \\
\hline Organizations & $\begin{array}{l}\text { Set of Organizational } \\
\text { Involvement (see Data } \\
\text { Types) }\end{array}$ & May contain zero, one, or many. \\
\hline Objectives & String & \\
\hline Degree Met & String & \\
\hline Intended Application & String & May contain zero, one, or many. \\
\hline Foreign Collaboration & $\begin{array}{l}\text { Set of Collaboration } \\
\text { (see Data Types) }\end{array}$ & May contain zero, one, or many. \\
\hline Sublocations & $\begin{array}{l}\text { Set of Sublocations } \\
\text { (see Data Types) }\end{array}$ & \\
\hline Project Start Period & Date & \\
\hline Project End Period & Date & \\
\hline
\end{tabular}

Entry 2.a.(ii)

\begin{tabular}{|l|l|l|}
\hline Name & Type & Notes \\
\hline Agreed Information & String & \\
\hline
\end{tabular}

Entry 2.a.(iii)

\begin{tabular}{|c|c|c|}
\hline Name & Type & Notes \\
\hline Site ID & $\begin{array}{l}\text { Site Code } \\
\text { (see Lookups) }\end{array}$ & $\begin{array}{l}\text { May contain zero or one. Must contain one to validate } \\
\text { for submission. }\end{array}$ \\
\hline Facility/LOF & String & $\begin{array}{l}\text { Free text field, but options may be provided from the } \\
\text { Facility/LOF lookup. }\end{array}$ \\
\hline MBA Code & String & $\begin{array}{l}\text { Free text field, but options may be provided from the } \\
\text { MBA Code lookup }\end{array}$ \\
\hline Key Measurement Point & String & \\
\hline Building & String & Must contain a value to validate for submission. \\
\hline Number of Floors & Integer & \\
\hline Size & Float & \\
\hline Size Units & $\begin{array}{l}\text { Unit of Area } \\
\text { (see Lookups) }\end{array}$ & $\begin{array}{l}\text { May contain zero or one. Must contain one to validate } \\
\text { for submission. }\end{array}$ \\
\hline Use & String & Must contain a value to validate for submission. \\
\hline Previous Use & String & \\
\hline Contents & String & \\
\hline Coordinates & $\begin{array}{l}\text { GeoCoordinates } \\
\text { (see Data Types) }\end{array}$ & $\begin{array}{l}\text { May contain zero or one. Must contain one to validate } \\
\text { for submission. }\end{array}$ \\
\hline
\end{tabular}

Entry 2.a.(iv)

\begin{tabular}{|l|l|l|}
\hline Name & Type & Notes \\
\hline Annex I Item & $\begin{array}{l}\text { Annex I } \\
\text { (see Lookups) }\end{array}$ & $\begin{array}{l}\text { May contain zero or one. Must contain one to validate } \\
\text { for submission. }\end{array}$ \\
\hline Voluntary Extension & String & $\begin{array}{l}\text { Required for submission (and may only contain a } \\
\text { value) if Annex I Item is "Voluntary Extension." }\end{array}$ \\
\hline Location & $\begin{array}{l}\text { Location } \\
\text { (see Data Types) }\end{array}$ & $\begin{array}{l}\text { May contain zero or one. Must contain one to validate } \\
\text { for submission. }\end{array}$ \\
\hline Brief Description & String & $\begin{array}{l}\text { May contain zero or one. Must contain one to validate } \\
\text { for submission. }\end{array}$ \\
\hline Capacity & Quantity & May contain zero, one, or many. \\
\hline Extent Used & Float & $\begin{array}{l}\text { Set of Sublocations } \\
\text { (see Data Types) }\end{array}$ \\
\hline Sublocations &
\end{tabular}


Entry 2.a.(v)

\begin{tabular}{|l|l|l|}
\hline Name & Type & Notes \\
\hline Mine/Plant Identifier & $\begin{array}{l}\text { Mine/Plant (see } \\
\text { Lookups) }\end{array}$ & $\begin{array}{l}\text { May contain zero or one. Must contain one to validate. } \\
\text { Other validation rules will vary depending on whether } \\
\text { a mine/plant or "State Total" is selected. }\end{array}$ \\
\hline Location & $\begin{array}{l}\text { Location } \\
\text { (see Data Types) }\end{array}$ & $\begin{array}{l}\text { May contain zero or one. Must contain one to validate } \\
\text { for submission. }\end{array}$ \\
\hline Operation & $\begin{array}{l}\text { Operation } \\
\text { (see Lookups) }\end{array}$ & $\begin{array}{l}\text { May contain zero or one. Must contain one to validate } \\
\text { for submission. }\end{array}$ \\
\hline Status & $\begin{array}{l}\text { Operation Status } \\
\text { (see Lookups) }\end{array}$ & $\begin{array}{l}\text { May contain zero or one. Must contain one to validate } \\
\text { for submission. }\end{array}$ \\
\hline $\begin{array}{l}\text { Estimated Annual } \\
\text { Capacity }\end{array}$ & $\begin{array}{l}\text { Quantity } \\
\text { (see Data Types) } \\
\text { for submission unless "State Total" is selected for } \\
\text { Mine/Plant Identifier. }\end{array}$ \\
\hline $\begin{array}{l}\text { Actual Current Year } \\
\text { Production }\end{array}$ & $\begin{array}{l}\text { Quantity } \\
\text { (see Data Types) }\end{array}$ & $\begin{array}{l}\text { May contain zero or one. Must contain one to validate } \\
\text { for submission if "State Total" is selected for } \\
\text { Mine/Plant Identifier. }\end{array}$ \\
\hline
\end{tabular}

Entry 2.a.(vi).(a)

\begin{tabular}{|l|l|l|}
\hline Name & Type & Notes \\
\hline Location & $\begin{array}{l}\text { Location } \\
\text { (see Data Types) }\end{array}$ & $\begin{array}{l}\text { May contain zero or one. Must contain one to validate } \\
\text { for submission. }\end{array}$ \\
\hline Chemical Composition & $\begin{array}{l}\text { Chemical Composition } \\
\text { (see Lookups) }\end{array}$ & $\begin{array}{l}\text { May contain zero or one. Must contain one to validate } \\
\text { for submission. }\end{array}$ \\
\hline Quantity & $\begin{array}{l}\text { Quantity } \\
\text { (see Data Types) }\end{array}$ & $\begin{array}{l}\text { May contain zero or one. Must contain one to validate } \\
\text { for submission. }\end{array}$ \\
\hline Intended Use Code & $\begin{array}{l}\text { Intended Use Code } \\
\text { (see Lookups) }\end{array}$ & $\begin{array}{l}\text { May contain zero or one. Must contain one to validate } \\
\text { for submission. }\end{array}$ \\
\hline Intended Use & String & Must contain a value to validate for submission. \\
\hline
\end{tabular}

Entry 2.a.(vi).(b)

\begin{tabular}{|l|l|l|}
\hline Name & Type & Notes \\
\hline Destination & $\begin{array}{l}\text { State } \\
\text { (see Lookups) }\end{array}$ & $\begin{array}{l}\text { May contain zero or one. Must contain one to validate } \\
\text { for submission. }\end{array}$ \\
\hline Interim Destinations & $\begin{array}{l}\text { Set of States } \\
\text { (see Lookups) }\end{array}$ & May contain zero, one, or many. \\
\hline Chemical Composition & $\begin{array}{l}\text { Chemical Composition } \\
\text { (see Lookups) }\end{array}$ & $\begin{array}{l}\text { May contain zero or one. Must contain one to validate } \\
\text { for submission. }\end{array}$ \\
\hline Quantity & $\begin{array}{l}\text { Quantity } \\
\text { (see Data Types) }\end{array}$ & $\begin{array}{l}\text { May contain zero or one. Must contain one to validate } \\
\text { for submission. }\end{array}$ \\
\hline Intended Use Code & $\begin{array}{l}\text { Intended Use Code } \\
\text { (see Lookups) }\end{array}$ & $\begin{array}{l}\text { May contain zero or one. Must contain one to validate } \\
\text { for submission. }\end{array}$ \\
\hline Intended Use & String & Must contain a value to validate for submission. \\
\hline Export Date & Date & Must contain a value to validate for submission. \\
\hline
\end{tabular}

Entry 2.a.(vi).(c)

\begin{tabular}{|l|l|l|}
\hline Name & Type & Notes \\
\hline Location & $\begin{array}{l}\text { Location } \\
\text { (see Data Types) }\end{array}$ & $\begin{array}{l}\text { May contain zero or one. Must contain one to validate } \\
\text { for submission. }\end{array}$ \\
\hline Chemical Composition & $\begin{array}{l}\text { Chemical Composition } \\
\text { (see Lookups) }\end{array}$ & $\begin{array}{l}\text { May contain zero or one. Must contain one to validate } \\
\text { for submission. }\end{array}$ \\
\hline Quantity & $\begin{array}{l}\text { Quantity } \\
\text { (see Data Types) }\end{array}$ & $\begin{array}{l}\text { May contain zero or one. Must contain one to validate } \\
\text { for submission. }\end{array}$ \\
\hline Import Date & Date & Must contain a value to validate for submission. \\
\hline Exporting State & $\begin{array}{l}\text { State } \\
\text { (see Lookups) }\end{array}$ & $\begin{array}{l}\text { May contain zero or one. Must contain one to validate } \\
\text { for submission. }\end{array}$ \\
\hline
\end{tabular}




\begin{tabular}{|l|l|l|}
\hline Name & Type & Notes \\
\hline Intended Use Code & $\begin{array}{l}\text { Intended Use Code } \\
\text { (see Lookups) }\end{array}$ & $\begin{array}{l}\text { May contain zero or one. Must contain one to validate } \\
\text { for submission. }\end{array}$ \\
\hline
\end{tabular}

\section{Entry 2.a.(vii)}

\begin{tabular}{|l|l|l|}
\hline Name & Type & Notes \\
\hline Location & $\begin{array}{l}\text { Location } \\
\text { (see Data Types) }\end{array}$ & $\begin{array}{l}\text { May contain zero or one. Must contain one to validate } \\
\text { for submission. }\end{array}$ \\
\hline Exemption & $\begin{array}{l}\text { Exemption } \\
\text { (see Lookups) }\end{array}$ & $\begin{array}{l}\text { May contain zero or one. Must contain one to validate } \\
\text { for submission. }\end{array}$ \\
\hline Element & $\begin{array}{l}\text { Material Code } \\
\text { (see Lookups) }\end{array}$ & $\begin{array}{l}\text { May contain zero or one. Must contain one to validate } \\
\text { for submission. }\end{array}$ \\
\hline Percent Uranium & Float & $\begin{array}{l}\text { May contain zero or one. Must contain one to validate } \\
\text { for submission. }\end{array}$ \\
\hline Weight & (see Data Types) & $\begin{array}{l}\text { May contain zero or one. Must contain one to validate } \\
\text { for submission. }\end{array}$ \\
\hline Intended Use Code & $\begin{array}{l}\text { Intended Use Code } \\
\text { (see Lookups) }\end{array}$ & Must contain a value to validate for submission. \\
\hline Intended Use & String &
\end{tabular}

Entry 2.a.(viii).(a)

\begin{tabular}{|l|l|l|}
\hline Name & Type & Notes \\
\hline Waste Type & String & Must contain a value to validate for submission. \\
\hline Number of Items & String & Must contain a value to validate for submission. \\
\hline Type of Items & String & Must contain a value to validate for submission. \\
\hline Conditioned Form & String & May contain zero or one. \\
\hline Quantity Pu & $\begin{array}{l}\text { Quantity } \\
\text { (see Data Types) }\end{array}$ & May contain zero or one. \\
\hline Quantity HEU & $\begin{array}{l}\text { Quantity } \\
\text { (see Data Types) }\end{array}$ & $\begin{array}{l}\text { May contain zero or one. } \\
\text { (see Data Types) }\end{array}$ \\
\hline Quantity U233 & $\begin{array}{l}\text { Quantity } \\
\text { (see Data Types) }\end{array}$ & May contain zero or one. \\
\hline Quantity Np/Am & $\begin{array}{l}\text { Location } \\
\text { (see Data Types) }\end{array}$ & $\begin{array}{l}\text { May contain zero or one. Must contain one to validate } \\
\text { for submission. }\end{array}$ \\
\hline Previous Location & $\begin{array}{l}\text { Location } \\
\text { (see Data Types) }\end{array}$ & $\begin{array}{l}\text { May contain zero or one. Must contain one to validate } \\
\text { for submission. }\end{array}$ \\
\hline New Location & \multicolumn{2}{|l}{} \\
\hline
\end{tabular}

Entry 2.a.(viii).(b)

\begin{tabular}{|l|l|l|}
\hline Name & Type & Notes \\
\hline Waste Type & String & Must contain a value to validate for submission. \\
\hline Number of Items & String & Must contain a value to validate for submission. \\
\hline Type of Items & String & Must contain a value to validate for submission. \\
\hline Conditioned Form & String & May contain zero or one. \\
\hline Quantity Pu & $\begin{array}{l}\text { Quantity } \\
\text { (see Data Types) }\end{array}$ & May contain zero or one. \\
\hline Quantity HEU & $\begin{array}{l}\text { Quantity } \\
\text { (see Data Types) }\end{array}$ & $\begin{array}{l}\text { May contain zero or one. } \\
\text { Quantity }\end{array}$ \\
\hline Quantity U233 & $\begin{array}{l}\text { Quantity } \\
\text { (see Data Types) }\end{array}$ & $\begin{array}{l}\text { May contain zero or one. } \\
\text { Quantity Np/Am }\end{array}$ \\
$\begin{array}{l}\text { Location } \\
\text { (see Data Types) }\end{array}$ & $\begin{array}{l}\text { May contain zero or one. Must contain one to validate } \\
\text { for submission. }\end{array}$ \\
\hline Location & $\begin{array}{l}\text { Location } \\
\text { (see Data Types) }\end{array}$ & $\begin{array}{l}\text { May contain zero or one. Must contain one to validate } \\
\text { for submission. }\end{array}$ \\
\hline Processing Location & Date & \\
\hline
\end{tabular}




\begin{tabular}{|l|l|l|}
\hline Name & Type & Notes \\
\hline End Date & Date & \\
\hline Processing Purpose & String & \\
\hline
\end{tabular}

Entry 2.a.(ix).(a)

\begin{tabular}{|l|l|l|}
\hline Name & Type & Notes \\
\hline Item Identity & String & Must contain a value to validate for submission. \\
\hline Annex II Paragraph & $\begin{array}{l}\text { Annex II } \\
\text { (see Lookups) }\end{array}$ & $\begin{array}{l}\text { May contain zero or one. Must contain one (and be a } \\
\text { selectable Annex II entry) to validate for submission. }\end{array}$ \\
\hline Quantity & $\begin{array}{l}\text { Quantity } \\
\text { (see Data Types) }\end{array}$ & $\begin{array}{l}\text { May contain zero or one. Must contain one to validate } \\
\text { for submission. }\end{array}$ \\
\hline Location of Intended Use & $\begin{array}{l}\text { Location } \\
\text { (see Data Types) }\end{array}$ & May contain zero or one. \\
\hline Export Date & Date & \\
\hline
\end{tabular}

Entry 2.a.(ix).(b)

\begin{tabular}{|c|c|c|}
\hline Name & Type & Notes \\
\hline Agency Request Number & String & $\begin{array}{l}\text { Should be validated as "MC-CCC-\#\#" or "MC-CCC- } \\
\text { \#\#.\#" where "CCC" is the country code and "\#\#" or } \\
\text { "\#\#.\#" is the request number. }\end{array}$ \\
\hline Agency Request Date & Date & \\
\hline Item Identity & String & Must contain a value to validate for submission. \\
\hline Annex II Paragraph & $\begin{array}{l}\text { Annex II } \\
\text { (see Lookups) }\end{array}$ & $\begin{array}{l}\text { May contain zero or one. Must contain one (and be a } \\
\text { selectable Annex II entry) to validate for submission. }\end{array}$ \\
\hline Quantity & $\begin{array}{l}\text { Quantity } \\
\text { (see Data Types) }\end{array}$ & $\begin{array}{l}\text { May contain zero or one. Must contain one to validate } \\
\text { for submission. }\end{array}$ \\
\hline Location of Intended Use & $\begin{array}{l}\text { Location } \\
\text { (see Data Types) }\end{array}$ & $\begin{array}{l}\text { May contain zero or one. Must contain one to validate } \\
\text { for submission. }\end{array}$ \\
\hline Not Received & Boolean & $\begin{array}{l}\text { Per the Formatting Guidelines for 2.a.(ix) Explanation } \\
\text { 8, if the import is not yet received "not received" } \\
\text { should be entered in the Date field. (This occurs if } \\
\text { 2.a.(ix) is submitted as a response to an Agency } \\
\text { request.) } \\
\text { Suggested alternative: a valid Entry will either contain } \\
\text { an Import Date or the Not Received field will be true. }\end{array}$ \\
\hline Import Date & Date & $\begin{array}{l}\text { To pass validation: } \\
\text { - Contains a value, and Not Received is not } \\
\text { checked, or } \\
\text { - Does not contain a value, and Not Received is } \\
\text { checked. }\end{array}$ \\
\hline
\end{tabular}

Entry 2.a.(x)

\begin{tabular}{|l|l|l|}
\hline Name & Type & Notes \\
\hline Fuel Cycle Stage & $\begin{array}{l}\text { Set of Fuel Cycle } \\
\text { Stages (see Lookups) }\end{array}$ & $\begin{array}{l}\text { May contain zero, one, or many. Must contain at least } \\
\text { one to validate for submission. }\end{array}$ \\
\hline Development Plans & String & String \\
\hline R\&D Plans & $\begin{array}{l}\text { Set of Collaboration } \\
\text { (see Data Type) }\end{array}$ & May contain zero, one, or many. \\
\hline Collaboration & $\begin{array}{l}\text { Set of Organization } \\
\text { Involvement } \\
\text { (see Data Type) }\end{array}$ & May contain zero, one, or many. \\
\hline
\end{tabular}


Entry 2.b.(i)

\begin{tabular}{|c|c|c|}
\hline Name & Type & Notes \\
\hline Fuel Cycle Stages & $\begin{array}{l}\text { Set of Fuel Cycle } \\
\text { Stages } \\
\text { (see Lookups) }\end{array}$ & $\begin{array}{l}\text { May contain zero, one, or many. Must contain at least } \\
\text { one to validate for submission. }\end{array}$ \\
\hline Location & $\begin{array}{l}\text { Location } \\
\text { (see Data Types) }\end{array}$ & $\begin{array}{l}\text { May contain zero or one. Must contain one to validate } \\
\text { for submission. }\end{array}$ \\
\hline Project Title & String & \\
\hline Project ID & String & \\
\hline Description & String & Must contain a value to validate for submission. \\
\hline Organizations & $\begin{array}{l}\text { Set of Organizational } \\
\text { Involvement (see Data } \\
\text { Types) }\end{array}$ & May contain zero, one, or many. \\
\hline Objectives & String & \\
\hline Degree Met & String & \\
\hline Intended Application & String & \\
\hline Foreign Collaboration & $\begin{array}{l}\text { Set of Collaboration } \\
\text { (see Data Types) }\end{array}$ & May contain zero, one, or many. \\
\hline Sublocations & $\begin{array}{l}\text { Set of Sublocations } \\
\text { (see Data Types) }\end{array}$ & May contain zero, one, or many. \\
\hline Project Start Period & Date & \\
\hline Project End Period & Date & \\
\hline
\end{tabular}

Entry 2.b.(ii)

\begin{tabular}{|c|c|c|}
\hline Name & Type & Notes \\
\hline Agency Request Number & String & $\begin{array}{l}\text { Should be validated as "MC-CCC-\#\#" or "MC-CCC- } \\
\text { \#\#.\#" where "CCC" is the country code and "\#\#" or } \\
\text { "\#\#.\#" is the request number. }\end{array}$ \\
\hline Agency Request Date & Date & \\
\hline Location & $\begin{array}{l}\text { Location } \\
\text { (see Data Types) }\end{array}$ & $\begin{array}{l}\text { May contain zero or one. Must contain one to pass } \\
\text { validation. }\end{array}$ \\
\hline Related Site Code & $\begin{array}{l}\text { Site Code } \\
\text { (see Lookups) }\end{array}$ & $\begin{array}{l}\text { May contain zero or one. Must contain one to pass } \\
\text { validation. }\end{array}$ \\
\hline Physical Features & String & \\
\hline Description of Activities & String & \\
\hline Sublocations & $\begin{array}{l}\text { Set of Sublocations } \\
\text { (see Data Types) }\end{array}$ & May contain zero, one, or many. \\
\hline Carried Out By & $\begin{array}{l}\text { Set of Organization } \\
\text { Involvement } \\
\text { (see Data Types) }\end{array}$ & $\begin{array}{l}\text { Identity of persons/entities carrying out activities. May } \\
\text { contain zero, one, or many. }\end{array}$ \\
\hline
\end{tabular}

Entry 2.c

\begin{tabular}{|l|l|l|}
\hline Name & Type & Notes \\
\hline Agency Request Number & String & $\begin{array}{l}\text { Should be validated as "MC-CCC-\#\#" or "MC-CCC- } \\
\text { \#\#.\#" where "CCC" is the country code and "\#\#" or } \\
\text { “\#\#.\#" is the request number. }\end{array}$ \\
\hline Agency Request Date & Date & \\
\hline Agency Question & String & \\
\hline Response & String & \\
\hline
\end{tabular}

\section{Entry Note}

\begin{tabular}{|l|l|l|}
\hline Name & Type & Notes \\
\hline Document References & $\begin{array}{l}\text { Set of Documents } \\
\text { (see Data Types) }\end{array}$ & $\begin{array}{l}\text { May contain zero, one, or many. Must contain at least } \\
\text { one to validate (as opposed to Document References in } \\
\text { base Entry definition). }\end{array}$ \\
\hline General Description & String & \\
\hline
\end{tabular}




\section{Submission Data Structure}

\section{Submission}

\begin{tabular}{|l|l|l|}
\hline Name & Type & Notes \\
\hline Internal ID & String & $\begin{array}{l}\text { Will be automatically generated (i.e., GUID) by the } \\
\text { PR3. }\end{array}$ \\
\hline Data Template & $\begin{array}{l}\text { Data Template } \\
\text { (see Lookups) }\end{array}$ & Must contain one. \\
\hline Status & $\begin{array}{l}\text { Status } \\
\text { (see Lookups) }\end{array}$ & Set to default automatically by the PR3. \\
\hline Description & String & $\begin{array}{l}\text { State } \\
\text { (see Lookups) }\end{array}$ \\
\hline State & $\begin{array}{l}\text { Submission Type } \\
\text { (see Lookups) }\end{array}$ & $\begin{array}{l}\text { Chosen as part of the creation process. Cannot be } \\
\text { changed. }\end{array}$ \\
\hline Submission Type & Date & \\
\hline Declaration Date & String & \\
\hline Declarable Comments & String & \\
\hline Undeclarable Comments & Set of Declarations & \\
\hline Declarations &
\end{tabular}

Additional Submission fields will also be provided for internal State use. These fields may be labeled by users and their contents will not be included in any submission to IAEA.

\section{Declaration}

\begin{tabular}{|c|c|c|}
\hline Name & Type & Notes \\
\hline Internal ID & String & $\begin{array}{l}\text { Will be automatically generated (i.e., GUID) by the } \\
\text { PR3. }\end{array}$ \\
\hline Declaration Number & Integer & \\
\hline Data Template & $\begin{array}{l}\text { Data Template } \\
\text { (see Lookups) }\end{array}$ & Must contain one. \\
\hline AP Article & $\begin{array}{l}\text { AP Article } \\
\text { (see Lookups) }\end{array}$ & $\begin{array}{l}\text { Chosen as part of the creation process. Cannot be } \\
\text { changed. }\end{array}$ \\
\hline Reporting Period Start & Date & $\begin{array}{l}\text { Populated with the as-of date for initial declarations. } \\
\text { Will not be required for 2.a.(ix).(b) declarations. }\end{array}$ \\
\hline Reporting Period End & Date & $\begin{array}{l}\text { Populated with the as-of date for initial declarations. } \\
\text { Will not be required for 2.a.(ix).(b) declarations. }\end{array}$ \\
\hline Declaration Type & $\begin{array}{l}\text { Declaration Type } \\
\text { (see Lookups) }\end{array}$ & Set to default automatically by the PR3. \\
\hline Details & Declaration Detail & $\begin{array}{l}\text { May contain zero or one. May be one of several types } \\
\text { of Declaration Details, for declarations that require } \\
\text { additional headers. }\end{array}$ \\
\hline Declarable Comments & String & \\
\hline Undeclarable Comments & String & \\
\hline Entries & Set of Entries & \\
\hline Document References & $\begin{array}{l}\text { Set of Documents } \\
\text { (see Data Types) }\end{array}$ & \\
\hline
\end{tabular}

Additional Declaration fields will also be provided for internal State use. These fields may be labeled by users and their contents will not be included in any submission to IAEA.

Declaration Details 2.a.(iii)

\begin{tabular}{|l|l|l|}
\hline Name & Type & Notes \\
\hline Site Code & $\begin{array}{l}\text { Site Code } \\
\text { (see Lookups) }\end{array}$ & May contain one or zero. \\
\hline Working Hours & String & \\
\hline Site Holidays & Set of Dates & \\
\hline
\end{tabular}




\section{Declaration Details 2.a.(ix).(b)}

Each Declaration is submitted in response to a specific Agency request. A separate Entry is added to the Declaration for each export in the request.

\begin{tabular}{|l|l|l|}
\hline Name & Type & Notes \\
\hline Agency Request Date & Date & \\
\hline Agency Request Number & String & $\begin{array}{l}\text { Should be validated as "MC-CCC-\#\#” or "MC-CCC- } \\
\text { \#\#.\#” where "CCC" is the country code and "\#\#" or } \\
\text { "\#\#.\#" is the request number. }\end{array}$ \\
\hline
\end{tabular}

\section{Declaration Details 2.b.(ii)}

Each Declaration is submitted in response to a specific Agency request. A separate Entry is added to the Declaration for each location of interest in the request.

\begin{tabular}{|l|l|l|}
\hline Name & Type & Notes \\
\hline Agency Request Date & Date & \\
\hline Agency Request Number & String & $\begin{array}{l}\text { Should be validated as "MC-CCC-\#\#” or "MC-CCC- } \\
\text { \#\#.\#” where "CCC" is the country code and "\#\#" or } \\
\text { "\#\#.\#” is the request number. }\end{array}$ \\
\hline
\end{tabular}

\section{Declaration Details 2.c}

Each Declaration is submitted in response to a specific Agency request. A separate Entry is added to the Declaration to respond to each question in the request.

\begin{tabular}{|l|l|l|}
\hline Name & Type & Notes \\
\hline Agency Request Date & Date & \\
\hline Agency Request Number & String & $\begin{array}{l}\text { Should be validated as "MC-CCC-\#\#” or "MC-CCC- } \\
\text { \#\#.\#" where "CCC" is the country code and "\#\#" or } \\
\text { "\#\#.\#" is the request number. }\end{array}$ \\
\hline
\end{tabular}

\section{Common Data Types}

\section{Collaboration}

\begin{tabular}{|l|l|l|}
\hline Name & Type & Notes \\
\hline State & String & Must contain a value to validate for submission. \\
\hline Organization & String & Must contain a value to validate for submission. \\
\hline Address & String & Must contain a value to validate for submission. \\
\hline Involvement & String & Must contain a value to validate for submission. \\
\hline
\end{tabular}

\section{Document}

MimeType and FileContents are used for attachments that are embedded in PR3 files. References to paper documents will only use Description, Document Title, and Document Type.

\begin{tabular}{|l|l|l|}
\hline Name & Type & Notes \\
\hline Document Title & String & Required. \\
\hline Mime Type & String & \\
\hline File Contents & Binary (Base64) & \\
\hline Description & String & \\
\hline Document Type & String & \\
\hline
\end{tabular}




\section{GeoCoordinates}

Will specify a latitude and longitude. The exact format is TBD, as there are several possible ways to represent this.

\section{Location}

\begin{tabular}{|l|l|l|}
\hline Name & Type & Notes \\
\hline Name & String & Must contain a value to validate for submission. \\
\hline Address & String & Must contain a value to validate for submission. \\
\hline Coordinates & GeoCoordinates & $\begin{array}{l}\text { May contain zero or one. Must contain one to validate } \\
\text { for submission. }\end{array}$ \\
\hline
\end{tabular}

\section{Organization Involvement}

\begin{tabular}{|l|l|l|}
\hline Name & Type & Notes \\
\hline Organization & String & Must contain a value to validate for submission. \\
\hline Brief Description & String & Must contain a value to validate for submission. \\
\hline
\end{tabular}

\section{Quantity}

\begin{tabular}{|l|l|l|}
\hline Name & Type & Notes \\
\hline Value & Float & Must contain a value to validate for submission. \\
\hline Units & $\begin{array}{l}\text { Unit of Quantity } \\
\text { (see Lookups) }\end{array}$ & Must contain a value to validate for submission. \\
\hline
\end{tabular}

\section{Reference}

Reference would either use State-Declaration-Entry format (referring to submitted Entries) or Internal ID (referring to Entries in development). When line items were added to a Submission and numbered, all references would be resolved to State-Declaration-Entry format.

Valid references in State-Declaration-Entry format may contain:

- State, Declaration, and Entry

- Declaration and Entry (for reference to the same State)

- State and Declaration (for reference to a Declaration)

- Declaration (for reference to a Declaration in the same State)

\begin{tabular}{|l|l|l|}
\hline Name & Type & Notes \\
\hline Reference Type & $\begin{array}{l}\text { Reference Type } \\
\text { (see Lookups) }\end{array}$ & Required. \\
\hline State & String & \\
\hline Declaration & Integer & \\
\hline Entry & Integer & \\
\hline Internal ID & String & Required if Entry not specified. \\
\hline Notes & String & \\
\hline
\end{tabular}

\section{Sublocation}

\begin{tabular}{|l|l|l|}
\hline Name & Type & Notes \\
\hline Building & String & Must contain a value to validate for submission. \\
\hline Room & String & \\
\hline Subarea & String & $\begin{array}{l}\text { Free text field, but options may be provided from the } \\
\text { Facility/LOF lookup. }\end{array}$ \\
\hline Facility/LOF & String & \\
\hline Managed Access & Boolean & \\
\hline
\end{tabular}




\section{Lookup Data}

\section{Annex I}

\begin{tabular}{|l|l|}
\hline Value & Description \\
\hline i & The manufacture of centrifuge rotor tubes or the assembly of gas centrifuges \\
\hline ii & The manufacture of diffusion barriers \\
\hline iii & The manufacture or assembly of laser-based systems \\
\hline iv & The manufacture or assembly of electromagnetic isotope separators \\
\hline v & The manufacture or assembly of columns or extraction equipment \\
\hline vi & The manufacture of aerodynamic separation nozzles or vortex tubes \\
\hline vii & The manufacture or assembly of uranium plasma generation systems \\
\hline viii & The manufacture of zirconium tubes \\
\hline ix & The manufacture or upgrading of heavy water or deuterium \\
\hline x & The manufacture of nuclear grade graphite \\
\hline xi & The manufacture of flasks for irradiated fuel \\
\hline xii & The manufacture of reactor control rods \\
\hline xiii & The manufacture of criticality safe tanks and vessels \\
\hline xiv & The manufacture of irradiated fuel element chopping machines \\
\hline xv & The construction of hot cells \\
\hline VE & Voluntary Extension \\
\hline
\end{tabular}

\section{Annex II}

Only the lowest-level items in each branch of the tree are selectable. Depending on how this data is stored, it might be useful to add either a Parent or Child field, as well as a Selectable flag for each item.

\begin{tabular}{|l|l|}
\hline Value & Description \\
\hline 1 & Reactors and Equipment Therefor \\
\hline 1.1 & Complete nuclear reactors \\
\hline 1.2 & Reactor pressure vessels \\
\hline 1.3 & Reactor fuel changing and discharging machines \\
\hline 1.4 & Reactor control rods \\
\hline 1.5 & Reactor pressure tubes \\
\hline 1.6 & Zirconium tubes \\
\hline 1.7 & Primary coolant pumps \\
\hline 2 & Non-Nuclear Materials for Reactors \\
\hline 2.1 & Deuterium and heavy water \\
\hline 2.2 & Nuclear grade graphite \\
\hline 3 & $\begin{array}{l}\text { Plants for the Reprocessing of Irradiated Fuel Elements, and Equipment Especially Designed or } \\
\text { Prepared Therefor }\end{array}$ \\
\hline 3.1 & Irradiated fuel element chopping machines \\
\hline 3.2 & Dissolvers \\
\hline 3.3 & Solvent extractors and solvent extraction equipment \\
\hline 3.4 & Chemical holding or storage vessels \\
\hline 3.5 & Plutonium nitrate to oxide conversion system \\
\hline 3.6 & Plutonium oxide to metal production system \\
\hline 4 & Plants for the Fabrication of Fuel Elements \\
\hline $4 .($ a) & $\begin{array}{l}\text { Plants for the fabrication of fuel elements includes the equipment which normally comes in direct } \\
\text { contact with, or directly processes, or controls, the production flow of nuclear material }\end{array}$ \\
\hline $4 .(b)$ & $\begin{array}{l}\text { Plants for the fabrication of fuel elements includes the equipment which seals the nuclear material } \\
\text { within the cladding }\end{array}$ \\
\hline 5 & $\begin{array}{l}\text { Plants for the Separation of Isotopes of Uranium and Equipment, Other Than Analytical } \\
\text { Instruments, Especially Designed or Prepared Therefor }\end{array}$ \\
\hline 5.1 & $\begin{array}{l}\text { Gas centrifuges and assemblies and components especially designed or prepared for use in gas } \\
\text { centrifuges }\end{array}$ \\
\hline
\end{tabular}




\begin{tabular}{|c|c|}
\hline Value & Description \\
\hline 5.1 .1 & Rotating components \\
\hline 5.1.1.(a) & Complete rotor assemblies \\
\hline 5.1.1.(b) & Rotor tubes \\
\hline 5.1.1.(c) & Rings or bellows \\
\hline 5.1.1.(d) & Baffles \\
\hline 5.1.1.(e) & Top caps/bottom caps \\
\hline 5.1 .2 & Static components \\
\hline 5.1.2.(a) & Magnetic suspension bearings \\
\hline 5.1.2.(b) & Bearings/dampers \\
\hline 5.1.2.(c) & Molecular pumps \\
\hline 5.1.2.(d) & Motor stators \\
\hline 5.1.2.(e) & Centrifuge housing/recipients \\
\hline 5.1.2.(f) & Scoops \\
\hline 5.2 & $\begin{array}{l}\text { Especially designed or prepared auxiliary systems, equipment and components for gas centrifuge } \\
\text { enrichment plants }\end{array}$ \\
\hline 5.2 .1 & Feed systems/product and tails withdrawal systems \\
\hline 5.2 .2 & Machine header piping systems \\
\hline 5.2 .3 & UF6 mass spectrometers/ion sources \\
\hline 5.2 .4 & Frequency changers \\
\hline 5.3 & $\begin{array}{l}\text { Especially designed or prepared assemblies and components for use in gaseous diffusion } \\
\text { enrichment }\end{array}$ \\
\hline 5.3 .1 & Gaseous diffusion barriers \\
\hline 5.3 .2 & Diffuser housings \\
\hline 5.3 .3 & Compressors and gas blowers \\
\hline 5.3 .4 & Rotary shaft seals \\
\hline 5.3 .5 & Heat exchanges for cooling UF6 \\
\hline 5.4 & $\begin{array}{l}\text { Especially designed or prepared auxiliary systems, equipment and components for use in gaseous } \\
\text { diffusion enrichment }\end{array}$ \\
\hline 5.4 .1 & Feed systems/product and tails withdrawal systems \\
\hline 5.4 .2 & Header piping systems \\
\hline 5.4 .3 & Vacuum systems \\
\hline 5.4 .4 & Special shut-off and control valves \\
\hline 5.4 .5 & UF6 mass spectrometers/ion sources \\
\hline 5.5 & $\begin{array}{l}\text { Especially designed or prepared systems, equipment and components for use in aerodynamic } \\
\text { enrichment plants }\end{array}$ \\
\hline 5.5 .1 & Separation nozzles \\
\hline 5.5 .2 & Vortex tones \\
\hline 5.5 .3 & Compressors and gas blowers \\
\hline 5.5.4 & Rotary shaft seals \\
\hline 5.5 .5 & Heat exchangers for gas cooling \\
\hline 5.5 .6 & Separation element housings \\
\hline 5.5 .7 & Feed systems/product and tails withdrawal systems \\
\hline 5.5 .8 & Header piping system \\
\hline 5.5 .9 & Vacuum systems and pumps \\
\hline 5.5 .10 & Special shut-off and control valves \\
\hline 5.5 .11 & UF6 mass spectrometers/ion sources \\
\hline 5.5 .12 & UF6/carrier gas separation systems \\
\hline 5.6 & $\begin{array}{l}\text { Especially designed or prepared systems, equipment and components for use in chemical } \\
\text { exchange or ion exchange enrichment plants }\end{array}$ \\
\hline 5.6 .1 & Liquid-liquid exchange columns (chemical exchange) \\
\hline 5.6 .2 & Liquid-liquid centrifugal contactors (chemical exchange) \\
\hline 5.6 .3 & Uranium reduction systems and equipment (chemical exchange) \\
\hline 5.6 .4 & Feed preparation systems (chemical exchange) \\
\hline 5.6 .5 & Uranium oxidation systems (chemical exchange) \\
\hline 5.6 .6 & Fast-reacting ion exchange resins/adsorbents (ion exchange) \\
\hline 5.6 .7 & Ion exchange columns (ion exchange) \\
\hline 5.6 .8 & Ion exchange reflux systems (Ion exchange) \\
\hline
\end{tabular}




\begin{tabular}{|c|c|}
\hline Value & Description \\
\hline 5.7 & $\begin{array}{l}\text { Especially designed or prepared systems, equipment and components for use in laser-based } \\
\text { enrichment plants }\end{array}$ \\
\hline 5.7 .1 & Uranium vaporization systems (AVLIS) \\
\hline 5.7 .2 & Liquid uranium metal handling systems (AVLIS) \\
\hline 5.7 .3 & Uranium metal 'product' and 'tails' collector assemblies (AVLIS) \\
\hline 5.7 .4 & Separator module housings (AVLIS) \\
\hline 5.7 .5 & Supersonic expansion nozzles (MLIS) \\
\hline 5.7 .6 & Uranium pentafluoride product collector (MLIS) \\
\hline 5.7 .7 & UF6 carrier gas compressors (MLIS) \\
\hline 5.7 .8 & Rotary shaft seals (MLIS) \\
\hline 5.7 .9 & Fluorination systems (MLIS) \\
\hline 5.7 .10 & UF6 mass spectrometers/ion sources (MLIS) \\
\hline 5.7 .11 & Feed systems/product and tails withdrawal systems (MLIS) \\
\hline 5.7 .12 & UF6/carrier gas separation systems (MLIS) \\
\hline 5.7 .13 & Laser systems (AVLIS, MLIS and CRISLA) \\
\hline 5.8 & $\begin{array}{l}\text { Especially designed or prepared systems, equipment and components for use in plasma separation } \\
\text { enrichment plants }\end{array}$ \\
\hline 5.8 .1 & Microwave power sources and antennae \\
\hline 5.8 .2 & Ion excitation coils \\
\hline 5.8 .3 & Uranium plasma generation systems \\
\hline 5.8 .4 & Liquid uranium metal handling systems \\
\hline 5.8 .5 & Uranium metal 'product' and 'tails' collector assemblies \\
\hline 5.8 .6 & Separator module housings \\
\hline 5.9 & $\begin{array}{l}\text { Especially designed or prepared systems, equipment and components for use in electromagnetic } \\
\text { enrichment plants }\end{array}$ \\
\hline 5.9 .1 & Electromagnetic isotope separators \\
\hline 5.9.1.(a) & Ion sources \\
\hline 5.9.1.(b) & Ion collectors \\
\hline 5.9.1.(c) & Vacuum housings \\
\hline 5.9.1.(d) & Magnet pole pieces \\
\hline 5.9 .2 & High voltage power supplies \\
\hline 5.9 .3 & Magnet power supplies \\
\hline 6 & $\begin{array}{l}\text { Plants for the Production of Heavy Water, Deuterium and Deuterium Compounds and Equipment } \\
\text { Especially Designed or Prepared Therefor }\end{array}$ \\
\hline 6.1 & Water-hydrogen sulphide exchange towers \\
\hline 6.2 & Blowers and Compressors \\
\hline 6.3 & Ammonia-hydrogen exchange towers \\
\hline 6.4 & Tower internals and stage pumps \\
\hline 6.5 & Ammonia crackers \\
\hline 6.6 & Infrared absorption analyzers \\
\hline 6.7 & Catalytic burners \\
\hline 7 & Plants for the Conversion of Uranium and Equipment Especially Designed or Prepared Therefor \\
\hline 7.1 & Especially designed or prepared systems for the conversion of uranium ore concentrates to UO3 \\
\hline 7.2 & Especially designed or prepared systems for the conversion of UO3 to UF6 \\
\hline 7.3 & Especially designed or prepared systems for the conversion of UO3 to UO2 \\
\hline 7.4 & Especially designed or prepared systems for the conversion of UO2 to UF4 \\
\hline 7.5 & Especially designed or prepared systems for the conversion of UF4 to UF6 \\
\hline 7.6 & Especially designed or prepared systems for the conversion of UF4 to U metal \\
\hline 7.7 & Especially designed or prepared systems for the conversion of UF6 to UO2 \\
\hline 7.8 & Especially designed or prepared systems for the convention of UF6 to UF4 \\
\hline
\end{tabular}

\section{AP Article}

\begin{tabular}{|l|l|}
\hline Value & Description \\
\hline 2.a.(i) & Government-sponsored NFC R\&D not involving nuclear material \\
\hline 2.a.(ii) & Information agreed with the Agency to facilitate safeguards implementation \\
\hline 2.a.(iii) & Buildings and sites \\
\hline
\end{tabular}




\begin{tabular}{|l|l|}
\hline Value & Description \\
\hline 2.a.(iv) & Manufacturing, assembly, and construction activities listed in Annex I \\
\hline 2.a.(v) & Mines and concentration plants \\
\hline 2.a.(vi).(a) & Source material inventories \\
\hline 2.a.(vi).(b) & Source material exports \\
\hline 2.a.(vi).(c) & Source material imports \\
\hline 2.a.(vii) & Safeguards-exempted nuclear material \\
\hline 2.a.(viii).(a) & Changes in location of intermediate and high level waste \\
\hline 2.a.(viii).(b) & Further processing of intermediate and high level waste \\
\hline 2.a.(ix).(a) & Exports of equipment and non-nuclear material listed in Annex II \\
\hline 2.a.(ix).(b) & Imports of equipment and non-nuclear material listed in Annex II \\
\hline 2.a.(x) & Nuclear fuel cycle R\&D ten-year plan \\
\hline 2.b.(i) & Privately-sponsored NFC R\&D not involving nuclear material \\
\hline 2.b.(ii) & General description of activities at locations identified by the Agency \\
\hline 2.c & $\begin{array}{l}\text { Upon request by the Agency, State to provide Agency with amplifications or clarifications } \\
\text { of any information provided under Article 2 }\end{array}$ \\
\hline Note & \multicolumn{2}{|}{} \\
\hline
\end{tabular}

\section{Chemical Composition}

Chemical Composition

Contributor

\begin{tabular}{|l|l|l|l|l|}
\hline Organization & Address & POC Name & POC Email & POC Phone \\
\hline TBD by State & TBD by State & TBD by State & TBD by State & TBD by State \\
\hline
\end{tabular}

\section{Declaration Type}

\begin{tabular}{|l|}
\hline Value \\
\hline New information \\
\hline No change \\
\hline Nothing to declare \\
\hline Consolidated update \\
\hline
\end{tabular}

\section{Entry Type}

Value

New entry

No change

Revised entry

\section{Exemption}

\begin{tabular}{|l|}
\hline Exemption \\
\hline Article 36b \\
\hline Article 37 \\
\hline
\end{tabular}

\section{Facility/LOF}

Facility/LOF Code list may be used to provide a dropdown/autocomplete list for Facility/LOF fields, but the list will not restrict entry in those fields.

\begin{tabular}{|l|l|}
\hline Code & Name \\
\hline TBD by & TBD by State/IAEA \\
State/IAEA & \\
\hline
\end{tabular}

\section{Fuel Cycle Stages}

\section{Fuel Cycle Stage}

Conversion of Nuclear Material 
Fuel Cycle Stage

Enrichment of Nuclear Material

Nuclear Fuel Fabrication

Reactors

Critical Facilities

Reprocessing of Nuclear Fuel

Processing of Waste

Source Material Recovery

\section{INFCIRC}

INFCIRC could be provided as part of the Data Template, rather than a table included in the lookup file.

\begin{tabular}{|l|l|}
\hline Number & Description \\
\hline TBD by & TBD by IAEA \\
IAEA & \\
\hline
\end{tabular}

\section{Intended Use Code}

\begin{tabular}{|l|l|}
\hline Code & Description \\
\hline NN & Non-Nuclear \\
\hline N & Nuclear \\
\hline ND & Not Designated \\
\hline
\end{tabular}

\section{Material Code}

\begin{tabular}{|l|l|}
\hline Code & Description \\
\hline $\mathrm{NU}$ & Natural Uranium \\
\hline $\mathrm{DU}$ & Depleted Uranium \\
\hline $\mathrm{Th}$ & Thorium \\
\hline $\mathrm{Pu}$ & Plutonium \\
\hline $\mathrm{U}-233$ & Uranium-233 \\
\hline $\mathrm{E}$ & Enriched Uranium \\
\hline
\end{tabular}

\section{MBA Code}

MBA Code may be used to provide a dropdown/autocomplete list for MBA Code fields, but does not restrict entry in those fields.

\begin{tabular}{|l|l|}
\hline Code & Name \\
\hline TBD by & TBD by State/IAEA \\
State/IAEA & \\
\hline
\end{tabular}

\section{Mine/Plant}

A list of mines and plants is updated by the State and is used to identify which locations require actual production to be declared per Agency request.

\begin{tabular}{|l|l|}
\hline Operation & Requires Actual Production to be Declared \\
\hline State Total & Yes \\
\hline TBD by State/IAEA & TBD by State/IAEA \\
\hline
\end{tabular}

\section{Operation}

Operation

U Mine

U Mine and Concentration

Th Concentration

Th Mine

U Plants 
Operation

Th Plants

\section{Operation Status}

Operation Status

Operating

Closed Down

Abandoned

Total

\section{Reference Type}

\section{Value}

Related

Update

\section{Site Code}

\begin{tabular}{|l|l|}
\hline Code & Name \\
\hline TBD by & TBD by IAEA/State from DIQ \\
IAEA/State \\
from DIQ
\end{tabular}

\section{State}

\begin{tabular}{|l|l|}
\hline Code & Name \\
\hline
\end{tabular}

TBD by IAEA TBD by IAEA

\section{Status}

\begin{tabular}{|l|l|l|}
\hline Value & Is Read-Only & Is Submitted \\
\hline In Progress & No & No \\
\hline Submitted & Yes & Yes \\
\hline Other statuses TBD & Other statuses TBD & Other statuses TBD \\
\hline
\end{tabular}

\section{Submission Type}

\begin{tabular}{|l|l|}
\hline Value & Description \\
\hline $3 . \mathrm{a}$ & Initial \\
\hline $3 . \mathrm{b}$ & Annual update for initial \\
\hline $3 . \mathrm{c}$ & Annual update (source material imports \& exports) \\
\hline $3 . \mathrm{d}$ & Quarterly update (Annex II exports) \\
\hline $3 . \mathrm{e}$ & Annual update (intermediate and high-level waste) \\
\hline $3 . \mathrm{f}$ & Response to agency request (2.a.(ii)) \\
\hline $3 . \mathrm{g}$ & Response to agency request (Annex II imports) \\
\hline $\begin{array}{l}\text { Response to } \\
\text { Agency } \\
\text { Request }\end{array}$ & Response to agency Request (2.c) \\
\hline General & General \\
\hline
\end{tabular}

\section{Unit of Area}

\section{Unit}

Square meters

(Other allowed units TBD by IAEA)

\section{Unit of Quantity}

\begin{tabular}{|l|}
\hline Unit \\
\hline $\mathrm{g}$ \\
\hline $\mathrm{Kg}$ \\
\hline Items \\
\hline
\end{tabular}


MT

(Other allowed units TBD by IAEA)

AP Article Declarations by Submission Type

\begin{tabular}{|l|l|l|}
\hline Submission Type & Allowed AP Articles & Required AP Articles \\
\hline 3.a & 2.a.(i), (iii), (iv), (v), (vi).(a), (vii), (x), 2.b.(i), Note & $\begin{array}{l}\text { 2.a.(i), (iii), (iv), (v), (vi).(a), } \\
\text { (vii), (x), 2.b.(i) }\end{array}$ \\
\hline 3.b & 2.a.(i), (iii), (iv), (v), (vi).(a), (vii), (x), 2.b.(i), Note & \\
\hline 3.c & 2.a.(vi).(b), (vi).(c), Note & \\
\hline 3.d & 2.a.(ix).(a), Note & \\
\hline 3.e & 2.a.(viii), Note & \\
\hline 3.f & 2.a.(ii), Note & \\
\hline 3.g & 2.a.(ix).(b), Note & \\
\hline Response & 2.b.(ii), 2.c, Note & \\
\hline General & $\begin{array}{l}\text { 2.a.(i), (ii), (iii), (iv), (v), (vi), (vii), (viii), (ix), (x), } \\
\text { 2.b.(i), (ii), 2.c, Note }\end{array}$ & \\
\hline
\end{tabular}

Due dates by Submission Type

\begin{tabular}{|l|l|}
\hline Submission Type & Due Date \\
\hline 3.a & 180 days of Entry-Into-Force date \\
\hline 3.b & Starting May 15 of the year following EIF, then every year after \\
\hline 3.c & Starting May 15 of the year following EIF, then every year after \\
\hline 3.d & 60 days of the end of each quarter \\
\hline $3 . \mathrm{e}$ & $\begin{array}{l}180 \text { days before further processing is carried out, and every May 15 of each year } \\
\text { following EIF }\end{array}$ \\
\hline 3.f & Agreed upon by state and IAEA \\
\hline 3.g & 60 days of IAEA request \\
\hline
\end{tabular}

\section{Data Template Identification}

This will likely be defined in the data template, rather than being a separate lookup value

\begin{tabular}{|l|l|l|}
\hline ID & Display Name & Icon \\
\hline ModelAP & AP & IAEA logo \\
\hline
\end{tabular}

\section{C.2 EURATOM extensions to the Model AP Data Structure}

The EURATOM data template contains the same structure as the Model AP, with the following additions:

\section{Base Entry Data Structure}

\begin{tabular}{|l|l|l|}
\hline Name & Type & Notes \\
\hline Security Level & String & \\
\hline
\end{tabular}

\section{Declaration}

\begin{tabular}{|l|l|l|}
\hline Name & Type & Notes \\
\hline Security Level & String & \\
\hline
\end{tabular}

\section{Declaration Details 2.a.(iii)}

\begin{tabular}{|l|l|l|}
\hline Name & Type & Notes \\
\hline Site Contact Details & String & \\
\hline Geographical Location & String & \\
\hline Site Holidays & String & \\
\hline
\end{tabular}




\begin{tabular}{|l|l|l|}
\hline Name & Type & Notes \\
\hline Working Hours & String & \\
\hline Site Address & String & \\
\hline
\end{tabular}

Data Template Identification

\begin{tabular}{|l|l|l|}
\hline ID & Display Name & Icon \\
\hline EURATOM & EURATOM AP & EU flag \\
\hline
\end{tabular}

\section{C.3 US extensions to the Model AP Data Structure}

The US data template contains the same structure as the Model AP, with the following additions:

\section{Base Entry Data Structure}

\begin{tabular}{|l|l|l|}
\hline Name & Type & Notes \\
\hline $\begin{array}{l}\text { Internal US Record } \\
\text { Keeping Information }\end{array}$ & String & \\
\hline US Reporting Code & String & \\
\hline
\end{tabular}

Entry 2.a.(v)

\begin{tabular}{|l|l|l|}
\hline Name & Type & Notes \\
\hline GPS Coordinates & $\begin{array}{l}\text { Set of GeoCoordinates } \\
\text { (see Data Types) }\end{array}$ & \\
\hline
\end{tabular}

\section{Data Template Identification}

\begin{tabular}{|l|l|l|}
\hline ID & Display Name & Icon \\
\hline USA & US AP & US flag \\
\hline
\end{tabular}

\section{C.4 AP Data Structure for China}

The AP for China uses similar data structures to those used in the Model AP, but with several modifications. It may be implemented as its own template rather than an extension of the Model AP. It is described in relation to the Model AP here to avoid repetition.

This data structure is based on limited information, so it may be incomplete or inaccurate. It will be revised as more information becomes available.

\section{Base Entry Data Structure}

The AP for China uses the same base Entry structure as the Model AP.

Entry 2.a.(i)

The AP for China Entry 2.a.(i) structure is the same as that for Entry 2.a.(iv) in the Model AP.

Entry 2.a.(ii)

The AP for China Entry 2.a.(ii) structure is the same as that for Entry 2.a.(v) in the Model AP.

Entry 2.a.(iii).(a)

The AP for China Entry 2.a.(iii).(a) structure is the same as that for Entry 2.a.(vi).(b) in the Model AP. 
Entry 2.a.(iii).(b)

The AP for China Entry 2.a.(iii).(b) structure is the same as that for Entry 2.a.(vi).(c) in the Model AP.

Entry 2.a.(iv)

The AP for China Entry 2.a.(iv) structure is the same as that for Entry 2.a.(vii) in the Model AP.

\section{Entry 2.a.(v) Export}

The AP for China Entry 2.a.(v) Export structure is the same as that for Entry 2.a.(viii).(a) in the Model $\mathrm{AP}$, with the following additional field:

\begin{tabular}{|l|l|l|}
\hline Name & Type & Notes \\
\hline Export Date & Date & \\
\hline
\end{tabular}

\section{Entry 2.a.(v) Import}

The AP for China Entry 2.a.(v) Import structure is the same as that for Entry 2.a.(viii).(a) in the Model AP, with the following additional field:

\begin{tabular}{|l|l|l|}
\hline Name & Type & Notes \\
\hline Import Date & Date & \\
\hline
\end{tabular}

\section{Entry 2.a.(vi)}

The AP for China Entry 2.a.(vi) structure is the same as that for Entry 2.a.(ix).(a) in the Model AP.

Entry 2.a.(vii)

The AP for China Entry 2.a.(vii) structure is the same as that for Entry 2.a.(x) in the Model AP.

\section{Entry 2.b}

The AP for China Entry 2.b structure is the same as that for Entry 2.a.(i) in the Model AP, with the addition of the following fields:

\begin{tabular}{|l|l|l|}
\hline Name & Type & Notes \\
\hline Agency Request Date & Date & \\
\hline Agency Request Number & String & $\begin{array}{l}\text { Should be validated as "MC-CCC-\#\#” or "MC-CCC- } \\
\text { \#\#.\#” where "CCC" is the country code and "\#\#" or } \\
\text { "\#\#.\#" is the request number. }\end{array}$ \\
\hline
\end{tabular}

\section{Entry 2.c}

The AP for China uses the same Entry 2.c structure as the Model AP.

\section{Entry 2.d}

The AP for China Entry 2.d structure is the same as that for Entry 2.c in the Model AP.

\section{Entry Note}

The AP for China uses the same Entry Note structure as the Model AP.

\section{Submission Data Structure}

\section{Submission}

The AP for China uses the same Submission structure as the Model AP. 


\section{Declaration}

The AP for China uses the same Submission structure as the Model AP.

\section{Declaration Details 2.b}

Each Declaration is submitted in response to a specific Agency request. A separate Entry is added to the Declaration for each location of interest in the request.

\begin{tabular}{|c|c|c|}
\hline Name & Type & Notes \\
\hline Agency Request Date & Date & \\
\hline Agency Request Number & String & $\begin{array}{l}\text { Should be validated as "MC-CCC-\#\#" or "MC-CCC- } \\
\text { \#\#.\#" where "CCC" is the country code and "\#\#" or } \\
\text { "\#\#.\#" is the request number. }\end{array}$ \\
\hline
\end{tabular}

\section{Common Data Types}

\section{Collaboration}

The AP for China uses the same Collaboration structure as the Model AP.

\section{Document}

The AP for China uses the same Document structure as the Model AP.

\section{GeoCoordinates}

The AP for China uses the same GeoCoordinates structure as the Model AP.

\section{Organization Involvement}

The AP for China uses the same Organization Involvement structure as the Model AP.

\section{Quantity}

The AP for China uses the same Quantity structure as the Model AP.

\section{Reference}

The AP for China uses the same Reference structure as the Model AP.

\section{Sublocation}

The AP for China uses the same Sublocation structure as the Model AP.

\section{Lookup Data}

The Lookup table structure and data is the same as for the Model AP, with the following exceptions:

\section{AP Articles}

\begin{tabular}{|l|l|}
\hline Value & Description \\
\hline 2.a.(i) & Annex I Manufacturing Activities in cooperation with NNWS \\
\hline 2.a.(ii) & Mines and Concentration Plants involved in production for NNWS \\
\hline 2.a.(iii).(a) & Pre-Safeguards Source Material Exports to a NNWS (nuclear and non-nuclear use) \\
\hline 2.a.(iii).(b) & Pre-Safeguards Source Material Imports to a NNWS (nuclear and non-nuclear use) \\
\hline 2.a.(iv) & Exempted Nuclear Material processed or used for a NNWS \\
\hline 2.a.(v) & Intermediate and High-Level Waste (exports and imports to/from NNWS) \\
\hline 2.a.(vi) & Exports of Annex II items to a NNWS \\
\hline
\end{tabular}




\begin{tabular}{|l|l|}
\hline Value & Description \\
\hline 2.a.(vii) & General Fuel Cycle Plans in cooperation with NNWS \\
\hline 2.b & Nuclear Fuel Cycle R\&D not involving nuclear material in cooperation with NNWS \\
\hline 2.c & $\begin{array}{l}\text { Upon request by the Agency, China shall provide amplifications or clarifications of any } \\
\text { information provided under Article 2 }\end{array}$ \\
\hline 2.d & $\begin{array}{l}\text { Upon request by the Agency, China shall provide confirmation of information submitted by } \\
\text { a NNWS }\end{array}$ \\
\hline
\end{tabular}

\section{Data Template Identification}

\begin{tabular}{|l|l|l|}
\hline ID & Display Name & Icon \\
\hline China & AP for China & Chinese flag \\
\hline
\end{tabular}

\section{C.5 AP Data Structure for France}

The AP for France uses similar data structures to those used in the Model AP, but with several modifications. It will likely be implemented as its own template, rather than an extension of the Model AP. It is described in relation to the Model AP here to avoid repetition.

\section{Entry Data Structures}

\section{Base Entry Data Structure}

The AP for France uses the same base Entry structure as the Model AP.

\section{Entry 2.a.(i)}

The AP for France uses the same Entry 2.a.(i) structure as the Model AP, with the following exceptions:

\begin{tabular}{|l|l|}
\hline Model AP Field Name & AP for France Field Name \\
\hline Foreign Collaboration & Information on the NNWS entity \\
\hline Location & Location of the entity in France \\
\hline Sublocations & Location of the activities and access information \\
\hline
\end{tabular}

\section{Entry 2.a.(ii)}

The AP for France uses the same Entry 2.a.(ii) structure as the Model AP.

\section{Entry 2.a.(iii)}

The AP for France Entry 2.a.(iii) structure is the same as that for Entry 2.a.(iv) in the Model AP, but with the following additions and exceptions:

\begin{tabular}{|l|l|l|}
\hline Name & Type & Notes \\
\hline $\begin{array}{l}\text { Information on the } \\
\text { NNWS entity }\end{array}$ & $\begin{array}{l}\text { Collaboration } \\
\text { (see Data Types) }\end{array}$ & May contain zero or one. \\
\hline
\end{tabular}

\begin{tabular}{|l|l|}
\hline Model AP Field Name & AP for France Field Name \\
\hline Location & Location of the entity in France \\
\hline Sublocations & Location of the activities and access information \\
\hline
\end{tabular}




\section{Entry 2.a.(iv)}

The AP for France Entry 2.a.(iv) structure is the same as that for Entry 2.a.(v) in the Model AP.

Entry 2.a.(v).(a)

The AP for France Entry 2.a.(v).(a) structure is the same as that for Entry 2.a.(vi).(b) in the Model AP.:

Entry 2.a.(v).(b)

The AP for France Entry 2.a.(v).(b) structure is the same as that for Entry 2.a.(vi).(c) in the Model AP.

Entry 2.a.(vi).(a)

The AP for France Entry 2.a.(vi).(a) structure is the same as that for Entry 2.a.(viii).(a) in the Model $\mathrm{AP}$, with the following additions and removals:

\begin{tabular}{|l|l|l|}
\hline Name & Type & Notes \\
\hline Export Date & Date & \\
\hline
\end{tabular}

\section{Model AP Field Name not used in AP for France}

Waste Type

Quantity Np/Am

\section{Entry 2.a.(vi).(b)}

The AP for France Entry 2.a.(vi).(b) structure is the same as that for Entry 2.a.(viii).(a) in the Model AP, with the following additions and removals:

\begin{tabular}{|l|l|l|}
\hline Name & Type & Notes \\
\hline Import Date & Date & \\
\hline
\end{tabular}

\section{Model AP Field Name not used in AP for France}

Waste Type

Quantity Np/Am

\section{Entry 2.a.(vii).(a)}

The AP for France Entry 2.a.(vii).(a) structure is the same as that for Entry 2.a.(ix).(a) in the Model AP, with the following additions:

\begin{tabular}{|l|l|l|}
\hline Name & Type & Notes \\
\hline Annex I Paragraph & $\begin{array}{l}\text { Annex I } \\
\text { (see Lookups) }\end{array}$ & $\begin{array}{l}\text { May contain zero or one. Must contain one (and be a } \\
\text { selectable Annex I entry) to validate for submission. }\end{array}$ \\
\hline
\end{tabular}

\section{Entry 2.a.(vii).(b)}

The AP for France Entry 2.a.(vii).(b) structure is the same as that for Entry 2.a.(ix).(b) in the Model AP, with the following additions:

\begin{tabular}{|l|l|l|}
\hline Name & Type & Notes \\
\hline Annex I Paragraph & $\begin{array}{l}\text { Annex I } \\
\text { (see Lookups) }\end{array}$ & $\begin{array}{l}\text { May contain zero or one. Must contain one (and be a } \\
\text { selectable Annex I entry) to validate for submission. }\end{array}$ \\
\hline
\end{tabular}




\section{Entry 2.a.(viii)}

The AP for France Entry 2.a.(viii) structure is the same as that for Entry 2.a.(x) in the Model AP, with the following additions, differences, and removals:

\begin{tabular}{|l|l|l|}
\hline Name & Type & Notes \\
\hline $\begin{array}{l}\text { Information on the } \\
\text { NNWS entity }\end{array}$ & $\begin{array}{l}\text { Collaboration } \\
\text { (see Data Types) }\end{array}$ & May contain zero or one. \\
\hline
\end{tabular}

\begin{tabular}{|l|l|}
\hline Model AP Field Name & AP for France Field Name \\
\hline R\&D Plans & General Plans for NFC and related R\&D \\
\hline Organizations & Partner entity in France \\
\hline
\end{tabular}

\section{Model AP Field Name not used in AP for France}

Development Plans

\section{Entry 2.b}

The AP for France Entry 2.b structure is the same as that for Entry 2.b.(i) in the Model AP.

\section{Entry 2.c}

The AP for France uses the same Entry 2.c structure as the Model AP.

\section{Entry Note}

The AP for France uses the same Entry Note structure as the Model AP.

\section{Submission Data Structure}

\section{Submission}

The AP for France uses the same Submission structure as the Model AP.

\section{Declaration}

The AP for France uses the same Submission structure as the Model AP.

\section{Common Data Types}

\section{Collaboration}

The AP for France uses the same Collaboration structure as the Model AP.

\section{Document}

The AP for France uses the same Document structure as the Model AP.

\section{GeoCoordinates}

The AP for France uses the same GeoCoordinates structure as the Model AP.

\section{Organization Involvement}

The AP for France uses the same Organization Involvement structure as the Model AP.

\section{Quantity}

The AP for France uses the same Quantity structure as the Model AP. 


\section{Reference}

The AP for France uses the same Reference structure as the Model AP.

\section{Sublocation}

The AP for France uses the same Sublocation structure as the Model AP.

\section{Lookup Data}

The Lookup table structure and data is the same as for the Model AP, with the following exceptions:

AP Article

\begin{tabular}{|c|c|}
\hline Value & Description \\
\hline 2.a.(i) & Description and Location of R\&D activities related to a NNWS \\
\hline 2.a.(ii) & $\begin{array}{l}\text { Information identified by Agency to increase effectiveness or efficiency at designated } \\
\text { facilities }\end{array}$ \\
\hline 2.a.(iii) & $\begin{array}{l}\text { Description of scale of operations for each Location engaged in Activities specified in } \\
\text { Annex I and linked to an NNWS }\end{array}$ \\
\hline 2.a.(iv) & $\begin{array}{l}\text { Location, operational status and estimated annual production of Mines and Concentration } \\
\text { Plants situated in France involved in production for a NNWS }\end{array}$ \\
\hline 2.a.(v).(a) & Exports of Source Material from France to NNWS Outside the Community \\
\hline 2.a.(v).(b) & Exports of Source Material to France from NNWS Outside the Community \\
\hline 2.a.(vi).(a) & $\begin{array}{l}\text { Information regarding exports from a NNWS outside of the Community of intermediate or } \\
\text { high level waste containing } \mathrm{Pu}, \mathrm{HEU} \text { or U- } 233 \text { on which safeguards have been terminated } \\
\text { under Article } 11\end{array}$ \\
\hline 2.a.(vi).(b) & $\begin{array}{l}\text { Information regarding imports to a NNWS outside of the Community of intermediate or } \\
\text { high level waste containing } \mathrm{Pu}, \mathrm{HEU} \text { or U- } 233 \text { on which safeguards have been terminated } \\
\text { under Article } 11\end{array}$ \\
\hline 2.a.(vii).(a) & $\begin{array}{l}\text { Export of Equipment manufactured in the context of the Annex I activities and specified } \\
\text { equipment and non-nuclear material listed in Annex II to a NNWS outside of the } \\
\text { Community }\end{array}$ \\
\hline 2.a.(vii).(b) & $\begin{array}{l}\text { Import of Equipment manufactured in the context of the Annex I activities and specified } \\
\text { equipment and non-nuclear material listed in Annex II from a NNWS outside of the } \\
\text { Community }\end{array}$ \\
\hline 2.a.(viii) & Civil Nuclear Fuel Cycle R\&D Ten Year Plan \\
\hline 2.b & $\begin{array}{l}\text { Provision of Information regarding Enrichment, Reprocessing or Processing of High Level } \\
\text { Waste that is not funded, authorized or controlled by, or carried out on behalf of the France }\end{array}$ \\
\hline 2.c & $\begin{array}{l}\text { Upon request by the Agency, France or Community or Both to provide Agency } \\
\text { amplifications or clarifications of any information provided under Article } 2\end{array}$ \\
\hline
\end{tabular}

Data Template Identification

\begin{tabular}{|l|l|l|}
\hline ID & Display Name & Icon \\
\hline France & AP for France & French flag \\
\hline
\end{tabular}

\section{Submission Type}

\begin{tabular}{|l|l|}
\hline Value & Description \\
\hline 3.a & Initial \\
\hline 3.b & Annual update for initial \\
\hline 3.c & Annual update \\
\hline 3.d & Quarterly update \\
\hline 3.e & Annual update \\
\hline
\end{tabular}




\begin{tabular}{|l|l|}
\hline Value & Description \\
\hline $3 . \mathrm{f}$ & Response to agency request (2.a.(ii)) \\
\hline 3.g & Response to agency request (2.a.(vii).(b)) \\
\hline Response to & Response to agency Request (2.c) \\
Agency & \\
Request & \\
\hline General & General \\
\hline
\end{tabular}

AP Article Declarations by Submission Type

\begin{tabular}{|l|l|l|}
\hline Submission Type & Allowed AP Articles & Required AP Articles \\
\hline $3 . \mathrm{a}$ & 2.a.(i), (iii), (iv), (viii), 2.b, Note & \\
\hline $3 . \mathrm{b}$ & 2.a.(i), (iii), (iv), (viii), 2.b, Note & \\
\hline $3 . \mathrm{c}$ & 2.a.(v), Note & \\
\hline $3 . \mathrm{d}$ & 2.a.(vii), Note & \\
\hline $3 . \mathrm{e}$ & 2.a.(vi), Note & \\
\hline $3 . \mathrm{f}$ & 2.a.(ii), Note & \\
\hline $3 . \mathrm{g}$ & 2.a.(vii), Note & \\
\hline Response & 2.c, Note & \\
\hline General & $\begin{array}{l}\text { 2.a.(i), (ii), (iii), (iv), (v), (vi), (vii), (viii), 2.b, 2.c, } \\
\text { Note }\end{array}$ & \\
\hline
\end{tabular}

\section{C.6 AP Data Structure for Russia}

The AP for Russia uses similar data structures to those used in the Model AP, but with several modifications. It will likely be implemented as its own template, rather than an extension of the Model AP. It is described in relation to the Model AP here to avoid repetition.

\section{Entry Data Structures}

\section{Base Entry Data Structure}

The AP for Russia uses the same base Entry structure as the Model AP.

\section{Entry 2.a.(i)}

The AP for Russia uses the same Entry 2.a.(i) structure as the Model AP, with the following exceptions:

\begin{tabular}{|l|l|}
\hline Model AP Field Name & AP for Russia Field Name \\
\hline Foreign Collaboration & Information on the NNWS entity \\
\hline Location & Location of the entity in Russia \\
\hline Sublocations & Location of the activities and access information \\
\hline
\end{tabular}

\section{Entry 2.a.(ii)}

The AP for Russia uses the same Entry 2.a.(ii) structure as the Model AP.

\section{Entry 2.a.(iii)}

The AP for Russia Entry 2.a.(iii) structure is the same as that for Entry 2.a.(iv) in the Model AP, but with the following additions and exceptions: 


\begin{tabular}{|l|l|l|}
\hline Name & Type & Notes \\
\hline $\begin{array}{l}\text { Information on the } \\
\text { NNWS entity }\end{array}$ & $\begin{array}{l}\text { Collaboration } \\
\text { (see Data Types) }\end{array}$ & May contain zero or one. \\
\hline
\end{tabular}

\begin{tabular}{|l|l|}
\hline Model AP Field Name & AP for Russia Field Name \\
\hline Location & Location of the entity in Russia \\
\hline Sublocations & Location of the activities and access information \\
\hline
\end{tabular}

\section{Entry 2.a.(iv)}

The AP for Russia Entry 2.a.(iv) structure is the same as that for Entry 2.a.(v) in the Model AP.

Entry 2.a.(v).(a)

The AP for Russia Entry 2.a.(v).(a) structure is the same as that for Entry 2.a.(vi).(b) in the Model AP.

Entry 2.a.(v).(b)

The AP for Russia Entry 2.a.(v).(b) structure is the same as that for Entry 2.a.(vi).(c) in the Model AP.

Entry 2.a.(vi)

The AP for Russia Entry 2.a.(vi) structure is the same as that for Entry 2.a.(viii).(a) in the Model AP, with the following additions and removals:

\begin{tabular}{|l|l|l|}
\hline Name & Type & Notes \\
\hline Export Date & Date & \\
\hline
\end{tabular}

\begin{tabular}{|l|}
\hline Model AP Field Name not used in AP for Russia \\
\hline Waste Type \\
\hline Quantity Np/Am \\
\hline
\end{tabular}

\section{Entry 2.a.(vii).(a)}

The AP for Russia Entry 2.a.(vii).(a) structure is the same as that for Entry 2.a.(ix).(a) in the Model AP.

Entry 2.a.(vii).(b)

The AP for Russia Entry 2.a.(vii).(b) structure is the same as that for Entry 2.a.(ix).(b) in the Model AP.

\section{Entry 2.b}

The AP for Russia Entry 2.b structure is the same as that for Entry 2.b.(i) in the Model AP.

\section{Entry 2.c}

The AP for Russia uses the same Entry 2.c structure as the Model AP.

\section{Submission Data Structure}

\section{Submission}

The AP for Russia uses the same Submission structure as the Model AP. 


\section{Declaration}

The AP for Russia uses the same Submission structure as the Model AP.

\section{Common Data Types}

\section{Collaboration}

The AP for Russia uses the same Collaboration structure as the Model AP.

\section{Document}

The AP for Russia uses the same Document structure as the Model AP.

\section{GeoCoordinates}

The AP for Russia uses the same GeoCoordinates structure as the Model AP.

\section{Organization Involvement}

The AP for Russia uses the same Organization Involvement structure as the Model AP.

\section{Quantity}

The AP for France uses the same Quantity structure as the Model AP.

\section{Reference}

The AP for Russia uses the same Reference structure as the Model AP.

\section{Sublocation}

The AP for Russia uses the same Sublocation structure as the Model AP.

\section{Lookup Data}

The Lookup table structure and data is the same as for the Model AP, with the following exceptions:

\section{AP Article}

\begin{tabular}{|c|c|}
\hline Value & Description \\
\hline 2.a.(i) & Description and location of R\&D activities related to a NNWS \\
\hline 2.a.(ii) & $\begin{array}{l}\text { Information identified by Agency to increase effectiveness or efficiency at designated } \\
\text { facilities }\end{array}$ \\
\hline 2.a.(iii) & $\begin{array}{l}\text { Description of scale of operations for each location engaged in activities specified in Annex } \\
\text { I and linked to a NNWS }\end{array}$ \\
\hline 2.a.(iv) & $\begin{array}{l}\text { Location and current annual production of uranium mines and concentration plants and } \\
\text { thorium concentration plants in the Russian Federation, involved in production for a NNWS }\end{array}$ \\
\hline 2.a.(v).(a) & Exports of source material out of the Russian Federation to a NNWS \\
\hline 2.a.(v).(a) & Imports of source material into the Russian Federation from a NNWS \\
\hline 2.a.(vi) & $\begin{array}{l}\text { Information regarding exports to a NNWS of intermediate or high-level waste containing } \\
\mathrm{Pu}, \mathrm{HEU} \text { or } \mathrm{U}-233\end{array}$ \\
\hline 2.a.(vii).(a) & Export of specified equipment and non-nuclear material listed in Annex II to a NNWS \\
\hline 2.a.(vii).(b) & Import of specified equipment and non-nuclear material listed in Annex II from a NNWS \\
\hline $2 . b$ & $\begin{array}{l}\text { Provision of information regarding enrichment, reprocessing or processing of high-level } \\
\text { waste that is not funded, authorized or controlled by, or carried out on behalf of the Russian } \\
\text { Federation }\end{array}$ \\
\hline 2.c & $\begin{array}{l}\text { Upon request by the Agency, the Russian Federation shall provide amplifications or } \\
\text { clarifications of any information provided under Article } 2\end{array}$ \\
\hline
\end{tabular}


Data Template Identification

\begin{tabular}{|l|l|l|}
\hline ID & Display Name & Icon \\
\hline Russia & AP for Russia & Russian flag \\
\hline
\end{tabular}

\section{Submission Type}

\begin{tabular}{|l|l|}
\hline Value & Description \\
\hline 3.a & Initial \\
\hline 3.b & Annual update for initial \\
\hline 3.c & Annual update \\
\hline 3.d & Quarterly update \\
\hline 3.e & Response to agency request (2.a.(ii)) \\
\hline 3.f & Response to agency request (2.a.(vii)) \\
\hline $\begin{array}{l}\text { Response to } \\
\text { Agency } \\
\text { Request }\end{array}$ & Response to agency Request (2.c) \\
\hline General & General \\
\hline
\end{tabular}

AP Article Declarations by Submission Type

\begin{tabular}{|l|l|l|}
\hline Submission Type & Allowed AP Articles & Required AP Articles \\
\hline 3.a & 2.a.(i), (iii), (iv), 2.b, Note & \\
\hline 3.b & 2.a.(i), (iii), (iv), 2.b, Note & \\
\hline 3.c & 2.a.(v), 2.a.(vi), Note & \\
\hline 3.d & 2.a.(vii), Note & \\
\hline 3.e & 2.a.(ii) & \\
\hline 3.f & 2.a.(vii), Note & \\
\hline Response & 2.c, Note & \\
\hline General & 2.a.(i), (ii), (iii), (iv), (v), (vi), (vii), 2.b, 2.c, Note & \\
\hline
\end{tabular}

\section{C.7 AP Data Structure for the UK}

The AP for the UK uses similar data structures to those used in the Model AP, but with several modifications. It will likely be implemented as its own template, rather than an extension of the Model AP. It is described in relation to the Model AP here to avoid repetition.

\section{Entry Data Structures}

\section{Base Entry Data Structure}

The AP for the UK uses the same base Entry structure as the Model AP.

\section{Entry 2.a.(i)}

The AP for the UK uses the same Entry 2.a.(i) structure as the Model AP.

Entry 2.a.(ii)

The AP for the UK uses the same Entry 2.a.(ii) structure as the Model AP.

Entry 2.a.(iii)

The AP for the UK Entry 2.a.(iii) structure is the same as that for Entry 2.a.(iv) in the Model AP. 


\section{Entry 2.a.(iv)}

The AP for the UK Entry 2.a.(iv) structure is the same as that for Entry 2.a.(v) in the Model AP.

Entry 2.a.(v).(a)

The AP for the UK Entry 2.a.(v).(a) structure is the same as that for Entry 2.a.(vi).(b) in the Model AP.

Entry 2.a.(v).(b)

The AP for the UK Entry 2.a.(v).(b) structure is the same as that for Entry 2.a.(vi).(c) in the Model AP.

\section{Entry 2.a.(vi)}

The AP for the UK Entry 2.a.(vi) structure is the same as that for Entry 2.a.(vii) in the Model AP.

Entry 2.a.(vii).(a)

The AP for the UK Entry 2.a.(vii).(a) structure is the same as that for Entry 2.a.(viii).(a) in the Model $\mathrm{AP}$, with the following additions and removals:

\begin{tabular}{|l|l|l|}
\hline Name & Type & Notes \\
\hline Export Date & Date & \\
\hline
\end{tabular}

\section{Model AP Field Name not used in AP for the UK}

Waste Type

Quantity Np/Am

\section{Entry 2.a.(vii).(b)}

The AP for the UK Entry 2.a.(vii).(b) structure is the same as that for Entry 2.a.(viii).(a) in the Model $\mathrm{AP}$, with the following additions and removals:

\begin{tabular}{|l|l|l|}
\hline Name & Type & Notes \\
\hline Import Date & Date & \\
\hline
\end{tabular}

\begin{tabular}{|l|}
\hline Model AP Field Name not used in AP for the UK \\
\hline Waste Type \\
\hline Quantity Np/Am \\
\hline
\end{tabular}

Entry 2.a.(viii).(a)

The AP for the UK Entry 2.a.(viii).(a) structure is the same as that for Entry 2.a.(ix).(a) in the Model AP.

\section{Entry 2.a.(viii).(b)}

The AP for the UK Entry 2.a.(viii).(b) structure is the same as that for Entry 2.a.(ix).(b) in the Model AP.

\section{Entry 2.a.(ix)}

The AP for the UK Entry 2.a.(ix) structure is the same as that for Entry 2.a.(x) in the Model AP. 


\section{Entry 2.b}

The AP for the UK Entry 2.b structure is the same as that for Entry 2.b.(i) in the Model AP.

\section{Entry 2.c}

The AP for the UK uses the same Entry 2.c structure as the Model AP.

\section{Entry Note}

The AP for the UK uses the same Entry Note structure as the Model AP.

\section{Submission Data Structure}

\section{Submission}

The AP for the UK uses the same Submission structure as the Model AP.

\section{Declaration}

The AP for the UK uses the same Submission structure as the Model AP.

\section{Common Data Types}

\section{Collaboration}

The AP for the UK uses the same Collaboration structure as the Model AP.

\section{Document}

The AP for the UK uses the same Document structure as the Model AP.

\section{GeoCoordinates}

The AP for the UK uses the same GeoCoordinates structure as the Model AP.

\section{Organization Involvement}

The AP for the UK uses the same Organization Involvement structure as the Model AP.

\section{Quantity}

The AP for the UK uses the same Quantity structure as the Model AP.

\section{Reference}

The AP for the UK uses the same Reference structure as the Model AP.

\section{Sublocation}

The AP for the UK uses the same Sublocation structure as the Model AP.

\section{Lookup Data}

The Lookup table structure and data is the same as for the Model AP, with the following exceptions:

\section{AP Article}

\begin{tabular}{|l|l|}
\hline Value & Description \\
\hline 2.a.(i) & Description and Location of R\&D activities related to a NNWS \\
\hline 2.a.(ii) & $\begin{array}{l}\text { Information identified by Agency to increase effectiveness or efficiency at designated } \\
\text { facilities }\end{array}$ \\
\hline
\end{tabular}




\begin{tabular}{|l|l|}
\hline Value & Description \\
\hline 2.a.(iii) & $\begin{array}{l}\text { Description of scale of operations for each Location engaged in Activities specified in } \\
\text { Annex I and linked to an NNWS }\end{array}$ \\
\hline 2.a.(iv) & $\begin{array}{l}\text { Location, operational status and estimated annual production of Mines and Concentration } \\
\text { Plants situated in UK involved in production for a NNWS }\end{array}$ \\
\hline 2.a.(v).(a) & Exports of Source Material to UK from NNWS Outside the Community \\
\hline 2.a.(v).(b) & Imports of Source Material from UK to NNWS Outside the Community \\
\hline 2.a.(vi) & $\begin{array}{l}\text { Materials Exempted from Safeguards under Article 37 that are Processed or Used for a } \\
\text { NNWS }\end{array}$ \\
\hline 2.a.(vii).(a) & $\begin{array}{l}\text { Information Regarding the processing of High Level Waste Containing Pu, HEU or U-233 } \\
\text { which have been terminated under Article 11 and have been Exported to a NNWS Outside } \\
\text { the Community }\end{array}$ \\
\hline 2.a.(vii).(b) & $\begin{array}{l}\text { Information Regarding the processing of High Level Waste Containing Pu, HEU or U-233 } \\
\text { which have been terminated under Article 11 and have been Imported from a NNWS } \\
\text { Outside the Community }\end{array}$ \\
\hline 2.a.(viii).(a) & Export of Equipment Listed in Annex II to a NNWS Outside the Community \\
\hline 2.a.(viii).(b) & Import of Equipment Listed in Annex II from a NNWS Outside the Community \\
\hline 2.a.(ix) & Civil Nuclear Fuel Cycle R\&D Ten Year Plan \\
\hline 2.b & $\begin{array}{l}\text { Provision of Information regarding Enrichment, Reprocessing or Processing of High Level } \\
\text { Waste that is not funded, authorized or controlled by, or carried out on behalf of the UK }\end{array}$ \\
\hline 2.c & $\begin{array}{l}\text { Upon request by the Agency, UK or Community or Both to provide Agency amplifications } \\
\text { or clarifications of any information provided under Article 2 }\end{array}$ \\
\hline
\end{tabular}

\section{Data Template lookup}

\begin{tabular}{|l|l|l|}
\hline ID & Display Name & Icon \\
\hline UK & AP for the UK & UK flag \\
\hline
\end{tabular}

\section{Submission Type}

\begin{tabular}{|l|l|}
\hline Value & Description \\
\hline $3 . \mathrm{a}$ & Initial \\
\hline $3 . \mathrm{b}$ & Annual update for initial \\
\hline $3 . \mathrm{c}$ & Annual update \\
\hline $3 . \mathrm{d}$ & Quarterly update \\
\hline $3 . \mathrm{e}$ & Annual update \\
\hline $3 . \mathrm{f}$ & Response to agency request (2.a.(ii)) \\
\hline 3.g & Response to agency request (2.a.(viii) \\
\hline $\begin{array}{l}\text { Response to } \\
\text { Agency } \\
\text { Request }\end{array}$ & Response to agency Request (2.c) \\
\hline General & General \\
\hline
\end{tabular}

AP Article Declarations by Submission Type

\begin{tabular}{|l|l|l|}
\hline Submission Type & Allowed AP Articles & Required AP Articles \\
\hline $3 . \mathrm{a}$ & 2.a.(i), (iii), (iv), (vi), (ix), 2.b, Note & \\
\hline $3 . \mathrm{b}$ & 2.a.(i), (iii), (iv), (vi), (ix), 2.b, Note & \\
\hline $3 . \mathrm{c}$ & 2.a.(v), Note & \\
\hline $3 . \mathrm{d}$ & 2.a.(viii), Note & \\
\hline $3 . \mathrm{e}$ & Note & \\
\hline $3 . \mathrm{f}$ & 2.a.(ii), Note & \\
\hline $3 . \mathrm{g}$ & 2.a.(viii), Note & \\
\hline Response & 2.c, Note & \\
\hline
\end{tabular}




\section{Appendix D: Report Definitions}

These outlines represent the minimum data required for each report. Additional details may be added to reports in the final product.

The scope, format, and content of some reports may vary based on user definable parameters at the time of execution.

\section{System Settings}

This report is available for all users, and is mainly intended to be used for administration and troubleshooting. The report will list the currently selected data template, all data templates available in this installation of the PR3, all lookup and authority data loaded by the PR3 (see the "Lookup Data" section), and any additional system settings and preferences the user may set.

- A table showing the currently selected data template, as well as all data templates available in this installation of the PR3.

- A table showing all of the values for each type of lookup or authority data.

- A summary of any additional system settings or preferences the user can configure in the PR3.

\section{Declarations in Submission (RP-001)}

This report will list either all Declarations (RP-001) or selected (RP-002) Declarations in the Submission, in order, along with details about the Entries included in each one.

The header of the report will contain information about the Submission, including the submission type, contributor, INFCIRC/State, submission date (if available), and comments.

Each Declaration will be listed, including its article, declaration type (New, Updated, Nothing to Declare, No Change, etc.), declaration number (if assigned), declaration period (either start/end or asof date), comments, and site (for 2.a.(iii) or other applicable articles).

Entries will be listed under each Declaration, and the fields shown will be based on the article type of the Declaration and its Entries (see "Entry Tables" below).

- Submission Header:

- Submission Type

- Contributor

- INFCIRC \#

- Submission Date

- Declarable Comments

- Undeclarable Comments

- Declarations list:

○ Header:

- Declaration Article

- Declaration Type (New, Updated, Nothing to Declare, No Change, etc.)

- Declaration Number (if assigned)

- Declaration Period (start/end or as-of)

- Declarable Comments

- Undeclarable Comments 
○ Entries list:

- Site (for applicable Articles)

- Based on Article type. See "Entries Tables" below.

\section{Selected Entries in Declaration (RP-001)}

The report will list the selected Entries included in the selected Declaration.

The header of the report will contain information about the Submission, including with its article, declaration type (New, Updated, Nothing to Declare, No Change, etc.), declaration number (if available), declaration period (either start/end or as-of date), comments, and site (for 2.a.(iii) or other applicable articles).

Entries will be listed, and the fields shown will be based on the article type (see "Entries Tables" below).

- Declaration Header:

- AP Article

- Contributor

- INFCIRC \#

- Declaration Type (New, Updated, Nothing to Declare, No Change, etc.)

- Declaration Number (if assigned)

- Submission Date (if available)

- Declaration Period (start/end or as-of)

- Declarable Comments

- Undeclarable Comments

- Site (for applicable Articles)

- Entries list:

○ Based on Article type. See "Entries Tables" below.

\section{Submission Due Dates (RP-002)}

The Due Dates report will show future Submission due dates based on a State's Entry Into Force date for a period specified by the user.

The header will show the selected Entry Into Force date and report period. A list of Submission due dates will be shown, including the Submission type and description, the due date, the declaration period, and a list of article types the Submission may contain.

- Parameters:

- Entry Into Force date (default: State EIF date)

- From date (default: current date)

- Header:

- Report period (default: 1 year)

- Entry Into Force date

- Report period

- State

- Due Dates table (in chronological order):

- Submission Type

- Submission Type Description

- Due Date 
- Declaration Period Start

- Declaration Period End

- Declaration Article(s) contained

\section{Selected Individual Entries (RP-005)}

This report will be used by local originators and reviewers working with individual Entries. The report will list selected Entries with details such as entry title, contributor, INFCIRC/State, article, status, the date and time last modified, and any Undeclarable or Declarable Comments.

- Entries detail data:

○ Entry Title

- Contributor

- INFCIRC \#

- Article

- Status

- Last Modified Date

- Declarable Comments

- Undeclarable Comments

\section{Entries Tables}

When a Declaration's Entries are shown in reports, the fields shown will be based on the Declaration's article type.

Article 2.a.(i)

- Entry Number (if assigned)

- References

- Fuel Cycle Stage(s)

- Location

- Project Title

- Project ID

- Relationship to State

- Description

- Organization(s)

- Objectives

- Degree Met

- Intended Application

- Foreign Collaboration(s)

- Sublocations

- Project Start Date

- Project End Date

- Declarable Comments

- Undeclarable Comments

Article 2.a.(ii)

- Entry Number (if assigned)

- References

- Agreed Information

- Declarable Comments 
- Undeclarable Comments

Article 2.a.(iii)

- Entry Number (if assigned)

- References

- Facility/LOF Code

- MBA Code

- Key Measurement Point

- Building

- Number of Floors

- Size + Size Unit

- Use and Previous Use

- Contents

- Coordinates

- MBA Code

- Declarable Comments

- Undeclarable Comments

Article 2.a.(iv)

- Entry Number (if assigned)

- References

- Annex I Item or Voluntary Extension

- Location

- Brief Description

- Capacity

- Extent Used (\%)

- Sublocations

- Declarable Comments

- Undeclarable Comments

Article 2.a.(v)

- Entry Number (if assigned)

- References

- Location

- Operation

- Operational Status

- Estimated Annual Capacity

- Actual Current Year Production

- Declarable Comments

- Undeclarable Comments

Article 2.a.(vi).(a)

- Entry Number (if assigned)

- References

- Location

- Chemical Composition

- Quantity

- Intended Use Code + Intended Use

- Declarable Comments

- Undeclarable Comments 
Article 2.a.(vi).(b)

- Entry Number (if assigned)

- References

- Destination

- Interim Destinations

- Chemical Composition

- Quantity

- Intended Use Code + Intended Use

- Export Date

- Declarable Comments

- Undeclarable Comments

Article 2.a.(vi).(c)

- Entry Number (if assigned)

- References

- Location

- Chemical Composition

- Quantity

- Import Date

- Exporting State

- Intended Use Code

- Declarable Comments

- Undeclarable Comments

Article 2.a.(vii)

- Entry Number (if assigned)

- References

- Location

- Exemption

- Element

- Percent Uranium

- Weight

- Intended Use Code + Intended Use

- Declarable Comments

- Undeclarable Comments

Article 2.a.(viii).(a)

- Entry Number (if assigned)

- References

- Waste Type

- Number/Type of Items

- Conditioned Form

- Quantities (Pu, HEU, U233, Np/Am)

- Previous Location

- New Location

- Declarable Comments

- Undeclarable Comments

Article 2.a.(viii).(b)

- Entry Number (if assigned)

- References 
- Waste Type

- Number/Type of Items

- Conditioned Form

- Quantities (Pu, HEU, U233, Np/Am)

- Location

- Processing Location

- Start/End Dates

- Processing Purpose

- Declarable Comments

- Undeclarable Comments

Article 2.a.(ix).(a)

- Entry Number (if assigned)

- References

- Item Identity

- Annex II

- Quantity

- Location of Intended Use

- Import Date (if received)

- Declarable Comments

- Undeclarable Comments

Article 2.a.(ix).(b)

- Entry Number (if assigned)

- References

- Item Identity

- Annex II

- Quantity

- Location of Intended Use

- Export Date

- Declarable Comments

- Undeclarable Comments

Article 2.a.(x)

- Entry Number (if assigned)

- References

- Fuel Cycle Stage

- Development Plans

- R\&D Plans

- Collaboration(s)

- Organization(s)

- Declarable Comments

- Undeclarable Comments

Article 2.b.(i)

- Entry Number (if assigned)

- References

- Fuel Cycle Stage(s)

- Location

- Project Title

- Project ID 
- Description

- Organization(s)

- Objectives

- Degree Met

- Intended Application

- Foreign Collaboration(s)

- Sublocations

- Project Start Date

- Project End Date

- Declarable Comments

- Undeclarable Comments

Article 2.b.(ii)

- Entry Number (if assigned)

- References

- Fuel Cycle Stage

- Physical Features

- Brief Description

- Sublocations

- Carried Out By

- Declarable Comments

- Undeclarable Comments

Article 2.c

- Entry Number (if assigned)

- References

- In Reference To

- Amplifications

- Declarable Comments

- Undeclarable Comments

Note

- Entry Number (if assigned)

- References

- Attachments (filenames)

- Declarable Comments

- Undeclarable Comments 


\section{Appendix E: Protocol Reporter 1 to Protocol Reporter 3 Data Translations}

Base Entry Fields

\begin{tabular}{|l|l|l|}
\hline PR 1 Field & PR 3 Field & Notes \\
\hline Entry Number & Entry Number & \\
\hline Reference & Reference & $\begin{array}{l}\text { Separate each Reference into Source, State, } \\
\text { Declaration, and Entry. If Source is included in } \\
\text { Entry, make a note in Undeclarable Comments. }\end{array}$ \\
\hline Comments & Declarable Comments & \\
\hline
\end{tabular}

Entry 2.a(i)

\begin{tabular}{|l|l|l|}
\hline PR 1 Field & PR 3 Field & Notes \\
\hline Fuel Cycle Stage & Fuel Cycle Stages & $\begin{array}{l}\text { Adds an item to the set if the value is found in } \\
\text { the lookup. If not, make a note in Undeclarable } \\
\text { Comments. }\end{array}$ \\
\hline Location & Location Name & $\begin{array}{l}\text { Address is a separate field in the PR3, which is } \\
\text { required. The user would have to manually } \\
\text { separate this data. }\end{array}$ \\
\hline General Description & Description & $\begin{array}{l}\text { May require the user to separate this data into } \\
\text { other fields. }\end{array}$ \\
\hline
\end{tabular}

\section{Entry2.a.(ii)}

Entry2.a.(ii) contains only the Base Entry Fields.

Entry2.a.(iii)

\begin{tabular}{|l|l|l|}
\hline PR 1 Field & PR 3 Field & Notes \\
\hline Facility(ies) on Site & Facility/LOF Code & \\
\hline Building & Building & $\begin{array}{l}\text { This is separated into several different fields in } \\
\text { the PR3. The user would have to manually } \\
\text { separate this data. }\end{array}$ \\
\hline $\begin{array}{l}\text { General Description, } \\
\text { Comments }\end{array}$ & Use & \\
\hline
\end{tabular}

\section{Entry2.a.(iv)}

\begin{tabular}{|l|l|l|}
\hline PR 1 Field & PR 3 Field & Notes \\
\hline Annex I Item & Annex I Item & $\begin{array}{l}\text { If the value is not found in the lookup, leave the } \\
\text { field blank and make a note in Undeclarable } \\
\text { Comments. }\end{array}$ \\
\hline Location & Location Name & $\begin{array}{l}\text { Address is a separate field in the PR3, which is } \\
\text { required. The user would have to manually } \\
\text { separate this data. }\end{array}$ \\
\hline $\begin{array}{l}\text { Description of Scale of } \\
\text { Operations }\end{array}$ & Brief Description & $\begin{array}{l}\text { The user will have to manually separate this into } \\
\text { Capacity and Extent Used. }\end{array}$ \\
\hline
\end{tabular}


Entry2.a.(v)

\begin{tabular}{|l|l|l|}
\hline PR 1 Field & PR 3 Field & Notes \\
\hline Operation & Operation & $\begin{array}{l}\text { If the value is not found in the lookup, leave this } \\
\text { field blank and make a note in Undeclarable } \\
\text { Comments. }\end{array}$ \\
\hline Status & Status & $\begin{array}{l}\text { If the value is not found in the lookup, leave this } \\
\text { field blank and make a note in Undeclarable } \\
\text { Comments. }\end{array}$ \\
\hline $\begin{array}{l}\text { Location } \\
\begin{array}{l}\text { Prtimated Annual } \\
\text { of element: U or Th) }\end{array}\end{array}$ & Location Name & $\begin{array}{l}\text { Address is a separate field in the PR3, which is } \\
\text { required. The user would have to manually } \\
\text { separate this data. }\end{array}$ \\
\hline
\end{tabular}

\section{Entry2.a.(vi).(a)}

\begin{tabular}{|l|l|l|}
\hline PR 1 Field & PR 3 Field & Notes \\
\hline Location & Location Name & $\begin{array}{l}\text { Address is a separate field in the PR3, which is } \\
\text { required. The user would have to manually } \\
\text { separate this data. }\end{array}$ \\
\hline Chemical Composition & Chemical Composition & $\begin{array}{l}\text { If the value is not found in the lookup, leave this } \\
\text { field blank and make a note in Undeclarable } \\
\text { Comments. }\end{array}$ \\
\hline $\begin{array}{l}\text { Quantity (tonnes of element: } \\
\text { U or Th) }\end{array}$ & Quantity & $\begin{array}{l}\text { Attempt to parse into a numeric value, and use } \\
\text { "tonnes" as the unit. If this fails, leave this field } \\
\text { blank and make a note in Undeclarable } \\
\text { Comments. }\end{array}$ \\
\hline Intended Use Code & Intended Use Code & $\begin{array}{l}\text { If the value is not found in the lookup, leave this } \\
\text { field blank and make a note in Undeclarable } \\
\text { Comments. }\end{array}$ \\
\hline Intended Use & Intended Use & \\
\hline
\end{tabular}

\section{Entry2.a.(vi).(b)}

\begin{tabular}{|l|l|l|}
\hline PR 1 Field & PR 3 Field & Notes \\
\hline Destination & Destination & $\begin{array}{l}\text { If the value is not found in the lookup, leave this } \\
\text { field blank and make a note in Undeclarable } \\
\text { Comments. }\end{array}$ \\
\hline Interim Destination(s) & Interim Destinations & $\begin{array}{l}\text { Attempt to parse into a list (by commas or line } \\
\text { breaks). If this fails or destinations are not found } \\
\text { in the lookup, leave this field blank and make a } \\
\text { note in Undeclarable Comments. }\end{array}$ \\
\hline Chemical Composition & Chemical Composition & $\begin{array}{l}\text { If the value is not found in the lookup, leave this } \\
\text { field blank and make a note in Undeclarable } \\
\text { Comments. }\end{array}$ \\
\hline $\begin{array}{l}\text { Quantity (tonnes of element: } \\
\text { U or Th) }\end{array}$ & Quantity & $\begin{array}{l}\text { Attempt to parse into a numeric value, and use } \\
\text { "tonnes" as the unit. If this fails, leave this field } \\
\text { blank and make a note in Undeclarable } \\
\text { Comments. }\end{array}$ \\
\hline
\end{tabular}




\begin{tabular}{|l|l|l|}
\hline PR 1 Field & PR 3 Field & Notes \\
\hline Export Date & Export Date & \\
\hline
\end{tabular}

Entry2.a.(vi).(c)

\begin{tabular}{|l|l|l|}
\hline PR 1 Field & PR 3 Field & Notes \\
\hline Location & Location Name & $\begin{array}{l}\text { Address is a separate field in the PR3, which is } \\
\text { required. The user would have to manually } \\
\text { separate this data. }\end{array}$ \\
\hline Chemical Composition & Chemical Composition & $\begin{array}{l}\text { If the value is not found in the lookup, leave this } \\
\text { field blank and make a note in Undeclarable } \\
\text { Comments. }\end{array}$ \\
\hline $\begin{array}{l}\text { Quantity (tonnes of element: } \\
\text { U or Th) }\end{array}$ & Quantity & $\begin{array}{l}\text { Attempt to parse into a numeric value, and use } \\
\text { "tonnes" as the unit. If this fails, leave this field } \\
\text { blank and make a note in Undeclarable } \\
\text { Comments. }\end{array}$ \\
\hline Use (intended) & Intended Use & $\begin{array}{l}\text { If the value is not found in the lookup, leave this } \\
\text { field blank and make a note in Undeclarable } \\
\text { Comments. }\end{array}$ \\
\hline Exporting State & Exporting State & Import Date \\
\hline Import Date & & \\
\hline
\end{tabular}

Entry2.a.(vii)

\begin{tabular}{|l|l|l|}
\hline PR 1 Field & PR 3 Field & Notes \\
\hline Location & Location Name & $\begin{array}{l}\text { Address is a separate field in the PR3, which is } \\
\text { required. The user would have to manually } \\
\text { separate this data. }\end{array}$ \\
\hline Exemption & Exemption & $\begin{array}{l}\text { If the value is not found in the lookup, leave this } \\
\text { field blank and make a note in Undeclarable } \\
\text { Comments. }\end{array}$ \\
\hline Material & Element & $\begin{array}{l}\text { If the value is not found in the lookup, leave this } \\
\text { field blank and make a note in Undeclarable } \\
\text { Comments. }\end{array}$ \\
\hline Quantity of Element & Quantity & $\begin{array}{l}\text { Attempt to parse the string into “value unit." If } \\
\text { this fails, leave this field blank and make a note } \\
\text { in Undeclarable Comments. }\end{array}$ \\
\hline Intended Use Code & Intended Use Code & $\begin{array}{l}\text { If the value is not found in the lookup, leave this } \\
\text { field blank and make a note in Undeclarable } \\
\text { Comments. }\end{array}$ \\
\hline Intended Use & Intended Use & \\
\hline
\end{tabular}

Entry2.a.(viii).(a)

\begin{tabular}{|l|l|l|}
\hline PR 1 Field & PR 3 Field & Notes \\
\hline $\begin{array}{l}\text { Waste Type Prior to } \\
\text { Conditioning }\end{array}$ & Waste Type & \\
\hline Conditioning Form & Conditioned Form & \\
\hline Number of Items & Number of Items & \\
\hline Quantity Pu & Quantity Pu & Attempt to parse the string into “value unit.” If \\
\hline
\end{tabular}




\begin{tabular}{|l|l|l|}
\hline PR 1 Field & PR 3 Field & Notes \\
\hline Quantity HEU & Quantity HEU & $\begin{array}{l}\text { this fails, leave this field blank and make a note } \\
\text { in Undeclarable Comments. }\end{array}$ \\
\hline Quantity U233 & $\begin{array}{l}\text { Attempt to parse the string into "value unit." If } \\
\text { this fails, leave this field blank and make a note } \\
\text { in Undeclarable Comments. }\end{array}$ \\
\hline Previous Location & Previous Location Name & $\begin{array}{l}\text { Attempt to parse the string into "value unit." If } \\
\text { this fails, leave this field blank and make a note } \\
\text { in Undeclarable Comments. }\end{array}$ \\
\hline New Location & $\begin{array}{l}\text { Address is a separate field in the PR3, which is } \\
\text { required. The user would have to manually } \\
\text { separate this data. }\end{array}$ \\
\hline & New Location Name & $\begin{array}{l}\text { Address is a separate field in the PR3, which is } \\
\text { required. The user would have to manually } \\
\text { separate this data. }\end{array}$ \\
\hline
\end{tabular}

Entry2.a.(viii).(b)

\begin{tabular}{|c|c|c|}
\hline PR 1 Field & PR 3 Field & Notes \\
\hline $\begin{array}{l}\text { Waste Type Prior to } \\
\text { Conditioning }\end{array}$ & Waste Type & \\
\hline Conditioning Form & Conditioned Form & \\
\hline Number of Items & Number of Items & \\
\hline Quantity $\mathrm{Pu}$ & Quantity $\mathrm{Pu}$ & $\begin{array}{l}\text { Attempt to parse the string into "value unit." If } \\
\text { this fails, leave this field blank and make a note } \\
\text { in Undeclarable Comments. }\end{array}$ \\
\hline Quantity HEU & Quantity HEU & $\begin{array}{l}\text { Attempt to parse the string into "value unit." If } \\
\text { this fails, leave this field blank and make a note } \\
\text { in Undeclarable Comments. }\end{array}$ \\
\hline Quantity U233 & Quantity U233 & $\begin{array}{l}\text { Attempt to parse the string into "value unit." If } \\
\text { this fails, leave this field blank and make a note } \\
\text { in Undeclarable Comments. }\end{array}$ \\
\hline Location & Location Name & $\begin{array}{l}\text { Address is a separate field in the PR3, which is } \\
\text { required. The user would have to manually } \\
\text { separate this data. }\end{array}$ \\
\hline Processing Location & Processing Location Name & $\begin{array}{l}\text { Address is a separate field in the PR3, which is } \\
\text { required. The user would have to manually } \\
\text { separate this data. }\end{array}$ \\
\hline Processing Dates & $\begin{array}{l}\text { Note in Undeclarable } \\
\text { Comments }\end{array}$ & $\begin{array}{l}\text { This is a free text field in the PR2 that is } \\
\text { separated into Start Date and End Date in the } \\
\text { PR3. The user would have to manually separate } \\
\text { this data. }\end{array}$ \\
\hline Processing Purpose & Processing Purpose & String \\
\hline
\end{tabular}

Entry2.a.(ix).(a)

\begin{tabular}{|l|l|l|}
\hline PR 1 Field & PR 3 Field & Notes \\
\hline Annex II Paragraph & Annex II & $\begin{array}{l}\text { If the value is not a selectable value found in the } \\
\text { lookup, leave this field blank and make a note in } \\
\text { Undeclarable Comments. }\end{array}$ \\
\hline
\end{tabular}




\begin{tabular}{|l|l|l|}
\hline PR 1 Field & PR 3 Field & Notes \\
\hline Identity of Specific Item(s) & Item Identity & Quantity \\
\hline Quantity (no. or wt.) & $\begin{array}{l}\text { Attempt to parse the string into "value unit." If } \\
\text { this fails, leave this field blank and make a note } \\
\text { in Undeclarable Comments. }\end{array}$ \\
\hline Location of Intended Use & $\begin{array}{l}\text { Location of Intended Use } \\
\text { Name }\end{array}$ & $\begin{array}{l}\text { Address is a separate field in the PR3, which is } \\
\text { required. The user would have to manually } \\
\text { separate this data. }\end{array}$ \\
\hline Export Date & Export Date & \\
\hline
\end{tabular}

Entry2.a.(ix).(b)

\begin{tabular}{|l|l|l|}
\hline PR 1 Field & PR 3 Field & Notes \\
\hline Annex II Paragraph & Annex II & $\begin{array}{l}\text { If the value is not a selectable value found in the } \\
\text { lookup, leave this field blank and make a note in } \\
\text { Undeclarable Comments. }\end{array}$ \\
\hline Identity of Specific Item(s) & Item Identity & $\begin{array}{l}\text { Attempt to parse the string into "value unit." If } \\
\text { this fails, leave this field blank and make a note } \\
\text { in Undeclarable Comments. }\end{array}$ \\
\hline Quantity (no. or wt.) & Quantity & $\begin{array}{l}\text { Address is a separate field in the PR3, which is } \\
\text { required. The user would have to manually } \\
\text { separate this data. }\end{array}$ \\
\hline Location of Intended Use & $\begin{array}{l}\text { Location of Intended Use } \\
\text { Name }\end{array}$ & \multicolumn{2}{|l}{} \\
\hline Import Date & Import Date &
\end{tabular}

\section{Entry2.a.(x)}

\begin{tabular}{|l|l|l|}
\hline PR 1 Field & PR 3 Field & Notes \\
\hline Fuel Cycle Stage & Fuel Cycle Stage & $\begin{array}{l}\text { Adds an item to the set if the value is found in } \\
\text { the lookup. If not, make a note in Undeclarable } \\
\text { Comments. }\end{array}$ \\
\hline $\begin{array}{l}\text { General Plans for } \\
\text { Development of the Nuclear } \\
\text { Fuel Cycle }\end{array}$ & Development Plans & \\
\hline $\begin{array}{l}\text { General Plans for Nuclear } \\
\text { Fuel Cycle-Related } \\
\text { Research and Development } \\
\text { Activities }\end{array}$ & R\&D Plans & \\
\hline
\end{tabular}

Entry2.b.(i)

\begin{tabular}{|l|l|l|}
\hline PR 1 Field & PR 3 Field & Notes \\
\hline Fuel Cycle Stage & Fuel Cycle Stages & Adds an item to the set. \\
\hline Location & Location Name & $\begin{array}{l}\text { Address is a separate field in the PR3, which is } \\
\text { required. The user would have to manually } \\
\text { separate this data. }\end{array}$ \\
\hline General Description & Description & $\begin{array}{l}\text { May require the user to separate this data into } \\
\text { other fields. }\end{array}$ \\
\hline
\end{tabular}


Entry2.b.(ii)

\begin{tabular}{|l|l|l|}
\hline PR 1 Field & PR 3 Field & Notes \\
\hline Location & Location Name & $\begin{array}{l}\text { Address is a separate field in the PR3, which is } \\
\text { required. The user would have to manually } \\
\text { separate this data. }\end{array}$ \\
\hline General Description & Description of Activities & $\begin{array}{l}\text { May require the user to separate this data into } \\
\text { other fields. }\end{array}$ \\
\hline Carried Out By & $\begin{array}{l}\text { Noted in Undeclarable } \\
\text { Comments }\end{array}$ & $\begin{array}{l}\text { This free text field is separated into a list of } \\
\text { structured data in the PR3. The user would have } \\
\text { to manually separate this data. }\end{array}$ \\
\hline
\end{tabular}

\section{Entry2.c}

\begin{tabular}{|l|l|l|}
\hline PR 1 Field & PR 3 Field & Notes \\
\hline $\begin{array}{l}\text { Response (Amplification } \\
\text { and clarification) }\end{array}$ & Amplifications & \\
\hline
\end{tabular}

\section{Entry Note}

\begin{tabular}{|l|l|l|}
\hline PR 1 Field & PR 3 Field & Notes \\
\hline General Description & General Description & \\
\hline
\end{tabular}




\section{Appendix F: Protocol Reporter 2 to Protocol Reporter 3 Data Translations}

\section{F.1 Model AP \\ Base Entry Fields}

\begin{tabular}{|l|l|l|}
\hline PR 2 Field & PR 3 Field & Notes \\
\hline Entry Number & Entry Number & \\
\hline Reference & Reference & $\begin{array}{l}\text { Created using the State-Declaration-Entry } \\
\text { format. }\end{array}$ \\
\hline Attachments & Attachments & Creates an item for each attachment. \\
\hline Comments & Declarable Comments & \\
\hline Entry Source & Undeclarable Comments & \\
\hline
\end{tabular}

\section{Entry 2.a.(i)}

\begin{tabular}{|l|l|l|}
\hline PR 2 Field & PR 3 Field & Notes \\
\hline Fuel Cycle Stage & Fuel Cycle Stages & Adds an item to the set. \\
\hline Location & Location Name & $\begin{array}{l}\text { Address is a separate field in the PR3, which is } \\
\text { required. The user would have to manually } \\
\text { separate this data. }\end{array}$ \\
\hline General Description & Description & $\begin{array}{l}\text { May require the user to separate this data into } \\
\text { other fields. }\end{array}$ \\
\hline
\end{tabular}

Entry 2.a.(ii)

\begin{tabular}{|l|l|l|}
\hline PR 2 Field & PR 3 Field & Notes \\
\hline Agreed Information & Agreed Information & \\
\hline
\end{tabular}

Entry 2.a.(iii)

\begin{tabular}{|l|l|l|}
\hline PR 2 Field & PR 3 Field & Notes \\
\hline Facility/LOF Code & Facility/LOF Code & \\
\hline Building & Building & $\begin{array}{l}\text { This is separated into several different fields in } \\
\text { the PR3. The user would have to manually } \\
\text { separate this data. }\end{array}$ \\
\hline General Description & Use & \\
\hline
\end{tabular}

\section{Entry 2.a.(iv)}

\begin{tabular}{|l|l|l|}
\hline PR 2 Field & PR 3 Field & Notes \\
\hline Annex I Item & Annex I Item & $\begin{array}{l}\text { If the value is not found in the lookup, leave the } \\
\text { field blank and make a note in Undeclarable } \\
\text { Comments. }\end{array}$ \\
\hline Location & Location Name & $\begin{array}{l}\text { Address is a separate field in the PR3, which is } \\
\text { required. The user would have to manually } \\
\text { separate this data. }\end{array}$ \\
\hline
\end{tabular}




\begin{tabular}{|l|l|l|}
\hline PR 2 Field & PR 3 Field & Notes \\
\hline $\begin{array}{l}\text { Description of Scale of } \\
\text { Operations }\end{array}$ & Brief Description & $\begin{array}{l}\text { The user will have to manually separate this into } \\
\text { Capacity and Extent Used. }\end{array}$ \\
\hline
\end{tabular}

Entry 2.a.(v)

\begin{tabular}{|l|l|l|}
\hline PR 2 Field & PR 3 Field & Notes \\
\hline Operation & Operation & $\begin{array}{l}\text { If the value is not found in the lookup, leave this } \\
\text { field blank and make a note in Undeclarable } \\
\text { Comments. }\end{array}$ \\
\hline Status & Status & $\begin{array}{l}\text { If the value is not found in the lookup, leave this } \\
\text { field blank and make a note in Undeclarable } \\
\text { Comments. }\end{array}$ \\
\hline Location & Location Name & $\begin{array}{l}\text { Address is a separate field in the PR3, which is } \\
\text { required. The user would have to manually } \\
\text { separate this data. }\end{array}$ \\
\hline $\begin{array}{l}\text { Estimated Annual } \\
\text { Production Capacity }\end{array}$ & Quantity & $\begin{array}{l}\text { Attempt to parse the string into “value unit." If } \\
\text { this fails, leave this field blank and make a note } \\
\text { in Undeclarable Comments. }\end{array}$ \\
\hline
\end{tabular}

Entry 2a.(vi).(a)

\begin{tabular}{|l|l|l|}
\hline PR 2 Field & PR 3 Field & Notes \\
\hline Location & Location Name & $\begin{array}{l}\text { Address is a separate field in the PR3, which is } \\
\text { required. The user would have to manually } \\
\text { separate this data. }\end{array}$ \\
\hline Chemical Composition & Chemical Composition & $\begin{array}{l}\text { If the value is not found in the lookup, leave this } \\
\text { field blank and make a note in Undeclarable } \\
\text { Comments. }\end{array}$ \\
\hline Quantity (tones of element) & Quantity & $\begin{array}{l}\text { Attempt to parse the string into "value unit." If } \\
\text { this fails, leave this field blank and make a note } \\
\text { in Undeclarable Comments. }\end{array}$ \\
\hline Intended Use Code & Intended Use Code & $\begin{array}{l}\text { If the value is not found in the lookup, leave this } \\
\text { field blank and make a note in Undeclarable } \\
\text { Comments. }\end{array}$ \\
\hline Intended Use & Intended Use & \\
\hline
\end{tabular}

Entry 2.a.(vi).(b)

\begin{tabular}{|l|l|l|}
\hline PR 2 Field & PR 3 Field & Notes \\
\hline Destination & Destination & $\begin{array}{l}\text { If the value is not found in the lookup, leave this } \\
\text { field blank and make a note in Undeclarable } \\
\text { Comments. }\end{array}$ \\
\hline Interim Destination(s) & Interim Destinations & $\begin{array}{l}\text { Attempt to parse into a list (by commas or line } \\
\text { breaks). If this fails or destinations are not found } \\
\text { in the lookup, leave this field blank and make a } \\
\text { note in Undeclarable Comments. }\end{array}$ \\
\hline Chemical Composition & Chemical Composition & $\begin{array}{l}\text { If the value is not found in the lookup, leave this } \\
\text { field blank and make a note in Undeclarable } \\
\text { Comments. }\end{array}$ \\
\hline
\end{tabular}




\begin{tabular}{|l|l|l|}
\hline PR 2 Field & PR 3 Field & Notes \\
\hline Quantity (tones of element) & Quantity & $\begin{array}{l}\text { Attempt to parse the string into "value unit." If } \\
\text { this fails, leave this field blank and make a note } \\
\text { in Undeclarable Comments. }\end{array}$ \\
\hline Export Date & Export Date & \\
\hline
\end{tabular}

Entry 2.a.(vi).(c)

\begin{tabular}{|l|l|l|}
\hline PR 2 Field & PR 3 Field & Notes \\
\hline Location & Location Name & $\begin{array}{l}\text { Address is a separate field in the PR3, which is } \\
\text { required. The user would have to manually } \\
\text { separate this data. }\end{array}$ \\
\hline Chemical Composition & Chemical Composition & $\begin{array}{l}\text { If the value is not found in the lookup, leave this } \\
\text { field blank and make a note in Undeclarable } \\
\text { Comments. }\end{array}$ \\
\hline Quantity (tones of element) & Quantity & $\begin{array}{l}\text { Attempt to parse the string into "value unit." If } \\
\text { this fails, leave this field blank and make a note } \\
\text { in Undeclarable Comments. }\end{array}$ \\
\hline Intended Use & Intended Use & $\begin{array}{l}\text { If the value is not found in the lookup, leave this } \\
\text { field blank and make a note in Undeclarable } \\
\text { Comments. }\end{array}$ \\
\hline Import Date & Exporting State & \\
\hline
\end{tabular}

Entry 2.a.(vii)

\begin{tabular}{|l|l|l|}
\hline PR 2 Field & PR 3 Field & Notes \\
\hline Location & Location Name & $\begin{array}{l}\text { Address is a separate field in the PR3, which is } \\
\text { required. The user would have to manually } \\
\text { separate this data. }\end{array}$ \\
\hline Exemption & Exemption & $\begin{array}{l}\text { If the value is not found in the lookup, leave this } \\
\text { field blank and make a note in Undeclarable } \\
\text { Comments. }\end{array}$ \\
\hline Material & Element & $\begin{array}{l}\text { If the value is not found in the lookup, leave this } \\
\text { field blank and make a note in Undeclarable } \\
\text { Comments. }\end{array}$ \\
\hline Intended Use Code & Quantity & $\begin{array}{l}\text { Attempt to parse the string into "value unit." If } \\
\text { this fails, leave this field blank and make a note } \\
\text { in Undeclarable Comments. }\end{array}$ \\
\hline Intended Use & $\begin{array}{l}\text { If the value is not found in the lookup, leave this } \\
\text { field blank and make a note in Undeclarable } \\
\text { Comments. }\end{array}$ \\
\hline
\end{tabular}

Entry 2.a.(viii).(a)

\begin{tabular}{|l|l|l|}
\hline PR 2 Field & PR 3 Field & Notes \\
\hline $\begin{array}{l}\text { Waste Type Prior to } \\
\text { Conditioning }\end{array}$ & Waste Type & \\
\hline Conditioned Form & Conditioned Form & \\
\hline
\end{tabular}




\begin{tabular}{|l|l|l|}
\hline PR 2 Field & PR 3 Field & Notes \\
\hline Number of Items & Number of Items & Quantity Pu \\
\hline Quantity Pu & Quantity HEU & $\begin{array}{l}\text { Attempt to parse the string into "value unit." If } \\
\text { this fails, leave this field blank and make a note } \\
\text { in Undeclarable Comments. }\end{array}$ \\
\hline Quantity HEU & $\begin{array}{l}\text { Attempt to parse the string into "value unit." If } \\
\text { this fails, leave this field blank and make a note } \\
\text { in Undeclarable Comments. }\end{array}$ \\
\hline Quantity U233 & Quantity U233 & $\begin{array}{l}\text { Attempt to parse the string into "value unit." If } \\
\text { this fails, leave this field blank and make a note } \\
\text { in Undeclarable Comments. }\end{array}$ \\
\hline Quantity Np/Am & Quantity Np/Am & $\begin{array}{l}\text { Attempt to parse the string into "value unit." If } \\
\text { this fails, leave this field blank and make a note } \\
\text { in Undeclarable Comments. }\end{array}$ \\
\hline Previous Location & Previous Location Name & $\begin{array}{l}\text { Address is a separate field in the PR3, which is } \\
\text { required. The user would have to manually } \\
\text { separate this data. }\end{array}$ \\
\hline New Location & New Location Name & $\begin{array}{l}\text { Address is a separate field in the PR3, which is } \\
\text { required. The user would have to manually } \\
\text { separate this data. }\end{array}$ \\
\hline
\end{tabular}

Entry 2.a.(viii).(b)

\begin{tabular}{|c|c|c|}
\hline PR 2 Field & PR 3 Field & Notes \\
\hline $\begin{array}{l}\text { Waste Type Prior to } \\
\text { Conditioning }\end{array}$ & Waste Type & \\
\hline Conditioned Form & Conditioned Form & \\
\hline Number of Items & Number of Items & \\
\hline Quantity Pu & Quantity $\mathrm{Pu}$ & $\begin{array}{l}\text { Attempt to parse the string into "value unit." If } \\
\text { this fails, leave this field blank and make a note } \\
\text { in Undeclarable Comments. }\end{array}$ \\
\hline Quantity HEU & Quantity HEU & $\begin{array}{l}\text { Attempt to parse the string into "value unit." If } \\
\text { this fails, leave this field blank and make a note } \\
\text { in Undeclarable Comments. }\end{array}$ \\
\hline Quantity U233 & Quantity U233 & $\begin{array}{l}\text { Attempt to parse the string into "value unit." If } \\
\text { this fails, leave this field blank and make a note } \\
\text { in Undeclarable Comments. }\end{array}$ \\
\hline Quantity Np/Am & Quantity Np/Am & $\begin{array}{l}\text { Attempt to parse the string into "value unit." If } \\
\text { this fails, leave this field blank and make a note } \\
\text { in Undeclarable Comments. }\end{array}$ \\
\hline Location & Location Name & $\begin{array}{l}\text { Address is a separate field in the PR3, which is } \\
\text { required. The user would have to manually } \\
\text { separate this data. }\end{array}$ \\
\hline Processing Location & Processing Location Name & $\begin{array}{l}\text { Address is a separate field in the PR3, which is } \\
\text { required. The user would have to manually } \\
\text { separate this data. }\end{array}$ \\
\hline Processing Dates & $\begin{array}{l}\text { Note in Undeclarable } \\
\text { Comments }\end{array}$ & $\begin{array}{l}\text { This is a free text field in the PR2 that is } \\
\text { separated into Start Date and End Date in the } \\
\text { PR3. The user would have to manually separate } \\
\text { this data. }\end{array}$ \\
\hline
\end{tabular}




\begin{tabular}{|l|l|l|}
\hline PR 2 Field & PR 3 Field & Notes \\
\hline Processing Purpose & Processing Purpose & String \\
\hline
\end{tabular}

Entry 2.a.(ix).(a)

\begin{tabular}{|l|l|l|}
\hline PR 2 Field & PR 3 Field & Notes \\
\hline Annex II Paragraph & Annex II & $\begin{array}{l}\text { If the value is not a selectable value found in the } \\
\text { lookup, leave this field blank and make a note in } \\
\text { Undeclarable Comments. }\end{array}$ \\
\hline Identity of Specific Item(s) & Item Identity & $\begin{array}{l}\text { Attempt to parse the string into "value unit." If } \\
\text { this fails, leave this field blank and make a note } \\
\text { in Undeclarable Comments. }\end{array}$ \\
\hline Quantity (no. or wt.) & Quantity & $\begin{array}{l}\text { Address is a separate field in the PR3, which is } \\
\text { required. The user would have to manually } \\
\text { separate this data. }\end{array}$ \\
\hline Location of Intended Use & $\begin{array}{l}\text { Location of Intended Use } \\
\text { Name }\end{array}$ & Export Date \\
\hline
\end{tabular}

Entry 2.a.(ix).(b)

\begin{tabular}{|l|l|l|}
\hline PR 2 Field & PR 3 Field & Notes \\
\hline Annex II Paragraph & Annex II & $\begin{array}{l}\text { If the value is not a selectable value found in the } \\
\text { lookup, leave this field blank and make a note in } \\
\text { Undeclarable Comments. }\end{array}$ \\
\hline Identity of Specific Item(s) & Item Identity & $\begin{array}{l}\text { Attempt to parse the string into "value unit." If } \\
\text { this fails, leave this field blank and make a note } \\
\text { in Undeclarable Comments. }\end{array}$ \\
\hline Quantity (no. or wt.) & Quantity & $\begin{array}{l}\text { Address is a separate field in the PR3, which is } \\
\text { required. The user would have to manually } \\
\text { separate this data. }\end{array}$ \\
\hline Location of Intended Use & $\begin{array}{l}\text { Location of Intended Use } \\
\text { Name }\end{array}$ & Import Date \\
\hline Import Date & & \\
\hline
\end{tabular}

Entry 2.a.(x)

\begin{tabular}{|l|l|l|}
\hline PR 2 Field & PR 3 Field & Notes \\
\hline Fuel Cycle Stage & Fuel Cycle Stage & $\begin{array}{l}\text { Adds an item to the set if the value is found in } \\
\text { the lookup. If not, make a note in Undeclarable } \\
\text { Comments. }\end{array}$ \\
\hline $\begin{array}{l}\text { General Plans for } \\
\text { Development of the Nuclear } \\
\text { Fuel Cycle }\end{array}$ & Development Plans & \\
\hline $\begin{array}{l}\text { General Plans for Nuclear } \\
\text { Fuel Cycle-related Research } \\
\text { and Development }\end{array}$ & R\&D Plans & \\
\hline
\end{tabular}

Entry 2.b.(i)

\begin{tabular}{|l|l|l|}
\hline PR 2 Field & PR 3 Field & Notes \\
\hline Fuel Cycle Stage & Fuel Cycle Stages & Adds an item to the set. \\
\hline
\end{tabular}




\begin{tabular}{|l|l|l|}
\hline PR 2 Field & PR 3 Field & Notes \\
\hline Location & Location Name & $\begin{array}{l}\text { Address is a separate field in the PR3, which is } \\
\text { required. The user would have to manually } \\
\text { separate this data. }\end{array}$ \\
\hline General Description & Description & $\begin{array}{l}\text { May require the user to separate this data into } \\
\text { other fields. }\end{array}$ \\
\hline
\end{tabular}

Entry 2.b.(ii)

\begin{tabular}{|l|l|l|}
\hline PR 2 Field & PR 3 Field & Notes \\
\hline Location & Location Name & $\begin{array}{l}\text { Address is a separate field in the PR3, which is } \\
\text { required. The user would have to manually } \\
\text { separate this data. }\end{array}$ \\
\hline General Description & Description of Activities & $\begin{array}{l}\text { May require the user to separate this data into } \\
\text { other fields. }\end{array}$ \\
\hline Carried out by & $\begin{array}{l}\text { Noted in Undeclarable } \\
\text { Comments } \\
\text { structured data in the PR3. The user would have } \\
\text { to manually separate this data. }\end{array}$ \\
\hline
\end{tabular}

Entry 2.c

\begin{tabular}{|l|l|l|}
\hline PR 2 Field & PR 3 Field & Notes \\
\hline Agency Question & In Reference To & \\
\hline $\begin{array}{l}\text { Response (Amplification } \\
\text { and clarification) }\end{array}$ & Amplifications & \\
\hline
\end{tabular}

\section{Entry Note}

\begin{tabular}{|l|l|l|}
\hline PR 2 Field & PR 3 Field & Notes \\
\hline General Description & General Description & \\
\hline
\end{tabular}

Declaration Details 2.b.(ii)

\begin{tabular}{|l|l|l|}
\hline PR 2 Field & PR 3 Field & Notes \\
\hline Agency Request Number & Agency Request Number & \\
\hline Agency Request Date & Agency Request Date & \\
\hline
\end{tabular}

Declaration Details 2.c

\begin{tabular}{|l|l|l|}
\hline PR 2 Field & PR 3 Field & Notes \\
\hline Agency Request Number & Agency Request Number & \\
\hline Agency Request Date & Agency Request Date & \\
\hline
\end{tabular}

\section{F.2 EURATOM extensions to the Model AP Data Structure}

Entries for the EURATOM data template are mapped the same as the Model AP.

\section{F.3 US Extensions to the Model AP Data Structure}

Entries for the US data template are mapped the same as the Model AP, with the following additional fields: 
Base Entry Data Structure

\begin{tabular}{|l|l|l|}
\hline PR 2 Field & PR 3 Field & Notes \\
\hline $\begin{array}{l}\text { Internal US Record Keeping } \\
\text { Information }\end{array}$ & $\begin{array}{l}\text { Internal US Record Keeping } \\
\text { Information }\end{array}$ & \\
\hline US Reporting Code & US Reporting Code & \\
\hline
\end{tabular}

Entry 2.a.(v)

\begin{tabular}{|l|l|l|}
\hline PR 2 Field & PR 3 Field & Notes \\
\hline GPS Coordinates & GPS Coordinates & $\begin{array}{l}\text { Attempt to parse string as GPS coordinates. If } \\
\text { this fails, leave the field blank and add a note in } \\
\text { Undeclarable Comments. }\end{array}$ \\
\hline
\end{tabular}

\section{F.4 AP Data Structure for China}

Where the AP for China matches the Model AP (as described in C.4), Entries are mapped as they are in the Model AP. Mappings for new fields will be determined when information regarding the PR2 data structure for China is made available by the Agency.

\section{F.5 AP Data Structure for France}

Where the AP for France matches the Model AP (as described in C.4), Entries are mapped as they are in the Model AP. This section includes only mappings for new fields.

Entry 2.a.(iii)

\begin{tabular}{|l|l|l|}
\hline PR 2 Field & PR 3 Field & Notes \\
\hline NNWS Entities & $\begin{array}{l}\text { Noted in Undeclarable } \\
\text { Comments }\end{array}$ & $\begin{array}{l}\text { NNWS Entries is a free text field in the PR2, but } \\
\text { a set of Collaboration records in the PR3. The } \\
\text { user would have to manually separate this data. }\end{array}$ \\
\hline
\end{tabular}

Entry 2.a.(vi).(a)

\begin{tabular}{|l|l|l|}
\hline PR 2 Field & PR 3 Field & Notes \\
\hline Export Date & Export Date & \\
\hline
\end{tabular}

Entry 2.a.(vi).(b)

\begin{tabular}{|l|l|l|}
\hline PR 2 Field & PR 3 Field & Notes \\
\hline Import Date & Import Date & \\
\hline
\end{tabular}

Entry 2.a.(vii).(a)

\begin{tabular}{|l|l|l|}
\hline PR 2 Field & PR 3 Field & Notes \\
\hline Annex I & Annex I & $\begin{array}{l}\text { If the value is not found in the lookup, leave the } \\
\text { field blank and make a note in Undeclarable } \\
\text { Comments. }\end{array}$ \\
\hline
\end{tabular}


Entry 2.a.(vii).(b)

\begin{tabular}{|l|l|l|}
\hline PR 2 Field & PR 3 Field & Notes \\
\hline Annex I & Annex I & $\begin{array}{l}\text { If the value is not found in the lookup, leave the } \\
\text { field blank and make a note in Undeclarable } \\
\text { Comments. }\end{array}$ \\
\hline
\end{tabular}

\section{F.6 AP Data Structure for Russia}

Where the AP for Russia matches the Model AP (as described in C.5), Entries are mapped as they are in the Model AP. This section includes only mappings for new fields.

Entry 2.a.(iii)

\begin{tabular}{|l|l|l|}
\hline PR 2 Field & PR 3 Field & Notes \\
\hline NNWS Entities & $\begin{array}{l}\text { Noted in Undeclarable } \\
\text { Comments }\end{array}$ & $\begin{array}{l}\text { NNWS Entries is a free text field in the PR2, but } \\
\text { a set of Collaboration records in the PR3. The } \\
\text { user would have to manually separate this data. }\end{array}$ \\
\hline
\end{tabular}

Entry 2.a.(vi)

\begin{tabular}{|l|l|l|}
\hline PR 2 Field & PR 3 Field & Notes \\
\hline Export Date & Export Date & \\
\hline
\end{tabular}

\section{F.7 AP Data Structure for the UK}

Where the AP for the UK matches the Model AP (as described in C.6), Entries are mapped as they are in the Model AP. This section includes only mappings for new fields.

Entry 2.a.(vii).(a)

\begin{tabular}{|l|l|l|}
\hline PR 2 Field & PR 3 Field & Notes \\
\hline Export Date & Export Date & \\
\hline
\end{tabular}

Entry 2.a.(vii).(b)

\begin{tabular}{|l|l|l|}
\hline PR 2 Field & PR 3 Field & Notes \\
\hline Import Date & Import Date & \\
\hline
\end{tabular}

